Portland State University

PDXScholar

\title{
Weder Bürger noch Mensch: Gefangener der Medien und des Rechtsstaats gekoppelte Entmenschlichung mit Radikalisierung Zwei Auffassungen Heinrich Bölls Die verlorene Ehre der Katharina Blum oder: wie Gewalt entstehen und wohin sie führen kann
}

Tyler Robert Russ

Portland State University

Follow this and additional works at: https://pdxscholar.library.pdx.edu/open_access_etds Let us know how access to this document benefits you.

Recommended Citation

Russ, Tyler Robert, "Weder Bürger noch Mensch: Gefangener der Medien und des Rechtsstaats gekoppelte Entmenschlichung mit Radikalisierung Zwei Auffassungen Heinrich Bölls Die verlorene Ehre der Katharina Blum oder: wie Gewalt entstehen und wohin sie führen kann" (2010). Dissertations and Theses. Paper 92.

https://doi.org/10.15760/etd.92

This Thesis is brought to you for free and open access. It has been accepted for inclusion in Dissertations and Theses by an authorized administrator of PDXScholar. Please contact us if we can make this document more accessible: pdxscholar@pdx.edu. 


\author{
Weder Bürger noch Mensch: \\ Gefangener der Medien und des Rechtsstaats \\ gekoppelte Entmenschlichung mit Radikalisierung \\ zwei Auffassungen Heinrich Bölls \\ Die verlorene Ehre der Katharina Blum oder: \\ wie Gewalt entstehen und wohin sie führen kann
}

\title{
by
}

Tyler Robert Russ

A thesis submitted in partial fulfillment of the requirements for the degree of

\author{
Master of Arts \\ in \\ German
}

Thesis Committee:

Steven N. Fuller, Chair

William B. Fischer

Richard H. Beyler

Portland State University
(C)2010 
Abstract

In his 1974 novella The lost Honor of Katharina Blum Heinrich Boell argues for the constitutional guarantee of presumption of innocence. He states that this principle is violated when defamatory media headlines make unwarranted accusations against a private citizen destroying their reputation as part of a targeted smear campaign. The novella characterizes such intentional campaigns as both criminalizing and dehumanizing. Boell argues that the government should influence the press to conform to the limits implied in the institution of freedom of press. He shows the helplessness of a private citizen under attack from a smear campaign when the government takes a laissez-faire attitude toward sensationalized media.

This thesis, "Neither citizen nor human: Prisoner of the media and the state: systematically linked dehumanization and radicalization: Two Interpretations of Heinrich Boell's: The Lost Honor of Katharina Blum," evaluates the sympathetic role that media and government play in the radicalization of the private citizen. This thesis establishes a direct relation between smear campaigns and radical or extremist behavior. This thesis shows that the victim of the media acts out erratically in a state of panic and terror brought on by feelings of helplessness. This thesis supports Boell's position that this erratic behavior leads to suicide or violence against perceived oppressors or others. This thesis argues for the habitualization of violence as a precise definition of the radicalization of the individual to violence. 
This thesis utilizes Boell's fictionalized account of Katharina Blum. This thesis makes comparisons between targeted smear campaigns in the BRD in the period 1967-1974, roughly the period of the Brandt Administration, and the case of Katharina Blum. This thesis demonstrates the systematically linked oppression of oppositional voices by the West German government with media-driven smear campaigns. Boell's essays on topics including human rights and the potential benefits of political radicals help inform this study.

Boell's novella demonstrates the vulnerability of all citizens to victimization of the press. Boell shows that violent radical behavior results from smear campaigns against private citizens. Boell argues that this radicalization is clearly rooted in a salesdriven media sympathetic to the state's abuses of power. 
Acknowledgements

I am indebted to my thesis advisor for his invaluable advice and comments leading to the gradual conceptualization of this thesis. I also owe a debt of gratitude to the many excellent professors at the German Summer School on the Pacific who assisted me with their German grammar and phrasing expertise. While the ideas presented here are my own, the fullness of the ideas and the greater freedom of expression afforded in some parts of this thesis are due to analytical criticism and help from these tireless mentors. Without their help, this article would not be nearly as readable or developed as it is now. My only hope is that they realize how truly grateful I am. 
Inhaltsangabe

$\begin{array}{ll}\text { Abstract } & \text { i }\end{array}$

Acknowledgements

Liste von Verkürzungen vii

\section{Kapitel: Böll 1938-1971}

Einleitung

Böll 1938-1945 2

Böll 1945-1971 4

Bölls Leben in der Öffentlichkeit: Kritik an der 6

Zeitung und an der Regierung

2. Juni 1967: Bölls Verteidigung von der 13

Studentenbewegung

Bölls Leben in der Weltöffentlichkeit 21

$\begin{array}{ll}\text { Zusammenfassung } & 28\end{array}$ 


\section{Kapitel: Böll 1971-1974; Katharina Blum}

Einleitung: Der Entstehungsanlass des Romans 30

Katharina Blum

Bölls Zeitungsartikel - Abrechnung mit der

Vergangenheit

Bölls Zeitungsartikel: Kritik an Verfolgung 37

Rufmordkampagne gegen Böll: Gekoppelten 47

Zeitungsberichten mit Polizeiaktionen

Bölls Intention: Enthüllung von Radikalisierung 53

Menschenwürde und Ehre $\quad 59$

Das Such nach Terroristen: systematische 67

Entmenschlichung und Radikalisierung

Liebe auf den ersten Blick: Das Zusammentreffen von $\quad 74$

Katharina und Ludwig von Innen angetrachtet

Vernehmungen: Das zufällige Zusammentreffen von 83

Katharina und Ludwig von außen angetrachtet

Die Entmenschlichung und Radikalisierung von $\quad 88$

Katharina durch staatliche Vernehmungen mit

Rufmordkampagne gekoppelt

Die Entmenschlichung von Götten beinhaltet

Katharinas verlorene Ehre 
Ungerechte Entmenschlichung: Ludwig als Mensch

95

Zusammenfassung

98

Literaturhinweise

100

Anhang A: Radikale im öffentlichem Dienst

103

Anhang B: Radikale

105 
Liste von Verkürzungen

$A P O$ - Außerparlamentarischen Opposition

$B M$ - Baader-Meinhof, Baader-Meinhof Gruppe; auch, die RAF

die Gruppe um Ulrike Meinhof und Andreas Baader

vgl. BM-Gruppe, BM-Leuten, BM-Mitgliedern, "BM“", BM-Hatz, BM-

Komplice, BM-Komplicenschaft, BM-Quartier, BM-Aktivistin, BM-Verdacht, BM-Bande

$B Z$ - Berliner Zeitung

$C D U-$ Christlich Demokratische Union

$C S U$ - Christlich-Soziale Union

$D K P$ - Deutsche Kommunistische Partei

$N A T O$ - Nordatlantische Vertragsorganisation (North Atlantic Treaty Organization)

PEN - Poets, Essayists and Novelists

Internationale Verband der Autoren gegen Zensur

$R A F$ - Rote Armee Fraktion

$S D S$ - Sozialistischen Studenten Bund

SEATO - Engl. Southeast Asia Treaty Organization (1977 aufgelöst)

SED - Sozialistische Einheitspartei Deutschlands Siehe II. Kapitel „Rufmordkampagne gegen Böll,“

Zitat erwähnt Karl-Eduard von Schnitzler

SPD - Sozialdemokratische Partei Deutschlands

$X Y$-Zimmermann - vgl. Fernsehsendung Aktenzeichen XY . . ungelöst

Mit Eduard Zimmerman, siehe I. Kapitel, „Bölls Zeitungsartikel: Kritik an

Verfolgung,“ Zitat aus „Will Ulrike Gnade oder freies Geleit“ 


\section{Kapitel: Böll 1938-1971}

\section{Einleitung}

Die 1974 erschienene Erzählung Die verlorene Ehre der Katharina Blum bleibt ein einflussreicher Erfolg in der deutschen Literatur. Bis 2007, „, hat es sich allein in Deutschland fast sechs Millionen Mal verkauft". ${ }^{1}$ Die verfilmte Version von Margarethe von Trotta und Volker Schlöndorff, die 1975 rasch nach der Veröffnung der Erzählung erschien und ein großer Erfolg des deutschen Kinos bleibt, unterstreicht das große Interesse, das die Erzählung in Deutschland weckte. Die Wirkung der Erzählung Katharina Blum ist zwiespältig; sie wurde von Geschehnissen in der BRD inspiriert und hatte einen großen Einfluss in der BRD. Der Einfluss in der BRD und im heutigen Deutschland von Bölls gesamten Schaffen und Tätigkeiten bleiben unleugbar. Böll war eine prominente Figur in der Nachkriegszeit. Sein Status als Mitbegründer der Gruppe 47 bis zur Verleihung des Nobelpreises für Literatur 1972 weist auf seine unbestreitbare Stelle als Persönlichkeit des öffentlichen Lebens in dieser Zeit in der BRD hin, in der er eine entscheidende und integrale Rolle spielte. Die Titelgeschichte „Wo ist Böll?” des am 2. August 2007 erschienenen ZEITmagazins deutet auf diesen Einfluss hin: „Einförmig pathetisch heißt es in den Archiven, Böll sei „ein Anwalt der Schwachen” gewesen, ein „,ehrenwerter Mann”, „das Gewissen der Nation”.,2 Er wollte die Ehre Deutschlands bewahren.

\footnotetext{
${ }^{1}$ Christiane Grefe und Adam Soboczynski, ,Wo ist Böll?” ZEITmagazin, Nr. 32, 2. August 2007, S. 18. ${ }^{2}$ Ebd., S. 14. 
Böll 1938-1945

Das historische Ereignis des NS-Aufstiegs zur Macht war für Böll von entscheidender Bedeutung. Als Jugendlicher ahnte er schon frühzeitig den kommenden Aufstieg der NSDAP zur Macht. Er schrieb später in Rücksicht auf das Phänomen der NS-Zeit: „Meine unüberwindliche (und bis heute unüberwundene) Abneigung gegen die Nazis war kein Widerstand, sie widerstanden mir, waren mir widerwärtig auf allen Ebenen meiner Existenz.”3 In der im Jahre 1959 erschienenen Kurzautobiografie „Über mich selbst” schilderte Böll den Vorgang seines politischen Engagements. Im ersten Abschnitt dieser Denkschrift über seiner Kindheit und Jugendzeit rührt er an der NSPartei im Zusammenhang mit dem Besuch von Adolf Hitler und dem zukünftigen Politiker Hermann Göring in seiner Heimatstadt Köln. Es wird deutlich, dass der soziale und politische Aufstieg des Nationalsozialismus seine Kindheit und sein Leben überschattete. Böll ahnte, ,daß der bürgerliche Unernst der Stadt gegen die neu heraufziehende Mechanik des Unheils nichts ausrichten würde“ ${ }^{4}$ Er notierte die Ungläubigkeit des Volkes in Köln, ,wo weltliche Macht nie so recht ernst genommen worden ist, geistliche Macht weniger ernst, als man gemeinhin in deutschen Landen glaubt“. ${ }^{5}$ Die zentralen Themen der Politik und Religion, die als weltliche Macht und geistliche Macht in einem angeblich autobiografischen Werk angedeutet sind, zeigen diese als dringliche und dringende Angelegenheiten Bölls. Diese Betonung

Vergangenen gegenwärtige Diskussionen: die RAF; das Gerechtigkeitsproblem; den Umweltschutz; die Medienkritik; das Ringen mit der Religion."

${ }^{3}$ Heinrich Böll, ,Was soll aus dem Jungen bloss werden?” Die Zeit, Nr. 36, 28. August 1981.

${ }^{4}$ Heinrich Böll, „Über mich selbst,” in der Heinrich-Boell.de Website.

${ }^{5}$ Ebd., Heinrich-Boell.de Website. 
unterstreicht zwei Grundereignisse Bölls, die sein Leben und sein Schreiben

beeinflussten: seine Überzeugung an Katholizismus und seine Teilnahme am II.

Weltkrieg.

Bölls religiöse Einstellungen kristallisierten sich im Krieg heraus. Seine Teilnahme am

Zweiten Weltkrieg gilt als ein bedeutendes Ereignis, das sein politisches Engagement

erklärt. Wie die Mehrheit von Radikalen, die als Jungendliche durch

außergewöhnliche Umstände radikalisiert worden sind, hatte dieses historische

Ereignis beim jungen Böll auch einen radikalisierenden Einfluss. ${ }^{6}$ Als die NSDAP den

Weltmachtangriff 1938/39 versuchte, war Böll gerade im den frühen 20er Jahren, im

richtigen Alter für den Wehrdienst: „Am 3. September wurde Böll, noch 21 Jahre alt,

als Soldat der Wehrmacht vereidigt."7 Schon während des Krieges erschienen seiner

religiösen Neigungen in Briefen. Er schrieb aus Stanislau am 6. Februar 1944, ,dass

die Gesetze Gottes im Krieg ebenso gelten wie im Frieden“. ${ }^{8}$ Seine religiösen

Gedanken und Anlass zum Schreiben formten sich schon im Krieg. Böll war bereits

ein erklärter Feind von Gewalttätigkeiten. Die pazifistische Einstellung könnte als eine

radikale Einstellung gegen Krieg bewertet werden. Diese früh im Leben geformten

\footnotetext{
${ }^{6}$ Vgl. hier: Heinrich Böll, „Ich habe die Nase voll!” in Gefahren von falschen Brüdern: Politische Schriften, Auswahl aus: >Einmischung erwünscht. Schriften zur Zeit< (München: Deutscher Taschenbuch Verlag, 1980), S. 52 .

„Natürlich glaube ich, daß überhaupt keine Kunst auf dieser Welt möglich ist, daß weder Kunst noch

Schriftstellerei - das sollte jeder wissen, der sie öffentlich verteidigt - ohne mindestens eine Beimischung von Anarchie denkbar sind. Diese Beimischung habe ich natürlich. [...] Aber, ich bin eben nicht nur Anarchist, ich bin auch Staatsbürger. Ich bin bewusster und überzeugter Bürger der Bundesrepublik Deutschland."

Vgl. hier auch: Christiane Grefe und Adam Soboczynski, „Wo ist Böll?” ZEITmagazin, Nr. 32, 2. August 2007, S. 21.

„Ich bin ein Anarchist, einer, der keine Autorität über sich anerkennt."

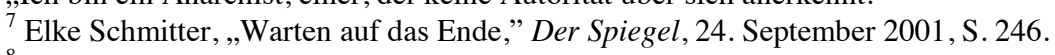

${ }^{8}$ Ebd., S. 246.
} 
Einstellungen Bölls erklären seine starke Kritik an der weltlichen Macht, das heißt die Regierung, die oft in der Praxis wesentlich widersprüchlich wirkt.

\section{Böll 1945-1971}

Böll, wie andere Heimkehrer der Stunde Null, wurde von der Erfahrung der NS-Zeit und des zweiten Weltkriegs beeinflusst. ${ }^{9}$ Die Schwierigkeiten der Heimkehrenden Soldaten, wie mit dem Schuldgefühl, der NSDAP gehört zu haben z.B., trafen diese Jungendlichen und wenigen Gebildeten stark. Böll beschrieb dieses Schuldgefühl in der autobiografischen „Über mich selbst” und schrieb, dass die rückkehrenden Soldaten, „das Unheil zu entziffern versuchten und die Formel nicht fanden; die Summe des Leidens war zu groß für die wenigen, die eindeutig als schuldig zu erkennen waren; es blieb ein Rest, der bis heute nicht verteilt ist““. ${ }^{10}$ Das Schuldgefühl wurde den Heimkehrern in der Zeit lebendig, obwohl die unerklärte Schuld durch eine Generalamnestie später existentiell abgeschafft wurde. ${ }^{11}$ Trotz der zahlreichen Probleme nach dem Krieg, beschäftigten sich manche von ihnen, und Böll unter diesen, mit universellen Werten, wie z.B. Demokratie und Menschenwürde.

\footnotetext{
${ }^{9}$ Vgl. hier: Norbert Frei, „Die Debatte im Zeichen der Wiederbewaffnung (1950/51),” in Vergangenheitspolitik, (München: Deutscher Taschenbuch Verlag, 2003), S. 195-234.

Vergleich hier besonders S. 207, über die Diskussion von der, ,Fragen nach Schuld und Sühne [...] mit denen sich „vor Korea" noch hatte herumschlagen müssen."

${ }^{10}$ Heinrich Böll, „Über mich selbst,” in der Heinrich-Boell.de Website.

${ }^{11}$ Vgl. hier: Norbert Frei, „Einleitung” und „, I. Vergangenheitspolitische Gesetzgebung: Weichenstellungen im Parlament und in der Regierung," in Vergangenheitspolitik, (München: Deutscher Taschenbuch Verlag, 2003), S. 7-133.

In der kurz nach Kriegsende Besatzungszeit entsprangen verschiedene Anschauungen, wie mit der NS-

Vergangenheit umzugehen: „Legende von der zweiten Schuld.” (S. 10): Die „Kollektivschuld These.” (S. 25): Ein klarer, ,Trennstrich [...] zwischen die Führung und Volk.” (S. 25)
} 
Der Krieg zwang diese Heimkehrer zur Radikalität gegen den Krieg. Manche Heimkehrer wollten die Gefahr eines neuen Krieges abschaffen. Sie hatten aber weder Erfahrung noch Ausbildung dieses Ziel durch bestimmte Schritte zu vollbringen. ${ }^{12}$ In den Worten des Heimkehrers Helmut Schmidt, wusste er nur, ,[d]ies alles darf nie wieder geschehen“. Obwohl er nicht wusste, wie man mit diesem Ziel umgehen solle, habe er sich, „, für Demokratie und soziale Gerechtigkeit engagiert“. ${ }^{13}$ Diese Äußerung könnte als eine allgemeine Einstellungserklärung der Heimkehrer gelten.

Sofort nach dem Krieg im Jahre 1946 verwirklichte Böll seine Rückkehr in die Literatur. Er fing das Studium der Germanistik an der Universität Köln an, das er aber nicht beendete. Da er 1939 zum Wehrdienst eingezogen wurde, unterbrach der Eintritt ins Heer seine damals anfangende literarische Karriere, die er nach dem Abiturabschluss 1937 als Lehrling im Buchhandel und als Autor begann. Ab 1947 erschienen Bölls Kurzgeschichten in Zeitungen und Zeitschriften. Bölls Schreiben dieser Zeit, besonders über den Krieg, wurde vom Publikum nicht gut Empfangen. Dieser Zustand wurde in einem am 22. August 1994 im Spiegel erschienenen Artikel über die Entdeckung eines Briefwechsels mit dem Freund Ernst-Adolf Kunz beschrieben und diskutiert: „Vom Krieg, von Trümmern und zerstörten Menschen, von den zentralen Themen des frühen Böll also, wollte das Publikum jener Jahre nichts wissen." ${ }^{14}$ Seine damaligen Schriften wurden für Publikation häufig abgelehnt: „Sogar Alfred Andersch, Rundfunkredakteur des Frankfurter Abendstudios, schickte

\footnotetext{
${ }^{12}$ Vgl. hier: Heinrich Böll, „Über mich selbst,” in der Heinrich-Boell.de Website. Bölls Überlegungen an den Soldaten, die, ,inzwischen unversehens Männer geworden”, sind. Vgl. hier auch: Norbert Frei, „I. Vergangenheitspolitische Gesetzgebung: Weichenstellungen im Parlament und in der Regierung," in Vergangenheitspolitik, (München: Deutscher Taschenbuch Verlag, 2003), S. 25-133.

${ }^{13}$ Helmut Schmidt, ,Was ich noch glaube”, Der Zeit, 11. September 2008, S. 8.

${ }^{14}$ Anonym, ,Schnaps für den Knaben,” Der Spiegel, 22. August 1994, S. 160-161a.
} 
seinem Schriftstellerkollegen Böll mehrere Erzählungen zurück."15 Endlich ermöglichte ihm seine Beziehung zur Gruppe 47 den gewünschten Erfolg in der Literatur, ,„[z]um ersehnten Durchbruch verhalf Böll jedoch erst der Preis der Gruppe 47“, welchen er im Jahre 1951 bekam. ${ }^{16}$ Bölls Kurzgeschichten und Romane erschienen ab 1951 immer häufiger bis 1971. Danach wurden seine Stellungnahmen und Schriften immer politischer: Katharina Blum markierte den Höhepunkt des Zusammenkommens von seinem Literaturschaffen und seinem politischen Engagement. Offensichtlich war Böll die Wichtigkeit der Presse in der öffentlichen Meinungsbildung schon damals persönlich bekannt. In einem Brief sprach sein Freund Ernst-Adolf Kunz eine der Hauptkennzeichen jenes Erfolgs an: „Du wirst 2x positiv im SPIEGEL genannt." ${ }^{17}$ Diese ehrenhafte Anerkennung wirkte als eine Art Beweis des Erfolgs.

Bölls Leben in der Öffentlichkeit: Bölls Kritik an der Zeitung und an der Regierung

Bölls politisches Engagement wurde erst in seiner Teilnahme an der Gruppe 47 deutlich. Als freier Schriftsteller war er an der Frage der Meinungsfreiheit persönlich interessiert. Er wollte das Recht der persönlichen Meinungsäußerungen in der BRD versichern. Seine Beziehung zur Presse veränderte sich stark von 1951 bis 1968. Die zunehmende Tendenz der Zeitung, Akademiker in Frage zu stellen, deutete auf eine Beschränkung der freien Meinungskultur. Böll nahm seine kritische Haltung zu der

\footnotetext{
${ }^{15}$ Ebd., S. 160-161a.

${ }^{16}$ Ebd., S. 160-161a.

${ }^{17}$ Ebd., S. 160-161a.
} 
Springer-Presse nicht allein. Schon zur Zeit der 68er Revolution wurde Kritik an den Hetzmethoden der Springer-Presse von Beobachtern inner- und außerhalb Deutschlands geübt. Diese Art von Kritik, die Böll an Bild und an den verschiedenen Organen der Springer-Presse in dieser Zeit hervorhob, wurde schon 1967 im Laufe der Studentenbewegung erläutert. Es gab auch eine allgemeine kritische Rezension auf die Meinungsorgane in der BRD, besonders auf die Springer-Presse.

Im Jahre 1968 wurde die Anti-Springer Resolution von der Gruppe 47 veröffentlicht, eine Stellungnahme ausführlich gegen die Methoden der Springer-Presse und den Sensationsjournalismus im Allgemein eingerichtet. Unter den Mitautoren zählten die Anhänger der Gruppe 47 Heinrich Böll, Alexander Mitscherlich, Walter Jens und Theodor W. Adorno mit. Ihre Kritik zielte auf der gegensätzlichen Reibung zwischen der konstitutionellen Rechtfertigung der Pressefreiheit und dem wirklichen politischen Agenda der Zeitung, nämlich eine allgemeine Hetzkampagne gegen Akademiker:

Dieses Klima ist systematisch vorbereitet worden von einer Presse, die sich als Hüterin der Verfassung aufführt und vorgibt, im Namen der Ordnung und der Mehrheit zu sprechen, mit dieser Ordnung aber nichts anderes meint als die Herrschaft über unmündige Massen und den Weg in einen neuen, autoritätsbestimmten Nationalismus. ${ }^{18}$

Diese Kritik entstammte aufgrund der verhetzenden Schlagzeilen und der Kriminalisierung der studentischen Demonstranten. Diese planvolle Hetze gegen Nichtkonformisten bestätigt sich durch sachliche, neutrale Begutachtungen von verschiedenen Zeitungen inner- und außerhalb Deutschlands.

\footnotetext{
${ }^{18}$ Anti-Springer Resolution. Abschnitt in: Anonym, ,"'Einseitig, lückenhaft, unsachlich”: Urteile über Springer und seine Zeitungen,” Der Spiegel, 6. Mai 1968, S. 44.
} 
Gegensätzliche Meinungen gegenüber der Springer-Presse kamen zur Sprache im Bericht, ,"'Einseitig, lückenhaft, unsachlich”: Urteile über Springer und seine Zeitungen“. In diesem Bericht wurden Kritiken aus internationalen Quellen dargestellt: „’The Guardian”, London und Manchester, vom 16. April: Deutsche Konservative wie Springer haben immer dazu geneigt, jeden Nichtkonformisten einen Kommunisten zu nennen.“"19 Manche wollten dieser Frage nachgehen: „Es muß darum schärfstens der Erklärung des Springer-Verlags widersprochen werden, er habe die sachliche Auseinandersetzung gesucht." ${ }^{20}$ Böll wollte auch diese Auseinandersetzung mit der Springer-Presse beleuchten.

Böll hatte die Absicht die Rolle der Zeitungen in Frage zu stellen. Er wollte die Gewalt der Springer-Presse enthüllen:

Man mag im Ausland gelegentlich denken, das Phänomen Axel Springer werde von Studenten und Intellektuellen in der Bundesrepublik in seiner Gefährlichkeit übertrieben. Dabei vergißt man leicht, daß Herrn Springers Lieblingswirkungsfeld Berlin ist; daß seine Zeitungen, die in der Bundesrepublik unter anderem laufen, in Berlin die öffentliche Meinung bilden und fast ausschließlich beherrschen. Die demagogisierte Berliner Bevölkerung [...] ist das Ergebnis Springerscher Manipulation. $^{21}$

Böll warnte vor dem Einfluss der Springer-Presse als der beherrschende

Meinungsapparat. Zu dieser Zeit konzentrierte sich Bölls Kritik auf die Zeitung: das heißt, statt die Studenten zu verteidigen kritisierte er die Zeitung und blieb in diesem Sinne politisch neutral. Böll verstand den Begriff die Presse im originellen Sinne mit der Zeitung und der Verfassung verbunden. Sie spielt eine besondere Rolle in einem

\footnotetext{
${ }^{19}$ Ebd., S. 44.

${ }^{20}$ Ebd., S. 44.

${ }^{21}$ Heinrich Böll, „Günter Wallraffs unerwünschte Reportagen,” in Gefahren von falschen Brüdern: Politische Schriften, Auswahl aus: >Einmischung erwünscht. Schriften zur Zeit< (München: Deutscher Taschenbuch Verlag, 1980), S. 8.
} 
Rechtsstaat. Die Presse gehört zum Fakt-bezogenen Teil der Gesellschaft und soll die Mitteilung der rationalen Ideen und Meinungen ermöglichen. Pressefreiheit soll rein theoretisch ein Gleichgewicht der Meinungen ermöglichen. Da man heute auch die verschiedenen Medien unter diesen Begriff versteht, mindert die Bedeutung der solchen Medien für die Meinungsfreiheit nicht. Böll meinte, dass die Pressefreiheit die Meinungsfreiheit unterstützen und fortentwickeln soll. Böll argumentierte, dass statt dieser Unterstützung von Meinungsfreiheit, ein Interessenkonflikt in den Pressenverlagen oft stattfindet. Nach Bölls Ansicht wirkte die Zeitung in Verknüpfung mit der Regierung. Böll selbst beschrieb die Bild-Zeitung im Jahre 1984 in seinem Nachwort zur Katharina Blum ,Zehn Jahre später“ als, „fast schon das regierungsamtliche Blatt. Ministerielle Verlautbarungen zu wichtigen politischen Themen erscheinen am Sonntag oder Montag in einer der >Bild<-Varianten. Zufall ist das nicht"“ ${ }^{22}$ Böll kritisierte die amtlichen Entscheidungen der Regierung, die oft mit der redaktionellen Meinungen der Zeitungen in Verbindung stehen. Böll verstand die Gewalt von der Regierung durch Polizeiaktionen und die Gewalt von Schlagzeilen in der Zeitung als ein verbundenes Phänomen.

Böll meinte, dass Pressefreiheit keinen Wert an sich trägt, sondern sie verbindet sich mit vielen Ideen und Konzepten, die grundsätzlich mit dem Begriff der persönlichen Freiheit und unveräußerliche Rechte korrespondieren. Pressefreiheit verbindet sich mit Meinungsfreiheit, indem die Presse keine eigenen partiellen Meinungen ausdrücken soll und keine oppositionellen Meinungen unterdrücken soll. Da die Presse den Zweck

\footnotetext{
${ }^{22}$ Heinrich Böll, ,Zehn Jahre später,” Nachbemerkung zur Katharina Blum, (München: Deutscher Taschenbuch Verlag, 2003), ab S. 145.
} 
das freie Kundtun der Meinungen in einem Rechtsstaat hat, soll der Begriff oppositionelle Meinungen ohne Bedeutung in einer Demokratie sein, trotzdem wurde es oft angewandt. Die Pressefreiheit steht in direktem Zusammenhang mit allen demokratischen Gründsätzen. Diese Grundsätze umfassen Meinungsfreiheit, Recht auf Bildung, Versammlungsfreiheit, Bewegungsfreiheit, Redefreiheit und Unschuldsvermutung unter anderen. Diese verschiedenen Rechte wirken im engen Zusammenhang, sie sind aber wirkungslos, wenn sie gegeneinander ausgespielt, oder im Einzelnen angewandt, worden sind. Böll zeigte, dass die aktuelle sogenannte Pressefreiheit eigentlich eine bloße Erlaubnis des Herausgebers ist, seine persönliche Meinung redaktionell darzustellen und diese andauernde Pressefreiheit dem Recht auf eine allgemeine Meinungsfreiheit widerspricht. Die Pressefreiheit und die Meinungsfreiheit stehen dann heute nur den Menschen zur Verfügung, die das Mittel der Medien besitzen oder besondere Beziehungen zu den Medien haben. Andersdenkende haben nicht dieselbe Gelegenheit, ihre Meinungen freimütig und in der Öffentlichkeit zu äußern. Dadurch werden die verschiedenen Meinungen in der Gesellschaft in einer bestimmten Richtung beeinflusst.

Böll zeigte, dass die Auflage der Zeitung durch sensationalisierte und vereinfachte Berichterstellung von privaten und öffentlichen Persönlichkeiten verstärkt wird, welcher Sensationalismus harmlos scheint, aber meist in der Richtung der wirtschaftlichen Interessen einseitig dargestellt wird. Böll warnte, dass diese Neigung die Schwächung der Grundrechte als Folge hervorbringt. Die Verdinglichung der Menschen in der Zeitung der modernen Marktwirtschaft ist unvermeidbar, denn sie 
gehört grundsätzlich zum ,Objektivismus’ der Marktwirtschaft, weil die Person selbst zum Marktartikel wird. Böll wollte aber, dass die Zeitung übertriebene Darstellungen von Menschen vermeidet. Böll argumentierte weiter, dass die Tendenz die akademische Einstellung vereinfacht darzustellen, das marktwirtschaftliche Profitsystem widerspiegelt: die Zeitung kennt nur ein Gesetz, das heißt Profit. Eine Verbindung zwischen Großindustrie und der Zeitung deutet auf gefährdete Grundrechte in jener Republik hin. Böll meinte, dass die vorhandenen autoritären Tendenzen der Zeitungsberichte mit dem marktwirtschaftlichen Anlass zur Vereinfachung oppositioneller Perspektiven gekoppelt war. Diese Kritik wurde in der Anti-Springer Resolution der Gruppe 47 ausgedrückt:

Das Bündnis von bedenkenlosem Konsumjournalismus und wiederauflebender nationalistischer Ideologie, das die demokratisch engagierten Studenten und Intellektuellen seit Jahren als "Linksmob", "Eiterbeule", "akademische Gammler", "Pöbel", "geistige Halbstarke", "Neurotiker", "Schreier" und "Schwätzer" verunglimpft, droht das Selbstverständnis der Deutschen in einer Welt der friedlichen Verständigung, der fortschreitenden Aufklärung und Zusammenarbeit auch zwischen verschiedenen Gesellschaftssystemen abermals zu zerstören. $^{23}$

Der politisch motivierte Angriff an Studenten und Professoren in der Zeitung, hat als

Folge, dass das Bildungsrecht in Frage gestellt wird. Die Bildung baut den Kern jener demokratischen Gesellschaft und versichert die Zukunft diese.

Böll bemerkte die Intensivierung der amtlichen Aktionen und die damit verknüpfte

Hetze von der Zeitung gegen politische Opposition. Böll wollte die drohende

\footnotetext{
${ }^{23}$ Anti-Springer Resolution. Abschnitt in: Anonym, ,,"Einseitig, lückenhaft, unsachlich”: Urteile über Springer und seine Zeitungen," Der Spiegel, 6. Mai 1968, S. 44.

Vgl. hier: Heinrich Böll, „,Der verwaltete Mensch,” Der Spiegel, 22. April 1974, S. 190.

„Sollte aus der Hitlerwelle auch nur andeutungsweise eine Hitlernostalgie werden, so wären Adlers "Studien zur

Deportation der Juden aus Deutschland" das wahre Gegenmittel."
} 
Anwendung roher Gewalt gegen Studenten und Andersdenkende abwenden. Bölls Plädoyer für diese Studenten war nicht als die Verleihung eines Sonderstatus an Studenten gemeint. Er wollte klar machen, in welcher Hinsicht er Veränderung suchte: „Ich plädiere hier nicht für Ausnahmegesetze, Privilegien für Autoren und Intellektuelle [...] die außerhalb des Gesetzes stünde[n]., ${ }^{, 24}$ Er wollte eher die Rechte und Würde dieser Studenten sicherstellen. Infolge eines Sternmarsches am 11. Mai 1968, der im Widerspruch zu den sogenannten Notstandsgesetzen stand, übte Böll scharfe Kritik an der deutschen Presse. Die Notstandsgesetze schränkten durch bestimmte Maßnahmen die Grundrechte der Bürger in der BRD ein und hatte bedeutende Folge auf Deutschlands pazifistische Einstellung in der Außenpolitik. ${ }^{25}$ Die Uniformität fast aller Zeitungen und Medien im Hinblick auf den Sternmarsch überraschte und entsetzte Böll: „Die deutsche Presse ist ja nicht nur konzentriert, auch konzertiert, derart konzertiert, [...] [e]s bleibt ja ohnehin nur das eine: zersetzen, zersetzen, zersetzen. Zersetzung ist hier die einzig mögliche Form der Revolution.” ${ }^{26}$ Es wurde nicht nur die Teilnehmerzahl an dem Protest in verschiedenen Zeitungen vermindert, um die große der Bewegung falsch darzustellen, sondern es wurde auch Teilnehmer als Linksradikale dargestellt, denn sie gehörten vermutlich einer extremistischen Randgruppe an: „,[D]och am Vortage des Sternmarsches noch, vom Funk und Fernsehen begünstigt, öffentlich kundtun, daß da obskure Elemente, hauptsächlich Kommunisten, ans Werk gehen, die Demokratie zu zerstören. [...] Wer

\footnotetext{
${ }^{24}$ Heinrich Böll, ,Gutachten zum Prozeß gegen Erich Fried,” in Gefahren von falschen Brüdern: Politische Schriften, Auswahl aus: >Einmischung erwünscht. Schriften zur Zeit< (München: Deutscher Taschenbuch Verlag, 1980), S. 27-8.

${ }^{25}$ Siehe: Anhang B: Radikale

${ }^{26}$ Heinrich Böll, „Notstandsnotizen,” in der Glasnost.de Website.
} 
war da nun in der Position der »Hysterie «? ${ }^{‘ 27}$ Durch die falsche Darstellung des Protests gegen die Notstandsgesetze zeigte die Zeitung, und hier auch „Funk und Fernsehen" dazu, ihrer beiderseitigen Unterstützung der Regierung und Fähigkeit zur Hetze der Demonstranten. Böll wurde von diesem Geschehen entsetzt und erwartete weitere Maßnahmen und Kritik von der Gruppe 47. Doch sie schwieg und Böll musste seine Stimme allein aufheben. Er kritisierte die Gruppe selbst:

Diesmal keine Resolution, kein Aufruf von der Gruppe 47. Nach diesem öffentlich begangenen politischen Selbstmord der Gruppe 47 frage ich mich, warum die Gruppe 47 die Anti-Springer-Resolution aufsetzte. Warum sollte einer nicht auch auf Springer-Mist krähen? [...] Der politische Moralismus der Gruppe 47 ist jedenfalls nach ihrer Notstandsabstinenz nur noch peinlich. ${ }^{28}$

Als die Gruppe nach 20 Jahren Aktivität ihre treibende Kraft verlor, wurde Böll mit der Politik der Gruppe unzufrieden und verlass diese.

2. Juni 1967: Bölls Verteidigung von der Studentenbewegung

Stellvertreter der Studentenbewegung äußerten unabhängig von Böll seine kritische Haltung zum Nachkriegsdeutschland. Sie spiegelte die Kritik wider, die Böll an der Zeitung nach der Auflösung der Gruppe 47 allein übte. Die Studentenbewegung, die in den 1960er Jahren auftauchte und als ein wesentlicher Bestandteil der 68er Bewegung gilt, stellte sich kritisch den vergangenen Generation gegenüber. Die Generation der Studentenbewegung betrachtete die Generation ihrer Eltern als Sympathisanten am Nationalsozialismus und kritisierte auch den US-amerikanischen Kapitalismus und die

${ }^{27}$ Ebd., Böll in der Glasnost.de Website.

${ }^{28}$ Ebd., Böll in der Glasnost.de Website. 
Außenpolitik der USA. Auf die Studenten der Studentenbewegung wirkte das

Gewissen der Nation, das die Vermeidung einer zweiten NS-Zeit bestrebte. Ulrike

Meinhof, auch von diesem kulturellen Gewissen angetrieben, schrieb schon im Jahre

1961:

The realization that this generation is innocent cannot, however, be used as an instrument by those who want to refuse young people the right to have their say about history; nor does it free this generation from facing the responsibilities of the present. ${ }^{29}$

Das verinnerlichte nationale Schuldgefühl aktivierte diese Jugendliche Änderungen in der Gesellschaft sofort energisch zu fordern. Dieser Änderungswunsch entstand aus der Liebe der Nation. In einer 1968 veröffentlichten Untersuchung über diese revolutionäre Zeit enthüllte der Forscher Wulf Schönbohm u.a. dem Beweggrund der revolutionären Studenten: „Die moralisch bestimmte, aus Idealen und Weltanschauungen bezogene Haltung der Studenten ist die zweite Grundlage der studentischen Kritik an der Politik."30 Diese moralische Kritik stimmt in gewissem Sinne mit Bölls Einstellung überein und spielte eine große Rolle bei der Vergangenheitsbewältigung der Studenten.

Böll unterstützte die Studentenbewegung und hatte eine ähnliche kritische Einstellung gegenüber den politischen und wirtschaftlichen Entwicklungen in der BRD in der Nachkriegszeit. Bölls Position wandte sich von einer Kritik an der Zeitung zu einer Verteidigung von Akademikern und Studenten. Böll lobte die Arbeit dieser Studenten: „Man denke sich doch einmal die Studentenbewegung aus unserer Geschichte fort,

\footnotetext{
${ }^{29}$ Ulrike Meinhof, ,Hitler within you,” in Everybody talks about the weather...we don't: The Writings of Ulrike Meinhof, Verfasserin: Karin Bauer, (New York: Seven Stories Press, 2008), S. 138.

${ }^{30}$ Wulf Schönbohm, Jürgen Bernd Runge und Peter Radunski, Die herausgeforderte Demokratie: Deutschlands Studenten zwischen Reform und Revolution, (Mainz: Hase \& Koehler Verlag, 1968), S. 23.
} 
stelle sich vor, sie habe nicht stattgefunden - wie gelähmt wäre unser

Bildungswesen denn heute?"31 Die Radikalen der Studentenbewegung ermöglichte eine öffentliche Kritik an der Nachkriegswirtschaft in der Bundesrepublik. Böll erkannte den großen Einfluss dieser Radikaler und meinte, dass diese Bewegung die gesellschaftliche Kritik ermöglichte: „Wer hat es denn riskiert, das praktizierte Bodenrecht, das Eigentum als erster in Frage zu stellen?"32 Die Studenten stellten auch das parlamentarische System Deutschlands in Frage.

Bölls Kritik an der gekoppelten Wirkung der Regierung und der Zeitung gegen Studenten und staatliche Opposition wurde nicht theoretisch, sondern sie basierte sich auf der faktischen Unterdrückung der Studenten. Da diese Studenten von staatlicher Gewalt betroffen waren, wollte Böll sich in diese Angelegenheit einmischen, denn die Studenten teilten seine Meinungen und er identifizierte sich mit ihnen. Das erste greifbare Ausüben dieser Gewalt geschah in der sogenannten Oster-Unruhen des 2. Juni 1967. Bundesdeutsche Studenten sammelten in Berlin und protestierten gegen den Besuch des Schahs von Persien. Böll selbst war kritisch der Beziehung Deutschland und Persien gegenüber. Er kritisierte diese Beziehung schriftlich 1976: „In einem Land, in dem der Schah und andere Ölpotentaten Milliarden investieren, mit der Angst vor dem Sozialismus zu drohen, dürfte ziemlich weit hergeholt sein.“33

\footnotetext{
${ }^{31}$ Heinrich Böll, ,Radikalität und Hoffnung,” in Gefahren von falschen Brüdern: Politische Schriften, Auswahl aus: >Einmischung erwünscht. Schriften zur Zeit< (München: Deutscher Taschenbuch Verlag, 1980), S. 20-1.

${ }^{32}$ Ebd., S. 21.

${ }^{33}$ Heinrich Böll, „Die Angst der Deutschen und die Angst vor ihnen,” in Gefahren von falschen Brüdern: Politische Schriften, Auswahl aus: >Einmischung erwünscht. Schriften zur Zeit< (München: Deutscher Taschenbuch Verlag, 1980), S.107-8.

„[L]ange bevor man über Faschismus spricht und nicht nur über den potentiellen, auch den historischen, muß man wissen, daß Angst eine der Ursachen des Faschismus ist. Man muß wissen, daß Zeitungen und Stimmungen immer noch von den Besitzenden gemacht werden. [...] [D]ann hat man die Angst zu einem Wahlhelfer gemacht, der kaum Argumente braucht und wenig Geld kostet. Man erinnere sich an die obskuren Wahlhilfefonds der CDU/CSU
} 
Während des Protests erschoss der Polizist Karl-Heinz Kurras den FU-Student Benno Ohnesorg mit einem Schuss in den Hinterkopf. Kurras Anlass zum Gebrauch seiner Dienstpistole bleibt ungeklärt und seit der Entdeckung von Kurras Stasiakten im Mai 2009 wird die Frage noch komplizierter. Trotzdem war diese Ausübung von staatlicher Gewalt gegenüber Studenten in dieser Zeit von größter historischer Bedeutung.

Die gekoppelte Aktion der Zeitungen mit der Regierung wurde in der Nachfolge dieses Geschehens deutlich. Der amtliche Gebrauch von Gewalt wurde in der Zeitung verteidigt und unterstützt. Die Unterstützung der Regierung von der Zeitung wurde einweiteres Mal offensichtlich in der Kritik an den Studenten. Am 6. Mai 1968 veröffentlichte die Redaktion der Spiegel-Zeitung einen Enthüllungsbericht über die springersche Einstellung mit dem Artikel, „"Eine ,Bild'-Schlagzeile ist mehr Gewalt als ein Stein am Polizisten-Kopf": Eine Dokumentation über die Oster-Unruhen und ihre Ursachen: die Rolle des Verlagshauses Axel Springer“.${ }^{34}$ Verschiedene einseitige Zitate aus den Springer-Zeitungen über dem Fall der Studenten-Unruhe sowie oppositionelle Meinungen dazu wurden in dem Enthüllungsbericht von Spiegel dargestellt. Der Artikel war kritisch im Allgemein gegenüber der Springer-Presse. Ein Auszug aus einem am 5. Juni 1967 in der Berliner-Zeitung veröffentlichten Artikel

aus dem dramatischen Wahljahr 1972; man denke an die Anzeigenkampagnen gegen Brandt und alle Formen des Sozialismus, and diese düsteren Maschenschaften [sic], deren sich die Verantwortlichen möglicherweise heute schämen. Das war klassischer Klassenkampf, von oben, nicht von unten.“ (S. 107)

${ }^{34}$ Anonym, ,"'Eine ,Bild'-Schlagzeile ist mehr Gewalt als ein Stein am Polizisten-Kopf': Eine Dokumentation über die Oster-Unruhen und ihre Ursachen: die Rolle des Verlagshauses Axel Springer"," Der Spiegel, 6. Mai 1968, S. 38.

Vgl. hier: Heinrich Böll, „Zehn Jahre später,” Nachwort zur Katharina Blum, (München: Deutscher Taschenbuch Verlag, 2003), S. 144.

Der Titel dieses Artikels leistete für Böll die nötige Vorarbeit, damit er später schreiben konnte, ,,[ü]ber die Gewalt von SCHLAGZEILEN ist noch zu wenig bekannt, und wohin die Gewalt von Schlagzeilen führen kann, darüber wissen wir nur wenig“". 
wurde zitiert, der die kritische Meinung von der Springer-Redaktion gegenüber den Studentendemonstranten widerspiegelte: „Was gestern in Berlin geschah - es hat nichts mehr mit Politik zu tun. Das war kriminell. Das war kriminell in übelster Weise. [...] Hysterie [...] und Terror sind keine Ausdrucksformen der politischen Auseinandersetzung." 35 Die Springer-Presse stellte die Studenten in ein groteskes Licht direkt nach der Erschießung von Benno Ohnesorg. Ihre Rolle als Mitschuldige bei dieser Gewalt wurde mit Hinterlist angedeutet. Diese Stellungnahme rechtfertigt die Gewalt von der Polizei an die Studenten. Ironischerweise wurde das einzige Opfer der Demonstration, der von der Polizei erschossene Benno Ohnesorg, der als Opfer des infamen 2. Junis gilt.

Böll und andere Schriftsteller in der Bundesrepublik äußerten heftige Kritik an der Regierung und den Gewalttaten der Polizei. Berichterstatter Sebastian Haffner beschrieb den 2. Juni 1967 in einem in dem Stern veröffentlichten Artikel als die, „Berliner Blutnacht““. Die gewalttätige staatliche Aktion, „, war ein systematischer, kaltblütig geplanter Pogrom, begangen von der Berliner Polizei an Berliner Studenten“. ${ }^{36}$ Er beschrieb die fragwürdigen Methoden der Polizei und die ungewöhnliche Behandlung von Demonstranten durch die Polizei:

Die Polizei hat die Demonstranten nicht, wie es üblich ist, verjagt und zerstreut, sie hat das Gegenteil getan: Sie hat sie abgeschnitten, eingekesselt, zusammengedrängt und dann auf die Wehrlosen,

\footnotetext{
35 Anonym, ,"'Eine „Bild'-Schlagzeile ist mehr Gewalt als ein Stein am Polizisten-Kopf”: Eine Dokumentation über die Oster-Unruhen und ihre Ursachen: die Rolle des Verlagshauses Axel Springer"," Der Spiegel, 6. Mai 1968, S. 38.

Der Text lautet weiter: „Diese Leute können von der Bevölkerung kein Verständnis mehr erwarten. Zwischen politischem Protest und sinnloser Pöbelei ist ein himmelweiter Unterschied."

${ }^{36}$ Sebastian Haffner, ,Nacht der langen Knüppel: Der 2. Juni 1967 - ein geplanter Pogrom,” Glasnost.de Website. (Sebastian Haffner ist das Pseudonym für Raimund Pretzel)
} 
übereinander Stolpernden, Stürzenden mit hemmungsloser Bestialität eingeknüppelt und eingetrampelt. ${ }^{37}$

Professor Alexander Mitscherlich, Mitautor der Streitschrift Anti-Springer Resolution, verteidigte im Zusammenhang mit der Oster-Unruhen die gegnerische Haltung der Studenten zur Springer-Presse. Seine erklärenden Stellungnahme bezüglich der studentischen Gegenreaktion wurde von einem am 5. Mai 1968 im Stern veröffentlichten Interview zitiert: „Weil die Springer-Zeitungen schon seit Anfang 1967 gegen die politisch engagierten Studenten gehetzt haben, die sie als “immatrikulierten Mob” bezeichneten, und weil sie deshalb an diesem Mordanschlag mitschuldig sind." ${ }^{38}$ Solche ungerechten Darstellungen sind nicht ohne Bedeutung, weil, ,der Springer-Konzern mehr als 80 Prozent der Presse beherrscht““. ${ }^{39}$ Diese Manipulation wird auch an Studenten angewandt: „Fast jeder Student hält sich eine überregionale Tageszeitung, wobei die Frankfurter Allgemeine Zeitung, Die Welt und die Süddeutsche Zeitung bevorzugt werden." ${ }^{40}$ Nach der Meinung von Professor Mitscherlich, ,,ist das Suchtmittel “Bild-Zeitung” zum Aufputschen eines Bevölkerungsteils gegen eine Minderheit eingesetzt worden“. ${ }^{41}$ Die Springer-Presse fand ihren politischen Anlass, die Studenten zu beschmieren, so Mitscherlich, bei ökonomischen Gründen: „Die Massenzeitungen sind in der technischen

\footnotetext{
${ }^{37}$ Ebd., Haffner in der Glasnost.de Website.

${ }^{38}$ Professor Mitscherlich, zit. nach: Anonym, ," Einseitig, lückenhaft, unsachlich": Urteile über Springer und seine Zeitungen," Der Spiegel, 6. Mai 1968, S. 44.

${ }^{39}$ Ebd., S. 44.

${ }^{40}$ Wulf Schönbohm, Jürgen Bernd Runge und Peter Radunski, Die herausgeforderte Demokratie: Deutschlands Studenten zwischen Reform und Revolution, (Mainz: Hase \& Koehler Verlag, 1968), S. 19.

${ }^{41}$ Anonym, ,"'Einseitig, lückenhaft, unsachlich”: Urteile über Springer und seine Zeitungen,” Der Spiegel, 6. Mai 1968, S. 44.
} 
Großgesellschaft die schärfste Waffe bestimmter Interessengruppen." ${ }^{42}$ Er stellte die unverschämte Behauptung auf, dass die Zeitung oppositionelle Meinungen und politische Engagierte absichtlich falsch darstellen.

Böll kritisierte im Zusammenhang mit dieser Verteidigung von der Zeitung die Instrumentalisierung der Wörter. Böll wollte der wörtlichen Gewalt der Zeitung widersprechen. Böll beschrieb die Gewalt von Wörtern im Zusammenhang mit dem Begriff Vorbeugemord. Der Gebrauch dieses Euphemismus in der Zeitung wirkte wie ein Freispruch für den Staat und für Karl-Heinz Kurras. Böll bemerkte in diesem Zusammenhang eine Schwierigkeit der Sprache von Juristen im Vergleich zu Autoren. Er hielt fest, „daß die Wörtlichkeit eines Autors eine andere ist als die der Legislative oder Exekutive. Ein Autor mag etwas Raub, Diebstahl, Mord, Erpressung nennen, was innerhalb des juristischen Vokabulariums nicht so genannt werden darf“ “ ${ }^{43}$ Dieser Unterschied spielte eine direkte Rolle in diesem Fall: „Mord nennen würde er die Tötung eines Menschen, der während einer ungeklärten Polizeiaktion ums Leben kam."44 Der Begriff Vorbeugemord wurde ohne Streit in der Zeitung übernommen. Böll meinte, dass im vorherigen Fall von Erich Fried, er halte, ,,die Frage der Urheberschaft für unwichtig, halte es aber für angebracht, festzustellen, daß gegen die Urheber des Wortes keine Klage erhoben wurde, auch nicht gegen die Verwendung des Wortes innerhalb eines Berichts über die Erschießung von Rauchs““. ${ }^{45}$ Diese Kritik

\footnotetext{
${ }^{42}$ Ebd., S. 44.

${ }^{43}$ Heinrich Böll, „Gutachten zum Prozeß gegen Erich Fried,” in Gefahren von falschen Brüdern: Politische Schriften, Auswahl aus: >Einmischung erwünscht. Schriften zur Zeit< (München: Deutscher Taschenbuch Verlag, 1980), S. 28.

${ }^{44}$ Ebd., S. 27-8.

${ }^{45}$ Ebd., S. 24.
} 
gilt bei dem Tod von Benno Ohnesorg, sowie bei dem Tod von Erich Fried und Georg von Rauchs.

Böll wollte es deutlich machen, dass polizeiliche Gewalt gegen Studenten, wie die Erschießung von Benno Ohnesorg z.B., nicht mit einem Rechtsstaat vereinbar ist. In der Denkschrift „Gutachten zum Prozeß gegen Erich Fried“ zeigte Böll die Bedeutung im Ausland von diesem Fall und in den Fällen von Georg von Rauchs und Erich Fried: „Vom Ausland aus, von jemand beobachtet wie Erich Fried, dessen Lebenslauf dem Gericht vorliegt, musste die Erschießung Georg von Rauchs düstere Assoziationen erwecken, besonders nach der Erschießung Benno Ohnesorgs." ${ }^{, 46}$ Ein solcher Gebrauch von Gewalt gegen die Bürger eines Rechtsstaats beschädigt das Ansehen eines Landes, das heißt, den Ruf im Ausland.

Das historische Ereignis des 2. Junis, den Tag an dem Benno Ohnesorg bei einer Demonstration erschossen wurde, verstärkte die Studentenbewegung und brachte linksextremische Terrororganisationen hervor. Dieses Geschehnis ist als der Entstehungsanlass der Studentenradikalen anerkannt. Diese Anerkennung wurde im am 1. Juni 2007 in der Berliner-Zeitung erschienenen Artikel „Ein tödlicher Moment” bestätigt: „Ausgehend von diesem 2. Juni 1967 radikalisiert sich die Studentenbewegung in Deutschland. ${ }^{, 47}$ Dieses Ereignis wird generell als der Beginn des Terrorismus in der BRD angetrachtet, als verschiedene radikale Assoziationen und Organisationen gleichzeitig erschienen. Unter denen zählten die Gruppe Außerparlamentarischen Opposition (APO) und die Sozialistischen Studenten Bund

\footnotetext{
${ }^{46}$ Ebd., S. 27.

${ }^{47}$ Holger Schmale, ,Ein tödlicher Moment,” Berliner-Zeitung, 1. Juni 2007, S. 3.
} 
$(S D S)$ mit. Der Artikel bestätigt die Wichtigkeit jenes Ereignisses: „Anfang der 70er-Jahre benutzt die "Bewegung 2. Juni” die Symbolkraft dieses Datums, des Todestags von Benno Ohnesorg, unverblümt für ihre terroristischen Ziele."48 Diese Gruppe entstammte von der studentischen Gruppe Kommune 1 und versteht sich als ein Teil der Studentenbewegung. Gudrun Ensslin, die später mit Ulrike Meinhof tätig war, erschien zum ersten Mal als Radikale im Zusammenhang mit dieser Gruppe. Die sogenannte Rote Armee Fraktion (RAF) stammte aus der 68- und Studentenbewegung und wurde offiziell am 14. Mai 1970 gegründet. Drei Woche später am 5. Juni 1970 erschien der Text Die Rote Armee aufbauen in der Zeitschrift Agit 883, die als die offizielle Ankündigung der RAF angesehen wird und vermutlich von Ulrike Meinhof geschrieben worden ist.

Bölls Leben in der Weltöffentlichkeit

Bölls Tätigkeit in der Gruppe 47 brachte ihm dem Deutschen PEN beizutreten. Der PEN ist ein Verein von, „Poets, Essayists and Novelists”, also von Schriftstellern, die sich gegen die Unterdrückung von Autoren aller Ländern einsetzen. Bölls Teilnahme am Internationalen PEN zwang Böll zur Verteidigung von Autoren in unterdrückten Ländern. Er bot Autoren aus dem Ausland Unterkunft, wie z.B. dem Autor des Exposés Der Archipel Gulag, Alexander Solschenizyn. Bölls erfolgreiches Schaffen, trotz mancher unsicherer Schritte, bestätigt die Ausmaße seiner selbstlosen Hingabe. Er kämpfte ständig für die Rechte und Sicherheit der Autoren im Ausland sowie für

\footnotetext{
${ }^{48}$ Ebd., S. 3.
} 
politisch unbewusste Bürger und die Garantien einer modernen Verfassung:

Freiheit, Brüderlichkeit und Gleichheit. Er wurde Präsident des Internationalen PEN-

Zentrums im Jahre 1971 und hielt Vorträge in verschiedenen Ländern, sodass er bald

als unoffizieller Diplomat Deutschlands galt. ${ }^{49}$

Seine Rolle als Stellvertreter der Menschenrechte im Ausland zwang er zur

Wahrnehmung von der Unterdrückung von Akademikern in Deutschland. Die

Unterdrückung von Akademikern und Protestlern in Deutschland wirkte scheinheilig

angesichts der Einmischung Deutschlands im Ausland, die lokal und international

sozialen Frieden und die Gewährleistung von Menschenrechten sichern sollte. Böll

erkannte die verwickelten Beziehung zwischen den Menschenrechten in eigenem Land

und denen im Ausland. ${ }^{50}$ Er nahm ernst die Verantwortung und Erwartungen auf

einem Menschenrechtsstellvertreter, der als Hoffnungsträger in der internationalen

Politik gilt, und wandte diese Verantwortung persönlich an und wirkte dabei als das

Gewissen der Nation. ${ }^{51}$ Böll stellte Vergleiche zwischen den

\footnotetext{
49 1970-1972 wurde Böll Präsident des Deutschen PEN-Zentrums und 1971-1974 wurde er Präsident des Internationalen PEN-Zentrums, welcher an der Friedensbewegung teilnahm. (Heinrich Böll Biografie in der LeMO Website)

${ }^{50}$ Pen Charter, \#4, in der InternationalPEN.org Website:

„PEN stands for the principle of unhampered transmission of thought within each nation and between all nations, and members pledge themselves to oppose any form of suppression of freedom of expression in the country and community to which they belong, as well as throughout the world wherever this is possible. PEN declares for a free press and opposes arbitrary censorship in time of peace. It believes that the necessary advance of the world towards a more highly organised political and economic order renders a free criticism of governments, administrations and institutions imperative. And since freedom implies voluntary restraint, members pledge themselves to oppose such evils of a free press as mendacious publication, deliberate falsehood and distortion of facts for political and personal ends." (durch Kursivschrift hervorgehoben)

${ }^{51}$ Vgl. hier: Heinrich Böll, „Die Raubtiere laufen frei herum,” in Gefahren von falschen Brüdern: Politische Schriften, Auswahl aus: >Einmischung erwünscht. Schriften zur Zeit< (München: Deutscher Taschenbuch Verlag, 1980), S. 29.

„Versuchen wir zunächst, uns von dem dummen Klischee zu befreien, wir, Intellektuelle und Schriftsteller, wären die Moralisten oder das Gewissen der Nation. Wir sind nichts weiter als in diesem Land arbeitende und Steuer zahlende Staatsbürger, die sich möglicherweise - ich betone: möglicherweise - gelegentlich besser artikulieren als irgendein Staatsbürger, der ebenso das Gewissen der Nation verkörpert, sei er Arbeiter, Bankdirektor, Lehrer, Abgeordneter. Der Beichtspiegel der Nation, falls Sie Ihr Gewissen prüfen möchten, ist das Grundgesetz; und da Gesetze, Politik, Rechtsprechung zunächst aus Worten bestehen, kommt uns Autoren, die wir mit Worten einen
} 
Menschenrechtsverletzungen in undemokratischen Ländern und in Deutschland an und kritisierte die Einmischung des Westens in Ländern wie Griechenland, der Türkei, Spanien und Indonesien. In Angesicht seines Einsatzes für die Menschenrechte gab er seine Stellungnahme gegen die scheinheilige Außenpolitik der Bundesrepublik ab: „Wer sich hierzulande für Solschenizyn, Bukowski, Amalrik, Grigorenko, Maximow und Galitsch verwenden zu müssen glaubt, muß sich erst einmal legitimieren." 52 Er bot der internationalen Einmischung eine Rechtfertigung an: „Diese Legitimation besteht darin, sich im eigenen Land für Minderheiten, gegen Pressedemagogie, gegen Hexenjagd artikuliert zu haben. Einmischung ist nur dann legitimiert, wenn sie national und international erfolgt." ${ }^{, 53}$ Die Pressedemagogie und staatliche Hexenjagd wurden Hauptthemen von Bölls Arbeit als Menschenrechtsstellvertreter. Bölls besondere Kenntnis auf dem Gebiet der Religion und seiner Zugehörigkeit zur katholischen Kirche beeinflussten nachhaltig sein politisches Denken und verstärkte seine kritische Einstellung Deutschlands Innen- und Außenpolitik gegenüber. ${ }^{54}$ Eine Nation, die als menschenrechtliche Stellvertreter der Weltpolitik anerkannt ist, ist in der internationalen Einmischung rechtfertigt: das heißt, eine christliche Stellung soll die internationale Einmischung rechtfertigen. Böll wollte behaupten, dass ein Staat, der in der internationalen Sphäre christlicher Stellvertreter ist, große Verantwortung

gewissen Umgang pflegen, vielleicht die Rolle der Interpreten zwischen den verschiedenen Wortbereichen zu, die immer wieder aneinandergeraten, wodurch Reibung und auch Gewalt entstehen." (durch Kursivschrift hervorgehoben)

${ }^{52}$ Heinrich Böll, „Gefahren von falschen Brüdern,” in Gefahren von falschen Brüdern: Politische Schriften, Auswahl aus: >Einmischung erwünscht. Schriften zur Zeit< (München: Deutscher Taschenbuch Verlag, 1980), S. 16.

${ }^{53}$ Ebd., S. 16.

${ }^{54}$ Elke Schmitter, „Warten auf das Ende,” Der Spiegel, 24. September 2001, S. 246. 
trägt. Böll konnte nicht selber die scheinheilige Ausnutzung von Religion die Erreichung von politischen Zielen in der Außenpolitik unterstützen.

Die Analyse von dieser Zeitperiode von Bölls literarischen Werken und politischen Aussagen wird durch seinen religiösen Zweifel kompliziert. Er kritisierte die Zeitung, die Regierung und die Gesellschaft auf einer christlichen Basis, verlor aber kurzweilig seine Identifikation mit der Kirche. Bölls Anlass zu gesellschaftlicher Kritik findet Basis in seinen religiösen Überlegungen und Hintergedanken, wurde aber von ihm auf eine menschenrechtliche und verfassungsmäßige Basis geübt. Bölls Entscheidung, seine Kritik an der Gesellschaft auf einer philosophischen statt einer religiösen Basis zu üben, ist mit seinem Zweifel an der Religion und an der gesellschaftlichen Form der Religion zu verstehen. In einer am 8. Dezember 1974 gehaltenen Rede, fragte sich Böll:

Ob ich ein Christ bin? Ich zweifle daran. [...] Ich habe 1973, ebenfalls öffentlich, schriftlich, gedruckt, den Titel »Christ« abgelegt. [...] Ich habe den Titel abgelegt im Zusammenhang mit Überlegungen zur Politik, die die Christen in diesem Lande machen. ${ }^{55}$

Nur später hielt er seine Kritik an der Gesellschaft und an der Religion auseinander.

Zu dieser Zeit hielt er sich an den, ,Titel Katholik: das ist ja etwas anderes, ein

anderes Wort. Und wenn die Katholiken dann sagen: christ-katholisch, dann klingt das

für mich doch schon sehr protestantisch“" ${ }^{56}$ Er blieb kritisch gegenüber der

katholischen Kirche und verließ sie 1976 kurz nach der Erscheinung von der

Erzählung Katharina Blum.

\footnotetext{
${ }^{55}$ Heinrich Böll, „Ich habe die Nase voll!” in Gefahren von falschen Brüdern: Politische Schriften, Auswahl aus: >Einmischung erwünscht. Schriften zur Zeit< (München: Deutscher Taschenbuch Verlag, 1980), S. 51.

Diese Rede fand am 8. Dezember 1974 statt.

${ }^{56}$ Ebd., S. 51 .
} 
Bölls Weltanschauung erklärt seinen Anlass zu Kritik an der deutschen Nachkriegsgesellschaft und -Regierung. Bölls sachliche Kritik an den westlichen Regierungen zielte sich auf verschiedene Gesichtspunkte der amtlichen Handlung in der Nachkriegszeit. Seine Kritik bezielte sich auf die neulich erreichte Wohlstandsgesellschaft in Westdeutschland, die seit dem Wirtschaftswunder von 1954 entstanden wurde und im Zusammenhang mit dem Schaffen einer sozialen Marktwirtschaft in der Bundesrepublik stand. Er gab kritische Kommentare des deutschen „Nachkriegskatholizismus” und der bezwungenen Verbreitung der westlichen Kultur und Religion im Osten. ${ }^{57}$ In seinem Aufsatz „Einmischung erwünscht“" kritisierte Böll die generelle Verbreitung der westlichen Kulturwerte im Osten. Böll notierte die zahlreiche Menge von Stellvertretern, „die die Fahne hochhalten, die Fahne der Freiheit, der Menschenwürde, der Demokratie, genauer jener Freiheit, die via NATO und SEATO [...] verteidigt wird““ ${ }^{58}$ Er meinte eher ihre scheinheilige Beschäftigung mit Menschenrechten. Er fügte sarkastisch dazu, er, „hätte fast einen der Urwerte vergessen, der da überall mitverteidigt wird: das christliche Erbe, das abendländische Kulturgut. Nein, daß ich das fast vergessen hätte!" ${ }^{59}$ Er meinte aber, dass die Religion der Baustein und die Rechtfertigung der internationalen Einmischung der westlichen Nationen sei. Verbunden mit der Rechtfertigung der internationalen Einmischung sind die kulturellen Werten und Religion, die Frieden und Sicherheit im Ausland bewirken sollen. Böll hielt fest an der

\footnotetext{
${ }^{57}$ Heinrich Böll, „Verzögerter Glückwunsch,” in Gefahren von falschen Brüdern: Politische Schriften, Auswahl aus: >Einmischung erwünscht. Schriften zur Zeit< (München: Deutscher Taschenbuch Verlag, 1980), S. 64.

${ }^{58}$ Heinrich Böll, ,Einmischung erwünscht, ” in Gefahren von falschen Brüdern: Politische Schriften, Auswahl aus: >Einmischung erwünscht. Schriften zur Zeit< (München: Deutscher Taschenbuch Verlag, 1980), S. 14.

${ }^{59}$ Ebd., S. 14.
} 
Weltanschauung der großen Bedeutung und Verantwortung eines christlichen Menschenrechtsstellvertreters.

Die große Ausbeutung von Religion für die Verbreitung der westlichen Kultur und Wirtschaft entsetzte Böll. Böll erkannte, dass die neulich gebaute Beziehung der Bundesrepublik zu den westlichen Mächten brachte Deutschland zur Teilnahme in dieser Einmischung. Er stellte diese Kritik auf dem Gebrauch des Begriffs christlich in der Weltöffentlichkeit und zielte diese Kritik auf die christlichen Parteien

Deutschlands: „Bisher haben weder CDU noch CSU und die ihnen am nächsten stehenden Blätter, am wenigsten die, die das Wort »christlich«im und am Kopf tragen, sich legitimiert." ${ }^{, 60}$ Böll meinte, dass als Stellvertreter christlicher Werte, soll das internationale Verhalten einer Nation dieses rechtfertigende Prinzip der Einmischung beweisen, das heißt, das Benehmen des Landes im Ausland als christlich erkennbar sein soll. Aber die Politik beutet die Religion als Nebensache aus und verstellt die wirklichen politischen und wirtschaftlichen Ziele, die in ihrem Interesse liegen. Böll argumentierte, dass, ,,das Christentum auf Verteidigung von Besitz und Privilegien reduziert", wurde. ${ }^{61}$ Bölls Kritik an der kapitalistischen Geldgier wurde in seinem Gottesglauben vertieft: „Was hat man den Völkern Südamerikas bisher an »Christlichkeit« geboten? Nicht viel mehr als den Materialismus der Macht (Macht als

\footnotetext{
${ }^{60}$ Heinrich Böll, „Gefahren von falschen Brüdern,” in Gefahren von falschen Brüdern: Politische Schriften, Auswahl aus: >Einmischung erwünscht. Schriften zur Zeit< (München: Deutscher Taschenbuch Verlag, 1980), S. 16.

${ }^{61}$ Heinrich Böll, ,Die unbequeme Hoffnung auf eine geistige Wende,” in Heinrich Böll: Gefahren von falschen Brüdern, Politische Schriften, Auswahl aus: >Einmischung erwünscht. Schriften zur Zeit< (München: Deutscher Taschenbuch Verlag, 1980), S. 74.
} 
Materie definiert) und des Besitzes." ${ }^{\text {62 }}$ Aus der vermeintlichen Beschädigung der marktwirtschaftlichen Ausnutzung von Religion stellte Böll seine intensive Kritik. Bölls Kritik enthielt eine misstrauische Haltung zur sozialen Marktwirtschaft gegenüber. ${ }^{63}$ Böll kritisierte das Fundament des westlichen marktwirtschaftlichen Systems, nämlich die zentrale Rolle des Geldes, das heißt die Geldwirtschaft. In seinem 1952 erschienenen Kurzgeschichte Der Lacher zeigte Böll die negative Folge im persönlichen Leben einer westlichen Marktwirtschaft: nämlich, die Entfremdung von der Arbeit. Böll verkündigte selbst auf einen kritischen Stil ein gemeinsames Fazit jener Geldwirtschaft: „Und verbirgt sich etwa hinter der These von der freien oder sozialen Marktwirtschaft keine Ideologie? Gibt es nicht die Ideologie des Profits um jeden Preis, innerhalb derer annonciert werden kann: Gold ist Liebe." ${ }^{94}$ Böll meinte, dass genau diese Liebe zu Geld einer gegensätzlichen Neigung zur Religion zeigt. ${ }^{65}$

\footnotetext{
${ }^{62}$ Ebd., S. 74.

${ }^{63}$ Vgl. hier: Heinrich Böll, „Das große Menschen-Fressen,” in Gefahren von falschen Brüdern: Politische Schriften, Auswahl aus: >Einmischung erwünscht. Schriften zur Zeit< (München: Deutscher Taschenbuch Verlag, 1980), S. 16.

Böll schrieb an, ,Free Trade und Wohltätigkeit”, dass, ,,an dieser Kombination hat sich bis heute in der Welt nicht viel geändert. Ich entnehme einem Bericht der amerikanischen Zeitschrift Ramparts über den Export von Nahrungsmitteln aus Ländern, in denen Hunger herrscht (und ich fand es bestätigt in einer Rede, die Willy Brandt am 12. 12. 74 vor der UNICEF in Genf gehalten hat): Jeder Amerikaner - vergessen wir das Wort Amerikaner sofort wieder, denn diese Untersuchungen wurden in Amerika nicht nur angestellt, sondern auch publiziert, und wir wollen uns nicht einbilden, wir lebten anders!: jeder Amerikaner verbraucht 2000 Pfund Getreide im Jahr, davon aber nur 200 für Brot und Backwaren, der Rest dient der Herstellung von Fleisch, Eiern, Alkohol; ein Pfund Weizen ergibt ein Pfund Brot: um ein Pfund Fleisch zu produzieren braucht man acht Pfund Getreide; wir essen also acht Pfund Brot, wenn wir ein Pfund Fleisch essen. Auf dem Umweg über verschiedene Absurditäten importieren wir also den Hunger in Länder, die wir zwingen, Nahrungs-, Futter- und Düngemittel zu exportieren, billig versteht sich, viel zu billig, wie die Bananen, die wir essen, und der Kaffee, den wir trinken - und dann geben wir ihnen einen Teil des Gewonnenen als Wohltätigkeit zurück. Ob angesichts solcher Absurditäten unsere Strukturen so verlockend für diese Länder sind, wage ich zu bezweifeln“.

${ }^{64}$ Heinrich Böll, ,Radikalität und Hoffnung,” in Gefahren von falschen Brudern: Politische Schriften, Auswahl aus: >Einmischung erwünscht. Schriften zur Zeit< (München: Deutscher Taschenbuch Verlag, 1980), S. 22.

Er merkte in beide Staatformen, in freier sowie sozialer Marktwirtschaften, weil, ,Gold Gott sei, und da dieser Gott in den meisten Fällen von Banken verwaltet und gehandelt wird, wird man wohl bald wissen, wo die Gotteshäuser stehen". (S. 22-3)

${ }^{65}$ Vgl. hier: Heinrich Böll, ,Textilien, Terroristen und Pfarrer,” in Gefahren von falschen Brüdern: Politische Schriften, Auswahl aus: >Einmischung erwünscht. Schriften zur Zeit< (München: Deutscher Taschenbuch Verlag, 1980), S. 82.
} 
Die Religion steht für die Liebe Gottes, aber die marktwirtschaftlich-politische Ausnutzung von Religion treibt die Liebe zu Geld an. Böll meinte auch, dass der Betrieb des „Profits um jeden Preis” Menschen- und Bürgerrechte verunsicherte, besonders für Frauen. Die Wohlstandsgesellschaft im Westen wird von Ostländern oft unterstützt. Er bemerkte ein tief gewurzeltes Problem der Geldwirtschaften:

„Irgendein unbekannter Oberschüler oder eine junge Frau, die in der Türkei von den Schergen der Junta torturiert werden, gehen auf das Konto einer Profit- oder Interessenpolitik. Auf der Tabelle, die die Börsenkurse anzeigt, wird Blut nie sichtbar." ${ }^{, 66}$ Da die westliche Geldwirtschaft die Liebe zu Geld verbirgt, musste Böll gegen ihre tadellose Darstellung protestieren.

\section{Zusammenfassung}

Böll schrieb die Erzählung Katharina Blum im Jahre 1974 mit einem Blick auf die

Studentenbewegung und auf die allgemeine Kritik dieser Zeit an den Springer-

Zeitungen. Böll gebrauchte Themen von der Studentenbewegung, die mit der radikalen Einstellung der Studenten zugeschrieben wurden. Unter diesen stehen die Wiederbewältigung der Vergangenheit und die Kritik an der internationalen Geldwirtschaft, oder an der sogenannten Globalisierung. Seine Kritik an der Zeitung wurde von 1968 zu 1971 zu einer Verteidigung von Menschenrechten im

\footnotetext{
„Was bedeutet Kleidung, ein bestimmtes Kleidungsstück, für den, der es nicht hat, aber gern hätte? Wir wissen es nicht genau, und auch die sehr gescheiten, sehr einfallsreichen Werbepsychologen der Textilindustrie - und sie wissen viel und wenden es klug an - wissen nicht alles."

${ }^{66}$ Heinrich Böll, ,Einmischung erwünscht,” in Gefahren von falschen Brüdern: Politische Schriften, Auswahl aus: >Einmischung erwünscht. Schriften zur Zeit< (München: Deutscher Taschenbuch Verlag, 1980), S. 14.
} 
Zusammenhang mit Studentenprotestlern verschoben. Böll wollte die Eskalation von Gewalt vermeiden, die von der Regierung einerseits und von den neulich geformten Radikalgruppen andererseits drohte. Bölls allgemeine Verteidigung von Menschenrechten, die durch seine Teilnahme an dem Internationalen PEN entwickelte, wurde in der Erzählung thematisiert. Das Zusammenkommen seines politischen Engagements und seines künstlerischen Impulses findet Ausdruck in Katharina Blum. 


\section{Kapitel: Böll 1971-1974; Katharina Blum}

\section{Einleitung: Der Entstehungsanlass des Romans Katharina Blum}

Bölls Roman wirkt als eine Abrechnung mit der Vergangenheit und zählt zur Literatur der Vergangenheitsbewältigung. In einer Analyse von Katharina Blum bemerkte Klaus Jeziorkowski, dass Böll seinen engagierten Roman, ,für die Schwachen und die Plattfüßler und gegen die Mächtigen, die vor 1945 Macht hatten und sie danach behielten oder wieder bekamen“, schrieb. ${ }^{67}$ Jeziorkowski stellte verschiedene, „Ereignisse des Zeitraums 1971/72”, im Zusammenhang mit der Veröffnung des Romans. ${ }^{68}$ Diese Zeit wurde durch politische Ereignisse innerhalb von Deutschland ausgezeichnet, ,die die Erzählung Die verlorene Ehre der Katharina Blum in Gang gesetzt haben““ ${ }^{69}$ Unter diesen Geschehnissen stehen intellektuellen sowie politischen Ereignissen. Jeziorkowski zählte die Erzählung unter diesen Ereignissen mit: „Postum erscheint Theodor W. Adornos Ästhetische Theorie. Eine Serie von Bombenanschlägen, die mit der Baader-Meinhof-Gruppe in Zusammenhang gebracht werden, verunsichert Deutschland."70 Besonders betont in der Erzählung ist die Frage der Menschenrechte im Zusammenhang mit dem Radikalen-Erlass und mit der Terrorismusdebatte. Jeziorkowski stellte den Roman in kulturellem sowie politischem Kontext. Im Jahre 1971 erschien ebenfalls Bölls Roman Gruppenbild mit Dame, welcher Roman von großer Bedeutung in der Bundesrepublik war.

\footnotetext{
${ }^{67}$ Klaus Jeziorkowski, „Die verlorene Ehre der Katharina Blum oder: Wie Gewalt entstehen und wohin sie führen kann," in Interpretationen Heinrich Böll: Romane und Erzählungen, (Stuttgart: Philipp Reclam jun. GmbH \& Co., 2000), S. 252.

${ }^{68}$ Ebd., S. 253.

${ }^{69}$ Ebd., S. 253.

${ }^{70}$ Ebd., S. 253.
} 
Aufgrund Bölls Handlung solcher wichtigen Themen wie der Frauenrechte und der Menschenwürde und seiner relevanten politischen Schreiben und Tätigkeiten in Deutschland und im Ausland für den Internationalen PEN bekam Böll 1972 den Nobelpreis für Literatur. Als Verteidiger der Menschenwürde neigte er zur Weltfigur, da er jenen ohne Bezug auf das Vaterland inspiriert und dabei seinen bloßen nationalen Status verlor. Böll musste sich seit dem Empfangen des Nobelpreises für Literatur unter den einflussreichsten internationalen Persönlichkeiten des öffentlichen Lebens verstehen. Diese Auszeichnung brachte seine Meinungen und Aussagen auf die Weltbühne. Böll wurde anerkannten Hoffnungsträger für Deutschland. Angesichts dieser Verantwortung der deutschen Meinungskultur gegenüber der internationalen Sphäre musste Böll sich auf aller eingeschränkt gültige, national-spezifischen und vorurteilsbehaftete Ansichten verzichten. Er gilt seit der Nobelpreisverleihung als Weltrepräsentant der höchsten universellen Werte. Die Verleihung des Nobelpreises auf Böll zog viel internationale Aufmerksamkeit auf Deutschlands politische Entscheidungen. Die Verleihung Böll den Nobelpreis war, ,eine Entscheidung von größter internationaler Resonanz, von konzentrierter Peinlichkeit für die nationalen Hysteriker, die ihn im selben Jahr zu einer Art kriminellen Bandenchef mystifiziert hatten, zur Schaltzentrale einer Mörderbande“, aufgrund seiner Behandlung der Ulrike Meinhof in einem Artikel im Spiegel. ${ }^{71}$

\footnotetext{
${ }^{71}$ Ebd., S. 255.
} 
Bölls Zeitungsartikel - Abrechnung mit der Vergangenheit

Am 10. Januar 1972 wurde Bölls Spiegel-Artikel „Will Ulrike Meinhof Gnade oder freies Geleit?“ veröffentlicht. In Anbetracht der, so Böll, „,üistere[n]

Rechtsvergangenheit“", der deutschen Nation, eröffnete er im Rückblick auf der Nachkriegsgeschichte Überlegungen an der Behandlung Ulrike Meinhof und andere Mitglieder der frühen Baader-Meinhof Gruppe und der RAF. Bölls Einrede für Ulrike Meinhof war gar keine Unterstützung der RAF oder ihre Aktionen. Dieser Artikel handelte von der folgenden erwarteten Gerichtsverhandlung im Fall Ulrike Meinhofs. Böll plädierte auf Gnade und auf ein gerechtes Ergebnis für sie: „Ulrike Meinhof will möglicherweise keine Gnade, wahrscheinlich erwartet sie von dieser Gesellschaft kein Recht. Trotzdem sollte man ihr freies Geleit bieten, einen öffentlichen Prozeß.,"72 Vor allem wollte Böll Gnade für Meinhof und ihre Sortie. Böll wandte seine Kritik an der gnadenlosen Regierung der Nachkriegszeit und gab ein Plädoyer für Ulrike Meinhof und die Gruppe um sie: „Wollen sie, daß ihre freiheitlich demokratische Grundordnung gnadenloser ist als irgendein historischer Feudalismus, in dem es wenigstens Freistätten gab, auch für Mörder, und erst recht für Räuber?"’73 Nach Böll wurde die gnadenlose Beurteilung von Meinhof eines Rechtsstaats unpassend. Böll blieb immer kritisch der NS-Zeit gegenüber und wollte das Ansehen Deutschlands im Ausland rechtfertigen. Die weitere mögliche Beschädigung des Rufs Deutschlands durch die ungerechte Behandlung und die nicht rechtlich zulässige

\footnotetext{
${ }^{72}$ Heinrich Böll, ,Will Ulrike Gnade oder freies Geleit?” Der Spiegel, 10. Januar 1972, S. 54.

${ }^{73}$ Ebd., S. 54.
} 
Verfolgung der Linksradikalen wäre besonders peinlich für das internationale Ansehen Deutschlands. In den Augen der Völkergemeinschaft würde die ungerechte Handlung Meinhof, so Böll, wohl peinlich gegen Deutschland wirken:

Will sie Gnade oder wenigstens freies Geleit? Selbst wenn sie keines von beiden will, einer muß es ihr anbieten. Dieser Prozeß muß stattfinden, er muß der lebenden Ulrike Meinhof gemacht werden, in Gegenwart der Weltöffentlichkeit. Sonst ist nicht nur sie und der Rest ihrer Gruppe verloren, es wird auch weiter stinken in der deutschen Publizistik, es wird weiter stinken in der deutschen Rechtsgeschichte. ${ }^{74}$

Bölls Schreiben war keine Unterstützung der Meinhof oder der Baader-Meinhof Gruppe, sondern ein Plädoyer gegen die Intensivierung der verfolgenden Methoden der Polizei gegen Meinhof und verschiedene Verdächtige, die in gar keiner Verbindung mit der Baader-Meinhof Gruppe standen.

Bölls Verteidigung von Radikalität findet in seinem Engagement für Menschenwürde und Menschenrechte Erklärung und ist als Nebensache seines politischen Engagements zu verstehen. Bölls eigene Teilnahme, als Verteidiger der Studentenbewegung und Unterstützer der Enteignet Springer Kampagne von der APO, entwickelten seine spätere Verteidigung von den Grundrechten für Ulrike Meinhof. Er betonte schriftlich den Anlass der Radikale öftermals und stellte die gewöhnliche Ansicht in Frage, dass ,Radikalität' den Gebrauch von Gewalt beinhaltet:

Und was ist ein Radikaler anderes als jemand, der bis an die Wurzel zu gehen versucht? [...] Gewiß sind nicht alle Radikale behutsam und nicht jeder, der sich so nennt, per se gerechtfertigt - aber auch nicht jeder, der so genannt wird, stellt eine Gefahr dar. Die Gefahr besteht wohl eher darin, daß es zuwenig Radikale im öffentlichen Dienst geben wird, daß man Nachdenklichkeit einschüchtert, eine Vordergrunddemokratie schafft, in der es kaum noch erlaubt sein wird, bis an die Wurzeln dieses unseres Staates, der Bundesrepublik

\footnotetext{
${ }^{74}$ Ebd., S. 54.
} 
Deutschland, zu gehen, die ja nicht zufällig entstanden ist, sondern Ursachen, unter anderem eben den Zweiten Weltkrieg als Ur-Sache hat, der ja ebenfalls nicht zufällig entstanden ist, sondern ebenfalls Ursachen hat, unter anderem die Ursache blinder Untertänigkeit [...] Der Ausdruck Radikale im öffentlichen Dienst ist also vieldeutig, und es ist lebensgefährlich, ihn ohne geschichtlichen Hintergrund mitzuliefern, auf alle jene anwenden zu wollen, die ebendas nicht sein wollen: untertänig, unterworfen, auf die Obrigkeit blind vertrauend. [...] [E]s geht hier nur um das Wort Radikalität. Ohne sie ist wissenschaftliche Arbeit gar nicht möglich, weder in der Philosophie noch in der Theologie oder Chemie, ohne sie ist Literatur gar nicht möglich, auch Demokratie nicht. ${ }^{75}$

Bölls Rede über Ulrike Meinhof und ihre Gruppe sicherte nie seine Unterstützung bei der Baader-Meinhof Gruppe zu. Er wollte eher ein Verständnis ihrer Motivationen verbreiten. Böll sah in den von den Radikalen entstammenden Schriften ein Mittel, diese zu verstehen. Böll empfahl die Polizei Meinhofs Schreiben zu lesen: „Es wäre gut, wenn Herr Kuhlmann, der Vorsitzende der Polizeigewerkschaft, dafür sorgte, daß seine Kollegen, die einen so gefährlichen und schlecht bezahlten Beruf ausüben, dieses Manifest einmal lesen.”76 Die Polizei könnten selbst die Gedanken der Meinhof und ,ihre Gruppe’ lesen.

Böll tat seine Meinung kund, dass der Feinderkenntnis hilfreich und abwehrend wirken konnte. Um sein Feind zu kämpfen soll man den Feind verstehen. Böll wollte Brüderlichkeit und Nächstenliebe auch für Meinhof: „Es kann kein Zweifel bestehen: Ulrike Meinhof hat dieser Gesellschaft den Krieg erklärt, sie weiß, was sie tut und

\footnotetext{
${ }^{75}$ Heinrich Böll, „,Radikaler im öffentlichen Dienst,” in Gefahren von falschen Brüdern: Politische Schriften, Auswahl aus: >Einmischung erwünscht. Schriften zur Zeit< (München: Deutscher Taschenbuch Verlag, 1980), S. 42-3.

${ }^{76}$ Heinrich Böll, „Will Ulrike Gnade oder freies Geleit?” Der Spiegel, 10. Januar 1972, S. 54.
} 
getan hat, aber wer könnte ihr sagen, was sie jetzt tun sollte?"

von Nächstenliebe war Radikal. Er drückte seine Meinung an Nächstenliebe so aus:

„Ich hätte sogar den Massenmörder Eichmann aus dem Wasser gezogen."78 Böll

wollte, dass die Prinzipien der Brüderlichkeit, Feindverständnis und Nächstenliebe

hier beherrschten. Es soll das Ziel einer Nation Terroristen zurück zum rechtlichen

Leben zu führen. Die in der Zeitungen übertriebenen Darstellungen von der

Tätigkeiten von der Meinhof und von der RAF verminderten ihren wesentlichen

Entstehungsanlass: die Versicherung von Grundrechten, Freimeinung der

Minderheiten, Hoffnung auf Frieden und Widerstellung gegen Wiederbewaffnung

unter anderen. Die RAF Organisation, die Ulrike Meinhof mitbegründete, ist

angenommen als die gewalttätigsten Terrororganisation in der BRD in dieser Zeit,

aber ihre Tätigkeiten zu dieser Zeit, so Böll, wurden in der Presse übertrieben:

\footnotetext{
${ }^{77}$ Ebd., S. 54.

${ }^{78}$ Christiane Grefe und Adam Soboczynski, „Wo ist Böll?” ZEITmagazin, Nr. 32, 2. August 2007, S. 21.

Vgl. hier: Anonym, „Nächstenliebe zum Klassenfeind?: DKP-Pfarrer Rolf Trommershäuser über seinen Konflikt mit der evangelischen Kirche," Der Spiegel, 18. Dezember 1972, S. 55.

Grundlegend zur Gedanken Bölls steht seine Überzeugung am Katholizismus. Das Konzept, „Nächstenliebe”, wie es, ,,in der Bibel”, steht, könnte hier Aufschluss über Grundgedanke Bölls geben. Nächstenliebe ist gleichbedeutend mit dem Konzept Brüderlichkeit. Brüderlichkeit ist anerkannt als eine der drei Kernelementen des modernen Rechtsstaats, wie mit der modernen Verfassung seit der Aufklärung assoziiert: die drei sind nämlich: Egalité, Fraternité, Liberté. Nächstenliebe ist möglich für beide die Regierung und Revolutionäre. Revolution und das Prinzip der Nächstenliebe, oder Brüderlichkeit, sind nicht auseinander schlagend, sondern das Gegenteil. In einem Interview mit Dem Spiegel gab DKP-Pfarrer Rolf Trommershäuser seine Stellungnahme zum Klassenkampf und zur Nächstenliebe. In diesem Zusammenhang sprach er von der Beziehung zwischen Kapitalist und Kommunist. Spiegel stellte Trommershäuser die Frage, soll er nicht seinen, „Nächsten lieben”, wie sich selbst, als es, ,in der Bibel”, steht? Sein Verständnis von Nächstenliebe ermöglicht einen Anfangspunkt der Sozialarbeit mit Anderen: „Nächstenliebe ist eine Umschreibung der Möglichkeit des Menschen, sich zusammenzuschließen, um das Leben zu meistern." Die Nächstenliebe, oder Brüderlichkeit, ist ein Mittel, das man an die Möglichkeiten der Andersdenkenden erinnert. Sie bewährte die mögliche Entwicklungen und Änderungen der Andersdenkenden. Diese Möglichkeiten gelten auch im Klassenkampf. Der Klassenkampf ist schon weniger gewaltsam als ausgemachter Krieg: „Und Klassenkampf ist nichts anderes als die Folge des Zusammenschlusses von Menschen, die erkennen, daß ihre Lage ähnlich ist." Meinhof und ihre Gruppe sahen ihre Rolle als Kommunisten im Klassenkampf gegen die Kapitalisten. Der Klassenkampf kann auch mit Nächstenliebe geführt worden sein: „Die Tatsache, daß er als Klassenfeind eingestuft wird, bedeutet nicht, daß ich ihn persönlich hasse.” Das Interview hängt auch mit der Diskussion der RAF und Sozialismus zusammen: „Ein Kommunist geht außerdem davon aus, daß auch der Unternehmer im Sozialismus glücklicher wird, als er im Kapitalismus ist. Ich meine nachweisen zu können, daß sein Privateigentum an den Produktionsmitteln ihn unglücklich und unfrei macht." Diese erweiterte Erklärung der Nächstenliebe verhilft die Plädoyer Bölls um Ulrike Meinhof und ihre Gruppe.
} 
Es ist eine Kriegserklärung von verzweifelten Theoretikern, von inzwischen Verfolgten und Denunzierten, die sich in die Enge begeben haben, in die Enge getrieben worden sind und deren Theorien weitaus gewalttätiger klingen, als ihre Praxis ist. ${ }^{79}$

Böll wollte die Anklagen gegen Meinhof und Anderen zu vermindern und zur Debatte führen: ,[K]önnte es sein, daß die freiheitlich-demokratische Grundordung von vielen dieser Radikalen nicht gefährdet, sondern gewünscht und angestrebt wird?" 80 Dass Ulrike Meinhof eigenes Gewinn nicht suchte, bleibt auch zweifellos. In der globalen Geldwirtschaft wirken ihre Antriebe unklar, denn ihre Arbeit ermöglichte ihr keinen finanziellen Gewinn. Sie fing als Altruistin an. Böll ahnte, dass sie die Freiheit für jeden Bürger gegen Faschismus und Meinungsunterdrückung versichern wollte: „Haben die Polizeibeamten, Juristen, Publizisten je bedacht, dass alle Mitglieder der Gruppe um Ulrike Meinhof, alle, praktische Sozialarbeit getan haben und Einblick in die Verhältnisse genommen, die möglicherweise zu dieser Kriegserklärung geführt haben?"81 Böll meinte, dass Meinhof und ihre Anhänger Idealisten waren und Verbesserungen in die Welt eintreiben wollten. Ihre Intentionen wurden durch die falsche Selbstbenennung verschwunden. Ulrike und ihre Sortie haben sich selbst nicht als Radikale verstanden, sondern falsch als Terroristen, und gab dabei die Regierung den Antrieb sie und die Gruppe um sie zu verfolgen. Sie haben sich selbst als, „terroristisch qualifizierten Vereinigung”, etikettiert, welche Aussonderung die

\footnotetext{
${ }^{79}$ Heinrich Böll, „Will Ulrike Gnade oder freies Geleit?” Der Spiegel, 10. Januar 1972, S. 54. „Es ist inzwischen ein Krieg von 6 gegen 60000 000. Ein sinnloser Krieg, nicht nur nach meiner Meinung, nicht nur generell, auch im Sinne des publizierten Konzeptes.”

${ }^{80}$ Heinrich Böll, ,Radikalität und Hoffnung,” in Gefahren von falschen Brüdern: Politische Schriften, Auswahl aus: >Einmischung erwünscht. Schriften zur Zeit< (München: Deutscher Taschenbuch Verlag, 1980), S. 20-1.

${ }^{81}$ Heinrich Böll, ,WWill Ulrike Gnade oder freies Geleit?” Der Spiegel, 10. Januar 1972, S. 54.
} 
Gruppe nicht richtig voll traf und stellten sich dabei außerhalb des Gesetzes. ${ }^{82}$

Meinhof wollte nie die Regierung überwinden. Sie wollte die starke Reaktion des

Staates gegen politische Opposition zeigen. Der Staat zeigte diese Reaktion.

Bölls Zeitungsartikel: Kritik an Verfolgung

In der Verfolgung von Ulrike Meinhof und Studenten der Studentenbewegung sah Böll Ähnlichkeiten mit den Methoden der NS-Zeitigen Behörden, die schon 1933 auftauchten. ${ }^{83}$ Die Menschenverfolgung dagegen Böll kämpfte - nämlich, die Erschießung von Benno Ohnesorg, die Unterdrückung des Sternmarsches und die Kriminalisierung von Meinhof und ihre Gruppe u.a. - wurde zwiespältig: die eine wurde von der Springer-Presse getrieben, das andere entstamm von der Regierung mit der Polizei als Mittel. Böll aber verstand diese als eine systematische Verknüpfung. In Bölls Zeitungsartikel über Ulrike Meinhof stellte er scharfe Kritik an der deutschen Nation auf verschiedene Gesichtspunkte. Böll hob Kritik an die NS-Zeit, die nachlässige Bewältigung der NS-Vergangenheit und die NS-zeitige Verfolgung der Minderheiten, damit er einen Vergleich mit der Nachkriegsregierung anbieten konnte. Böll stellte bestandene Ähnlichkeiten zwischen der Nachkriegsgeschichte Deutschlands in der BRD und der Vorkriegsgeschichte Deutschlands fest. Bölls Kritik

\footnotetext{
${ }^{82}$ Rolf Gössner, Menschenrechte in Zeiten des Terrors, (Hamburg: Konkret Literatur Verlag, 2007), S. 109. Als, „terroristisch qualifizierten Vereinigung“, konnte die Gruppe den Schutz des Gesetzes nicht genießen. ${ }^{83}$ Vgl. Hier: Heinrich Böll, ,Will Ulrike Gnade oder freies Geleit?” Der Spiegel, 10. Januar 1972, S. 54. Böll wiederholte die unpassende Darstellung der Gruppe in der Medien. Böll notierte auch die verhetzende Qualität des Namens: „Hebt man die Kränkung, die in der Bezeichnung "Bulle” liegt, gegen das Wort "Bande” auf." Weder den Name „BM-Bande” noch „BM-Gruppe” wurden von Ulrike Meinhof, Andreas Baader oder Gudrun Ensslin selbst angewandt. Diese Namen entstammen von der Presse, wobei die informellen Aktionen der rebellischen Studenten zur Aktivitäten der ,Terroristen' aufgehoben wurden.
} 
wurde nicht auf amtlicher Gewalt gegen Studenten geschränkt, sondern er wandte sie auch an Deutschlands Nachkriegsregierung im Allgemein an: „Daß wir etwa über die Folgen des Krieges sehr viel, über den Krieg selbst, seine Entstehung, seine Verheerungen, wenig nachdenken. Und dieses Modell wird ja auch auf die Nachkriegsgeschichte der Bundesrepublik weitgehend angewendet." ${ }^{84}$ Die Antriebe von der NS-Zeit kamen noch mal ans Licht. Die damaligen Zeitgenossen der NS-Zeit, so Böll, „die so mühelos und schmerzlos vom Faschismus in die freiheitlich demokratische Grundordnung übergewechselt haben oder worden sind“", tauchten noch mal wieder auf. ${ }^{85}$ Dieser Übergang zur Demokratie wurde oberflächlich durchgeführt. Diese Ehemalige Politiker und Offiziere waren, so Böll, ,’desillusioniert”, ein bißchen reumütig, sehr rasch bekehrt, und ihre Schmerzen waren nicht viel mehr als ein bißchen Hitlerjugendwehwehchen““ ${ }^{86}$ Böll forderte eine kritische Analyse der Regierung: „Vertrauen in die Verwaltung kann erst entstehen, wenn man gelernt hat, wie Verwaltung mißbraucht werden kann, sobald das Recht abgeschafft ist, wenn Gehorsam blind wird. ${ }^{, 87}$ Bölls Gegenstellung zur gesellschaftlichen Kontrolle muss man im Zusammenhang mit dem Sinne von der Rolle des modernen Rechtsstaats anbetrachten. Sowie die Grundrechte und demokratischen Grundsätze der Verfassung im engen Zusammenhang stehen, stehen auch im engen Zusammenhang die staatliche Gewaltmechanismen. Böll beschrieb 1976 diesen weit reichenden Verhältnisse:

\footnotetext{
${ }^{84}$ Heinrich Böll, ,Textilien, Terroristen und Pfarrer,” in Gefahren von falschen Brüdern: Politische Schriften, Auswahl aus: >Einmischung erwünscht. Schriften zur Zeit< (München: Deutscher Taschenbuch Verlag, 1980), S. 79 .

${ }^{85}$ Heinrich Böll, „Will Ulrike Gnade oder freies Geleit?” Der Spiegel, 10. Januar 1972, S. 54.

${ }^{86}$ Ebd., S. 54.

${ }^{87}$ Heinrich Böll, „Der verwaltete Mensch,” Der Spiegel, 22. April 1974, S. 190.
} 
Und es gibt da nicht nur die alte »Nobility«, nicht nur alte und neu- alte Großindustrie, es gibt da noch die fast ganz und gar neuen Herzöge. Könige, Kardinäle und Königsmacher, deren Herrschaft über ihre Provinz in den meisten Fällen auf einem Stück Papier, der modernen Art des Lehens, einer Zeitungslizenz von einer der Besatzungsmächte beruht: die Zeitungs-, Illustrierten-, Magazin- und ZeitschriftenKönige, dieser neue Adel, der natürlich »seine Schwierigkeiten « hat, diese »Konzentrierten und Konzentrierer « - was werden sie tun? [...] Beim Nachdenken über Herrschaftsverhältnisse in der Bundesrepublik kam ich zu Überlegungen, die ich in diesem Aufsatz auszudrücken versuche: Wem gehört die Bundesrepublik Deutschland, wer beherrscht sie? Es mag sein, daß manche Bitterkeit in diesem Aufsatz zu sehr ironisch verbrämt ist; daß manche Einzelheit mehr Einblick in die bundesdeutschen Verhältnisse voraussetzt, als ich vermitteln kann. [...] Dieser Aufsatz ist ein Versuch, sich einem komplizierten Problem anzunähern. [...] Würde ich gefragt, von wo die Bundesrepublik bedroht ist: ob von rechts oder von links, ich würde sagen: von rechts. ${ }^{88}$

Böll ahnte die mögliche Gefahr Freiheitsmechanismen zum Kontrollmechanismen zu werden: „Wird da die Waage der blinden Justitia zum Symbol einer blinden Öffentlichkeitsarbeit? Ausgewogenheit in einer Gesellschaft, die sich ausdrücklich als eine Gesellschaft von Interessenvertretern definiert?"89 Böll gab diese verschiedene Mechanismen und ihre komplizierte Verhältnisse acht. Böll wollte das Recht bewahren.

Die Rolle des Staates und des Bürgers werden heute so verstanden, wie von Professor Dr. Peter-Alexis Albrecht formuliert: „Der Mensch hat eine eigene Würde. Dies ist die Botschaft der Aufklärung. Kern dieser Würde ist die Freiheit des Willens. [...] Freiheit lebt von der Achtung der Würde anderer. Sie ist die Freiheit des

\footnotetext{
${ }^{88}$ Heinrich Böll, „Die Angst der Deutschen und die Angst vor ihnen,” in Gefahren von falschen Brüdern: Politische Schriften, Auswahl aus: >Einmischung erwünscht. Schriften zur Zeit< (München: Deutscher Taschenbuch Verlag, 1980), S. 108-9.

${ }^{89}$ Heinrich Böll, ,Radikalität und Hoffnung,” in Gefahren von falschen Brüdern: Politische Schriften, Auswahl aus: >Einmischung erwünscht. Schriften zur Zeit< (München: Deutscher Taschenbuch Verlag, 1980), S. 23.
} 
Andersdenkenden, Anderslebenden, Andershandelnden." ${ }^{90}$ Böll kämpfte genau für diese Freiheit, jener Freiheit der modernen Verfassung. Albrecht notierte auch die Beziehung zwischen Freiheit und Sicherheit: „Sicherheit ist nichts anderes als eine ausbalancierte Freiheit aller. Nicht Sicherheit geht der Freiheit voraus, sondern Freiheit ist die Garantie der Sicherheit oder auch nur des Gefühls von Sicherheit."91 Im Fall, dass Sicherheit den Vorrang genieße, werden die Unterdrückung der oppositionellen Meinungen und die Verfolgung der Regimekritiker beinhalten worden. Die Preisgabe der Freiheit für Sicherheit hat nur eine Folge - Unterdrückung. Böll teilte diese Einstellung mit. Böll drückte sich an so einem Ende der Kritik aus: „Das kann nur bedeuten: nichtssagend, tot, leer, langweilig. Es bedeutet das Ende der Kritik. Man stelle sich das einmal vor: eine ausgewogene Literatur." 92 Das Ende der Kritik, d.h. das Ende der Recht auf Meinungsäußerung, beinhaltet den Tod der Literatur und die Rückkehr zur Zensur. ${ }^{93}$ Böll kämpfte gegen diesen möglichen Schluss.

Böll wollte die Gesellschaft und die Politiker sich an die Verfolgung der Nationalsozialistischenregierung erinnern, die damals gesellschaftliche Unterstützung hatte, damit er einen Vergleich mit der Verfolgung von Linksextremisten in der Nachkriegszeit anbieten konnte: „Haben alle, die einmal verfolgt waren, von denen einige im Parlament sitzen, der eine oder andere in der Regierung, haben sie alle

\footnotetext{
${ }^{90}$ Prof. Dr. Peter-Alexis Albrecht, zit. nach: Rolf Gössner, Menschenrechte in Zeiten des Terrors, (Hamburg: Konkret Literatur Verlag, 2007), S. 7.

Originalabdruck: Albrecht, Die vergessene Freiheit, in Frankfurter Allgemeine Zeitung (FAZ) 25.4.03.

${ }^{91}$ Ebd., S. 7.

${ }^{92}$ Heinrich Böll, ,Radikalität und Hoffnung,” in Gefahren von falschen Brüdern: Politische Schriften, Auswahl aus: >Einmischung erwünscht. Schriften zur Zeit< (München: Deutscher Taschenbuch Verlag, 1980), S. 23.

${ }^{93}$ Vgl. hier: Heinrich Böll, ,Verzögerter Glückwunsch,” in Gefahren von falschen Brüdern: Politische Schriften, Auswahl aus: >Einmischung erwünscht. Schriften zur Zeit< (München: Deutscher Taschenbuch Verlag, 1980), S. 67.

„[D]er weitaus größte Teil der Menschheit besteht ja nicht aus »Autoren «, die sich frei machen und für frei halten können."
} 
vergessen, was es bedeutet, verfolgt und gehetzt zu sein."94 Böll wollte die gnadenlose Qualität der Gesellschaft in der Zeit in Frage stellen: „Weiß keiner mehr, was es bedeutet, einer gnadenlosen Gesellschaft gegenüberzustehen? Wollen die ehemals Verfolgten die verschiedenen Qualitäten des Verfolgtseins gegeneinander ausspielen?" 95 Manche Leute, die die NS-Zeit überlebten, waren verfolgt durch die NS-Regierung: ,Waren nicht auch sie, die ehemals Verfolgten, einmal erklärte Gegner eines Systems, und haben sie vergessen, was sich hinter dem reizenden Terminus "auf der Flucht erschossen” verbarg?"96 Böll warf die moralische Frage der radikalen Aktivitäten und die gegenseitige moralische Frage der Täterbehandlung des Staates auf. Böll wollte, dass eine große Verfolgung des Menschen und die Verletzung der Menschenrechte in Deutschland nie wieder stattfinden konnte.

Böll stellte seine Kritik an der Zeitung und an der Regierung als eine untrennbare Kritik. Böll machte einen scharfen Vergleich zwischen der Bild-Zeitung und der verhetzenden Methoden der NS-Zeit: „Wer von ihnen weiß schon, was es bedeutet, in einem Rechtsstaat gehetzt zu werden von "Bild”, das eine weitaus höhere Auflage hat als der "Stürmer" sie gehabt hat?"97 Publikationen der Springer-Presse wurden die meistgelesenen Zeitungen damals wie heute. Böll klagte Springer direkt an: „,[U]nd man sollte auch Herrn Springer öffentlich den Prozeß machen, wegen Volksverhetzung." 98 Böll wollte die Zeitung und ihre Rolle in der Gewalt und Radikalisierung in der BRD in Frage stellen: „Es wäre eine Aufgabe der Kriminologie,

\footnotetext{
${ }^{94}$ Heinrich Böll, „Will Ulrike Gnade oder freies Geleit?” Der Spiegel, 10. Januar 1972, S. 54.

${ }^{95}$ Ebd., S. 54.

${ }^{96}$ Ebd., S. 54.

${ }^{97}$ Ebd., S. 54.

${ }^{98}$ Ebd., S. 54.
} 
das einmal zu erforschen: was ZEITUNGEN anrichten können, in all ihrer

bestialischen »Unschuld «." 99 Die Rolle der Zeitungen in diesem Prozess ist noch nicht

generell gekannt. Die Kultur selbst, die soziale Wirklichkeit, wird von Meinungen und

Annehmungen, das heißt psychologisch, gebildet. Böll bemerkte aber eine mögliche

Folge solche nachlässige Berichten:

Die Überschrift "Baader-Meinhof-Gruppe mordet weiter" ist eine Aufforderung zur Lynchjustiz. Millionen, für die "Bild" die einzige Informationsquelle ist, werden auf diese Weise mit verfälschten Informationen versorgt. Man hat ja wohl genug von den Verdächtigten oder nur verdächtig Aussehenden des Herrn XY Zimmermann gehört. $^{100}$

\footnotetext{
${ }^{99}$ Heinrich Böll, ,Zehn Jahre später,” Nachwort zur Katharina Blum, (München: Deutscher Taschenbuch Verlag, 2003), S. 144.

Vgl. hier: Heinrich Böll, „Will Ulrike Gnade oder freies Geleit?” Der Spiegel, 10. Januar 1972, S. 54.

„Man kann die Nase schon voll kriegen, und ich habe sie voll. Wahrscheinlich wird "Bild” bald so weit sein, einen so armen Teufel wie Hermann Göring, der sich leider selbst umbringen mußte, unter die Opfer des Faschismus zu zählen."

${ }^{100}$ Heinrich Böll, „Will Ulrike Gnade oder freies Geleit?” Der Spiegel, 10. Januar 1972, S. 54.

Böll betonte immer wieder im Roman die pazifistische Tendenzen der manchen Radikale. Er betonte die arglose Einstellung der RAF Gruppe. Die Presse stellte diese Terroristen als unmenschliche Kommandos dar. Nach Böll wollten die Anhänger der RAF keine unnötige Gewalt. Nach ihrer Absicht wollten sie gesellschaftliche Änderungen, nicht verletzte Opfer: „Die Kriegserklärung, die im Manifest enthalten ist, richtet sich eindeutig gegen das System, nicht gegen seine ausführenden Organe." Solche Art nationalistische Terroristen wollen eine Veränderung in der Gesellschaft derer Heimat. Sie kämpfen gegen die Korrumpierung aus Liebe der Heimat. Man kann auch dazu merken, dass Ulrike Meinhof Antikriegartikel schrieb, bevor ihre Tätigkeiten als Studentenradikalen und mit dem in der Medien sogenannten BM-Gruppe. Ulrike Meinhof, die später zum Feind der deutschen Regierung werden sollte, wollte die Wiederaufrüstung Deutschlands vermeiden. Obwohl sie später als Täterin und Mitbegründerin der RAF-Organisation bekannt wurde, schrieb sie wohl bekannte gesellschaftlichkritische Artikel für die Zeitschrift konkret vor der Gründung der RAF. In Meinhofs 1962 erschienene Schreiben „Die Würde des Menschen“ meinte sie, dass die Wiederaufrüstung Deutschlands sinnlos sei. Über die zwei, „Haupterkenntnissen”, eines Rechtsstaats, die die deutsche Verfassung informieren sollten, behauptete sie, „1. Demokratie ist die einzige Menschenwürde sichernde Form staatlichen Zusammenlebens [...] [und] 2. Krieg ist im 20. Jahrhundert nicht mehr möglich". Ihrem Verständnis der Nachkriegskonstitution nach, wurde die Wiederaufrüstung Deutschlands unmöglich. Der moderne Rechtsstaat soll Menschenrechte bewahren. Krieg soll als veraltetes Organ der feudalen Beziehungen anbetrachtet worden: „Gemäß diesen zwei Erfahrungen wurde mit dem Grundgesetz der Rechtsstaat geschaffen, und zwar so wohldefiniert und total, so durchdacht und vielfältig gewährleistet, wie es ihn vorher in Deutschland nicht gab, und Wehrpflicht und Remilitarisierung waren von vornherein verfassungsmäßig, das schien: katexochen aus der projektierten Existenz der Bundesrepublik ausgeschlossen."

Ulrike Marie Meinhof, „Die Würde des Menschen,” in Ulrike Marie Meinhof: Die Würde des Menschen ist antastbar: Aufsätze und Polemiken, (Berlin: Wagenbachs Taschenbücherei, 1986.), S. 27.
} 
Böll meinte, dass diese Lynchjustiz, anders gesagt Selbstjustiz, wird durch Verhetzung oder Hysterie hervorgebracht und diese Hysterie sei mit Terror zu vergleichen. ${ }^{101}$

Bölls Kritik wurde am intensivsten auf die Zeitung gelegt, findet aber Anwendung auf alle Medien. Böll wurde kritisch der Dramatisierung in Spielfilme der Baader-Meinhof Gruppe gegenüber. Nach Böll spielte sie eine besondere Rolle in dem Durcheinander der eigentlichen Geschehen: „Die nach Indizien zurechtdramatisierten Spielfilmrekonstruktionen, die Herr Zimmermann als Illustrationen zeigt, sind doch nichts weiter als [...] einer undurchsichtigen Mischung von fact und fiction.." ${ }^{\text {102 }}$ Böll verwandte seine Kritik immer im Angesicht der NS-Vergangenheit: „Wie wär's, wenn Herr XY Zimmermann einen der immer noch gesuchten Naziverbrecher in der heiligen Krimistunde suchen ließe? Nur als Probe, um zu testen, wie's deutsche Krimigemüt drauf reagieren würde?"103 Diese Art Kritik wurde von Bölls Zeitgenossen nicht gut empfangen.

Böll wollte den Zustand des Verfolgtseins in der Nachkriegszeit aufklären. Die existentielle Lage der Ulrike Meinhof und der Baader-Meinhof Gruppe war, seiner Meinung nach, wirklich. Auch Böll verstand seine Kritik als unkonventionell im Sinne von Verfolgung: „Ich gebe gern zu, daß ich das Wort “verfolgt” nicht mit dem juristischen Terminus "gesucht” gleichzusetzen vermag, daß ich es auch existentiell und mit einem Anhauch von Metaphysik verwende."104 Böll musste sich mit dem

\footnotetext{
${ }^{101}$ Vgl. hier: Heinrich Böll, „Notstandsnotizen,” in der Glasnost.de Website. Seine Kritik an der Zeitung: „Wer war da nun in der Position der »Hysterie «?”

${ }^{102}$ Heinrich Böll, „Will Ulrike Gnade oder freies Geleit?” Der Spiegel, 10. Januar 1972, S. 54.

${ }^{103}$ Ebd., S. 54.

${ }^{104}$ Heinrich Böll, ,Verfolgt war nicht nur Paulus,” Der Spiegel, 31. Januar 1972, S. 60.
} 
instrumentalisierten Sinne des Begriffs auseinandersetzen. Böll wollte den existentiellen Sinn des Wortes betonen: ,[U]nd in diesem Zusammenhang ist ein verfolgter Nazi für mich auch ein Verfolgter, wobei hinzugefügt werden muß, daß er’s leichter hat, Versteck und Freunde zu finden“, als die ,Terroristen’ der spät 60er und früh 70er erlebten. ${ }^{105}$ Böll zeigte, dass die gesellschaftliche Unterstützung einer Organisation nicht auf eine moralische Rechtfertigung deutet. In diesem Zusammenhang bemerkte er, „daß die Nazis zur Erreichung ihrer politischen Ziele keine Bankraube unternehmen mußten: Der Bankier von Schröder und die deutsche Industrie rückten das Geld freiwillig raus““. ${ }^{106}$ Die sogenannte Baader-Meinhof Gruppe musste Raub unternehmen das Überleben zu versichern und ihre Zielen zu erreichen, denn sie hatte keine gesellschaftliche Unterstützung besonders aufgrund der Sondergesetze dieser Zeit.

Die offene staatliche Verfolgung von Linksextremisten, die sogar ehemalige Sozialarbeiter waren, um die Brandtzeit, genauer vom 2. Juni 1967 bis die 1974 Erscheinung der Katharina Blum, erscheint der Weltöffentlichkeit scheinheilig, so Böll, wenn man diese Verfolgung mit der Behandlung der Soldaten und Kriegsverbrechern der Zweiten Weltkrieg im Vergleich nimmt. ${ }^{107}$ Angesichts der

\footnotetext{
${ }^{105}$ Ebd., S. 60.

${ }^{106}$ Ebd., S. 60.

${ }^{107}$ Vgl. hier: Heinrich Böll, ,,Textilien, Terroristen und Pfarrer,” in Gefahren von falschen Brüdern: Politische Schriften, Auswahl aus: >Einmischung erwünscht. Schriften zur Zeit< (München: Deutscher Taschenbuch Verlag, 1980), S. 78-9.

„Ich denke mir, daß eines Tages, vielleicht schon bald, Historiker sich daran begeben werden, alles, was vor und nach dem 2. Juni 1967 bis auf den Heutigen Tag (Laudatio am 7. Dezember 1975 gehalten) geschehen ist, chronologisch zu ordnen, - nicht nur generationspsychologisch, auch politisch und und geistesgeschichtlich zu interpretieren. Und nicht nur nach der äußeren und inneren Entwicklung der verschiedensten Bewegungen und Gruppen, auch das, wovon man so wenig hört, was außerhalb dieser Gruppen geschah: die gesamte Reaktion der veröffentlichten Meinung. Ich betone: die gesamte! Und daß jemand den Mut haben wird, herauszufinden, wie viel diese publizierte öffentliche Meinung zu der schrecklichen Entwicklung beigetragen haben könnte.”
} 
Unbestrafften Kriegsverbrechern, die in der Adenauerzeit mit großer Gnade freigelassen worden sind, musste Böll seine Kritik erheben. ${ }^{108}$ Böll musste diesen Protest gegen die scheinheilige Gesetzanwendung als Gewissensfrage erheben, denn er selbst wurde als Wehrmachtsoldat freigelassen. Genau wie die freigelassenen Soldaten der NS-Zeit, so Böll, von denen er einer war, verdienten die Betroffenen Gnade. ${ }^{109}$ Eine Regierung, die Gnade anbietet und früher anbot, genau die gleiche hochgepriesene Gnade, wofür die Gesellschaft der Nachkriegszeit die Soldaten, Minderbelastete und anderen anbot, jedoch diese Gnade im Fall der ,verzweifelten' Jungen zurückhält, war Böll unangemessen:

Für einen so abscheulichen Satrapen wie Baldur von Schirach, der einige Millionen junger Deutscher in die verschiedensten Todesarten trieb und zu den verschiedensten Mordarten ermutigte, sogar für ihn gab es Gnade. Ulrike Meinhof muß damit rechnen, sich einer totalen Gnadenlosigkeit ausgeliefert zu sehen. ${ }^{110}$

Die scheinheilige Entscheidungen der Nachkriegsregierung, besonders die existentielle Freilassung der Wehrmacht Soldaten im Vergleich mit der Gefangenheit der Meinhof und ihre Gruppe aus moralischen Gründen, riefen eine starke Reaktion von Böll hervor. Böll kritisierte den scheinheiligen Gegensatz der Tat und des Wortes. Böll betonte den Unterschied zwischen der existentiellen und der moralischen Beurteilung: „[W]elch ein schrecklicher Vergehen darin liegen mag, in einer Gesellschaft, die sich weitgehend christlich definiert, um Gnade zu bitten und den Zustand des Verfolgtseins

\footnotetext{
${ }^{108}$ Für eine Diskussion, siehe: Norbert Frei, „Das Problem der Kriegsverbrecher,” in Vergangenheitspolitik, (München: Deutscher Taschenbuch Verlag, 2003), S. 133-266.

${ }^{109}$ Vgl. hier: Ebd., S. 202.

„Die Ehre des deutschen Soldaten ist für uns unantastbar und steht fest."

${ }^{110}$ Heinrich Böll, „Will Ulrike Gnade oder freies Geleit?” Der Spiegel, 10. Januar 1972, S. 54.
} 
auch existentiell und metaphysisch und nicht rein moralisch zu definieren."111 Böll meinte, dass die westlichen Nationen, die sich mit dem Christentum identifizieren, nicht als ein bloßer kulturellen Anhang, sondern als ein lebendiger Teil von der Kultur, verantwortlich für die Entfremdung und die Vertreibung von Terroristen aus der Gesellschaft sind.

Die RAF lenkte den Verdacht auf den Staat, dass der Staat den Anlass finden wollte, eine Fahndung gegen Linksradikalen im Allgemein herzustellen. Sie tat das verborgene Motiv der Regierung kund: „Es ist richtig, wenn behauptet wird, mit dem immensen Fahndungsaufwand gegen uns sei die ganze sozialistische Linke in der Bundesrepublik und Westberlin gemeint."112 Die Regierung, so Meinhof, benutzte Meinhofs Situation aus, damit einer allgemeine Widerstand gegen Andersdenkende, die Linke und jegliche staatliche Opposition ankündigt wurde. Böll warnte von dieser Tendenz auch:

In einer Gesellschaft, die Radikalität und Extremismus pauschal denunziert, ohne sich auf eine Skala von Differenzierungen einzulassen, muß natürlich ein Wort aufkommen, das, auf Funk- und Fernsehsendungen, Zeitungen und Zeitschriften angewendet, immer mehr zur Mode wird: ausgewogen. ${ }^{113}$

Böll war kein Unterstützer der RAF, der Baader-Meinhof Gruppe, oder des Terrorismus. Er war Verteidiger von Menschenrechten in der Bundesrepublik. Die scheinbare Unterstützung Bölls für Ulrike Meinhof zeigt Bölls Reaktion auf der Freilassung der Wehrmacht Soldaten des II. Weltkriegs und auf der NS-Zeit ähnlichen

\footnotetext{
${ }^{111}$ Heinrich Böll, „Verfolgt war nicht nur Paulus,” Der Spiegel, 31. Januar 1972, S. 60.

${ }^{112}$ Ulrike Meinhof et al., ,I. Konkrete Antworten auf konkrete Fragen,” Das Konzept Stadtguerilla, in der Nadir.org Website.

${ }^{113}$ Heinrich Böll, ,,Radikalität und Hoffnung,” in Gefahren von falschen Brüdern: Politische Schriften, Auswahl aus: >Einmischung erwünscht. Schriften zur Zeit< (München: Deutscher Taschenbuch Verlag, 1980), S. 23.
} 
Verfolgungsmethoden der Nachkriegsregierung gegen Meinhof. Er wollte Gnade für diese verzweifelte Jugendliche.

Rufmordkampagne gegen Böll: Gekoppelten Zeitungsberichten mit Polizeiaktionen

Bölls Entscheidung, die Bild-Zeitung und die NS-Vergangenheit zu kritisieren und die Fragestellung der Richtigkeit des Ergebnisses um Ulrike Meinhof wegen ihrer RAF assoziierten Tätigkeiten, hatte zur Folge, dass er in den Massenmedien böse behandelt wurde und von der Regierung als Feind angesehen war. Die Konterpolemik gegen Böll aufgrund seines Artikels „Will Ulrike Gnade oder freies Geleit?“ fang schon früh im Jahre 1972. Böll bekam diese verknüpfte Hetze hauptsächlich in Erwiderung auf seinen Spiegel-Artikel. Klaus Jeziorkowski bestätigt die Rufmordkampagne gegen Böll in seinem Artikel über Katharina Blum: „Sofort nach dem Artikel setzt die Hetze gegen Böll ein: Er wird als Sympathisant und Munitionslieferant der Terroristen in einer Reihe von Medien diffamiert." ${ }^{114}$ Die Rufmordkampagne wurde hauptsächlich durch die Springer-Presse geführt, ,unter denen Bild, Die Welt, Quick, Bayern-Kurier und das ZDF-Magazin“. ${ }^{115}$ Diese Zeitungen gaben sehr starke Kritik an Böll: ,”Bild” verglich den Schriftsteller mit Goebbels und dem SED-Agitator Karl-Eduard von Schnitzler." ${ }^{116}$ Auch betont wurde eine Assoziation zwischen Böll und terroristischen

\footnotetext{
${ }^{114}$ Klaus Jeziorkowski, „Die verlorene Ehre der Katharina Blum oder: Wie Gewalt entstehen und wohin sie führen kann," in Interpretationen Heinrich Böll: Romane und Erzählungen, (Stuttgart: Philipp Reclam jun. GmbH \& Co., 2000), S. 254.

Vgl. hier: Anonym, ,"'Mord beginnt beim bösen Wort”: SPIEGEL-Serie über Sympathisanten und sogenannte Sympathisanten," Der Spiegel, 3. Oktober 1977, S. 28.

${ }_{115}$ Ebd., S. 254-5.

116 Anonym, „Bölls „ZEITUNG”-Story: „Jetzt bumst's”,” Der Spiegel, 29. Juli 1974, S. 72.
} 
Gruppen in der BRD: „,'Quick” schrieb: “Die Bölls sind gefährlicher als BaaderMeinhof.","117 Diese verschiedenen Zeitungen, alle im Besitz von der Springer-Presse, nahmen an der Rufmordkampagne teil. Sie wollten Böll zum staatlichen Feind machen.

Diese Hetze wurde auch auf Bölls Familie angewandt. Die vernichtenden Kritik und die ungerechten Polizeiaktionen gegen ihn und seine Familie, die von der SpringerPresse und der Regierung in Erwiderung auf seinen Spiegel-Artikel kamen, bestätigten Bölls Behauptung von der systematisch gekoppelten Aktion der redaktionellen Meinungen mit polizeilichen Aktionen. Bölls Sohn Raimund geriet in den Verdacht der BM-Komplizenschaft im Februar 1974 kurz vor der Erscheinung der Erzählung. Er wurde mit Schlagzeilen getroffen: „,'Bild” meldete den Fall am 8. Februar unter der Schlagzeile “Bölls Sohn von Polizei verhört” “"118 Raimund wurde in dieser Zeit stark verhetzt:

Zum andern veröffentlichte die Bild-Zeitung am 12. Februar 1974, drei Tage nach einem Sprengstoffanschlag in Köln, einen herabsetzenden, denunziatorischen Artikel über Raimund Böll, der - nach dunklen Andeutungen über Kontakte zur terroristischen Szene - mit dem Hinweis schloß, seine Wohnung liege »nur 800 Meter Luftlinie« vom Ort des Attentats entfernt. ${ }^{119}$

Die enge Verbindung zwischen der Medien und den polizeilichen Aktionen der Regierung wurde auch in diesem Prozess klargemacht: „In einem Hamburger BMQuartier waren Pässe Raimund Bölls und seiner Frau Lila gefunden worden; ihre

\footnotetext{
${ }^{117}$ Ebd., S. 72.

${ }^{118}$ Ebd., S. 72 .

${ }^{119}$ Werner Bellmann, „Die verlorene Ehre der Katharina Blum oder: Wie Gewalt entstehen und wohin sie führen kann," in Interpretationen: Erzählungen des 20. Jahrhunderts Band 2, (Stuttgart: Reclam, 1996), S. 187-8.
} 
Kölner Wohnung wurde von der Polizei durchsucht, das Ehepaar verhört."120 Sie, „gaben an, einige Zeit vorher die gesuchte BM-Aktivistin Margrit Schiller in ihrer Wohnung empfangen“. ${ }^{121}$ Sie verstanden ihre, ,Anwerbungsversuchen jedoch als überzeugte Gewalt-Gegner”, und das, ,,Verschwinden ihrer Pässe hätten sie nicht bemerkte [sic]““. ${ }^{122}$ Solcher Gebrauch von Verhörungen und Vernehmungen wurde in Bölls Erzählung widerspiegelt und baute eine von den Hauptdarstellungsstrategien des Romans. Da Böll die Erzählung Katharina Blum infolge einer sich gegen ihn einrichtete Rufmordkampagne schrieb, erklärt seinen Anlass zum Schreiben. Die Rufmordkampagne und verknüpfte polizeiliche Aktionen gegen Böll inspirierten ihn zu seinem Roman.

Der Roman Katharina Blum enthielt biografische und autobiografische Züge. Autobiografisch ist der Roman eine Auseinandersetzung von Böll und Terroristen, er wollte sich selbst aus dem Sympathisantenverdacht ausziehen. Die persönlichen Ereignisse Bölls mit Ulrike Meinhof, die im Roman dargestellt sind, sind eher eine Art Auseinandersetzung seinem Leben mit dem Meinhofs, als ein Beweis der Sympathie: „In einigen Kommentaren zu Bölls Spiegel-Artikel war insinuiert, er habe möglicherweise selber schon gesuchten BM-Leuten Unterschlupf gewährt."123 Der Verdacht ging weiter: „[A]m Tag der Festnahme Baaders in Frankfurt, am 1. Juni 1972, wurde Bölls Landhaus in der Eifel von Polizei umstellt, die nach weiteren BMMitgliedern fahndete."124 Auf diese Weise fügte Böll das Geschehnis der

\footnotetext{
${ }^{120}$ Anonym, „Bölls „ZEITUNG”-Story: „Jetzt bumst's”,” Der Spiegel, 29. Juli 1974, S. 72.

${ }^{121}$ Ebd., S. 72.

${ }^{122}$ Ebd., S. 72.

${ }^{123}$ Ebd., S. 72.

${ }^{124}$ Ebd., S. 72.
} 
Durchsuchung seines Landhauses als verdächtigter Sympathisant mit Meinhof und der RAF. Die Zeitung und die Regierung waren scheinbar in Übereinstimmung, der Verdacht wurde schon publiziert:

Zwei Beleitumstände dieses Vorgangs waren es, die Heinrich Böll mit besonderer Verbitterung zur Kenntnis nahm. Zum einen meldete die im Springer-Verlag erscheinende Berliner Zeitung (BZ) die Haussuchung schon sieben bis acht Stunden vor ihrer tatsächlichen Durchführung (am Nachmittag des 7. Februar), was auf eine Zusammenarbeit der Springer-Presse mit der Polizei schließen ließ und zur Folge hatte, daß die Polizeiaktion in Köln, einschließlich der Abführung des Verdächtigten, zu einem spektakulären Presse-Ereignis wurde. ${ }^{125}$

Solche Geschehen beweisen die gekoppelte Natur der Zeitung mit der Regierung und unterstützten Bölls Behauptung von dieser Verknüpfung. Die öffentliche Ansage der Haussuchung am Vorabend des eigentlichen Geschehens beweist ohne Zweifel die wirkliche Verbindung zwischen der Zeitung und der Regierung. Die Regierung zeigte ihre Teilnahme durch polizeiliche Aktion. Böll spiegelte in dem Roman diese, so Böll, „,merkwürdig und gruselig” Situation wider, mit, ,ein quasi ironisch-indirekter Reflex: Katharina Blum verhilft ihrem geliebten "Banditen” zum Unterschlupf im rheinischen Landhaus eines Bekannten“. ${ }^{126}$ Böll spiegelte solche Geschehnisse der ungerechten Handlung von der Zeitung im Leben der Katharina wider.

Der publizierte Verdacht gegen Böll spiegelte sich in beleidigender Rezension seiner Werke wider. Bölls entscheidender Relevanz in dieser Zeit ist nicht zu verleumden. Trotz Bölls Position als Nobelpreisträger und Verteidiger von Deutschlands internationalem Ansehen wurde die Zeitung immer kritischer Bölls Schreiben

\footnotetext{
${ }^{125}$ Werner Bellmann, ,Die verlorene Ehre der Katharina Blum oder: Wie Gewalt entstehen und wohin sie führen kann," in Interpretationen: Erzählungen des 20. Jahrhunderts Band 2, (Stuttgart: Reclam, 1996), S. 187-8.

${ }^{126}$ Anonym, „Bölls „ZEITUNG”-Story: ,Jetzt bumst's”,” Der Spiegel, 29. Juli 1974, S. 72.
} 
gegenüber. Der objektive Wert der Erzählung wurde bis auf das Niveau der

persönlichen Gefühle Bölls vernichtet:

Bölls neue Erzählung ist gewiß keine Schlüsselgeschichte über "Bild" und BM - wohl aber ein Reflex auf die speziellen Erfahrungen des Autors aus jenem Frühjahr 1972, in dem er, der gegen die boulevardjournalistische BM-Hatz und das von ihr erzeugte "Klima der Denunziation" aufgetreten war, sich schließlich selber als BMKomplice und "Salonanarchist" denunziert und "gehetzt" fühlte. ${ }^{127}$

Böll selbst kämpfte gegen die vereinfachende Neigung der Rezension, die die

Geschichte auf einer Basis von persönlichen Gefühl stellte: „,[M]an muß die Texte in die Zeit zurückversetzen, in der sie geschrieben sind.” ${ }^{128}$ Böll glaubte das sei, ,eines der wichtigsten Prinzipien bei der Beurteilung von Literatur, dass man in die Zeit, in der sie geschrieben sind, zurückgehen muß, und zwar ganz“.${ }^{129}$ Nach Bölls eigener Bewältigung der Geschichte, muss die Erzählung zurück in der Zeit versetzt worden. Er betonte auch die Wichtigkeit der zeitgeschichtlichen, sozialen und persönlichen Interpretationen, die verschiedene Geschehnisse im passenden Zusammenhang stellen:

„Sich auch vorstellen muß, wie war das damals, was passierte damals, als das geschrieben worden ist." ${ }^{\prime 130}$ Böll verstand die Bedeutung der zeitgeschichtlichen Ereignisse in der Entstehung von Literatur. Werner Bellmann teilte diese Interpretation mit:

Gegenüber manchen Tendenzen in der Interpretationsliteratur zu Katharina Blum, die Relevanz zeitgeschichtlicher Bezüge und

\footnotetext{
${ }^{127}$ Anonym, ,Bölls „ZZITUNG”-Story: ,Jetzt bumst's”,” Der Spiegel, 29. Juli 1974, S. 72.

Hier steht $\gg \mathrm{BM} \ll$ für $»$ Baader-Meinhof $«$ oder $» B M-G r u p p e \ll$ oder $» B M-B a n d e \ll$.

${ }^{128}$ Werner Bellmann und Christine Hummel, Herausgeb., Erläuterungen und Dokumente: Heinrich Böll: Die verlorene Ehre der Katharina Blum, (Stuttgart: Philipp Reclam jun. GmbH \& Co, 1999), S. 27.

Böll im Gespräch mit Heinrich Vormweg, Dezember 1982. Das Zitat erschien ursprünglich in : Vormweg, Heinrich, „Böll vor 1945,” In Bernd Balzer (Hrsg.): Heinrich Böll 1917-1985, Bern [u.a.] 1992, S. 13-23.

${ }^{129}$ Ebd., S. 27.

${ }^{130}$ Ebd., S. 27.
} 
Entstehungshintergründe zu relativieren, sei hier hervorgehoben, daß diese »Gegenwartsgeschichte « in einen ganz bestimmten gesellschaftlich-politischen Kontext hineingeschrieben wurde, in einer Zeit, die sich mit Begriffen wie >Terrorismus-Debatte<, $>$ Sympathisanten-Problem<, >Radikalen-Erlaß<, >APO<, und >Ölkrise< etikettieren lässt. $^{131}$

Bellmann bestätigt Bölls eigene Ansichten von der Beurteilung von Literatur und zählte diese verschiedene zeitgeschichtliche Geschehnisse mit Relevanz zur Erzählung.

Der Knöpfungspunkt von Bölls Schreiben „Will sie Gnade oder freies Geleit?“ vom Gerichtsfall Ulrike Meinhof und an den zwei Jahre später erschienenen Katharina Blum ruft ein Vergleich von Meinhof und Blum vor. Böll wollte das Treiben zur Gewalt der beiden zeigen. Böll spiegelte im Roman die Situation Blum mit der von Meinhof meistens in Bezug auf ihre Darstellung in den Medien wider. Die beiden konfrontieren eine Rufmordkampagne, in der sie sexuell freizügig geschildert sind, Verdachte ohne konstitutionelle Garantien sind als Fakten in Schlagzeilen gehegt und ihre Darstellungen weisen auf rechtlicher Lynchjustiz oder Selbstjustiz hin. ${ }^{132}$ Die beide fuhren Gewalt nach dessen Kampagne. Genau diesen Anlass zur Gewalt wollte Böll enthüllen. Die Knöpfungspunkte sind jedoch auf verschiedene Weise geschränkt. Der Roman ist eigentlich eine Auseinandersetzung von Böll und dem Gebrauch von Gewalt. Böll war kein Unterstützer von Gewalt, weder von der Regierung noch von

\footnotetext{
${ }^{131}$ Werner Bellmann, „Die verlorene Ehre der Katharina Blum oder: Wie Gewalt entstehen und wohin sie führen kann," in Interpretationen: Erzählungen des 20. Jahrhunderts Band 2, (Stuttgart: Reclam, 1996), S. 184.

${ }^{132}$ Noch eine Spur, dass Katharina und Meinhof zu vergleichen sind, hängt von dem Name Blum ab. Böll wählte den Name „Blum” vom Namen eines Politikers des 19. Jahrhunderts Robert Blum. Er nahm an der Wiener Revolution Oktober 1848 teil und wurde im nächsten Monat wegen seiner Teilnahme erschossen. Der Name „Blum” soll diese ,revolutionäre’ Assoziation und die Warnung vor Selbstjustiz hervorrufen.
} 
Terroristen. Böll wollte sich selbst aus dem terroristischen Verdacht ausziehen, aber auch die richtige Frage der Menschen- und Grundrechte aufwerfen.

Bölls Intention: Die Enthüllung von Entmenschlichung und Radikalisierung

Bölls Hauptansicht in dem Roman war den entmenschlichenden und radikalisierenden Einfluss der gekoppelten Aktionen der Regierung mit der verwirrenden Wirkung der Zeitung auf einen normalen Bürger zu zeigen. Er enthüllte die gekoppelten Mechanismen der redaktionellen Meinungen und Schlagzeilen mit staatlichen Aktionen in der Entstehung von Rufmordkampagnen. Böll wollte den Prozess von Rufmordkampagnen zur nachfolgenden Gewalt aus Hilflosigkeit der Betroffene verdeutlichen. Werner Bellmann teilte diese Ansicht in seinem Artikel über Katharina Blum:

Von ihrer Grundkonzeption her ist Bölls Erzählung jedoch eine Fallstudie über journalistischen Machtmißbrauch. Sie demonstriert, daß im Medium der Sprache Menschen Gewalt angetan werden kann und daß insbesondere gewisse Praktiken des auf die Sensationsgier spekulierenden Enthüllungsjournalismus Gewaltausübung darstellen. ${ }^{133}$

Der Roman offenbart die Starke des heutigen Sensationalismus und enthüllt die Tendenz der einseitigen Darstellungen in der Presse. Böll wollte dem Leser das Prozess beibringen, wobei das Leben eines normalen Menschen durch Vermutung und falsch Berichterstattungen in den Medien zerstört werden könne. Böll wollte zeigen, dass das Vorhandensein der gekoppelten Mechanismen der Politik mit der Presse ein

\footnotetext{
${ }^{133}$ Werner Bellmann, „Die verlorene Ehre der Katharina Blum oder: Wie Gewalt entstehen und wohin sie führen kann,” in Interpretationen: Erzählungen des 20. Jahrhunderts Band 2, (Stuttgart: Reclam, 1996), S. 196.
} 
Zeichen der gefährdeten Stelle der Meinungsfreiheit und der darauf basierten

Demokratie war. Böll meinte, dass die Hilflosigkeit aufgrund einer Rufmordkampagne Gewalttaten von der Betroffenen einleitet. Böll wollte den Leser eine Alternative zur konventionellen Zeitungsberichten anbieten. Er wollte eine Gegeneinanderstellung von einer reinen Fakt-bezogenen Fassung eines Geschehnisses mit einer sensationalisierten Zeitungs-ähnlichen Fassung anbieten, damit der Leser den Prozess des Sensationalismus und der Verdinglichung des Menschens durchsehen könnte. Bemerkenswert am Schreibstil von Katharina Blum ist die vom Autor selbst ankündigte Absicht, die Geschichte der Katharina Blum in einer Berichtform darzustellen. Böll reproduzierte auch die Welt der Zeitung in seiner Erzählung durch den Gebrauch von Zeitungsartikeln und Schlagzeilen, die in dem gebräuchlichen Stil geschrieben sind. Die Zeitungstextstücke wirken lächerlich im Vergleich zu dem trockenen Schreibstil Bölls Berichterstatters. Durch die Nebeneinanderstellung vom trockenen Stil des Berichterstatters mit dem sensationalisierten Schreibstil der „ZEITUNG“, die vermutlich neutral und sachlich wirken sollte, wird das Wesen derartigen Journalismus und gewöhnlichen Sensationsmacherei der Boulevardzeitungen deutlicher. Vom Bericht selbst erfahren wir, dass die Hauptquellen aus, „Vernehmungsprotokolle[n] der Polizeibehörde, Aussage von Rechtsanwalt Dr. Hubert Blorna und Aussage von Staatsanwalt Peter Hach“, (7) bestehen. ${ }^{134}$ Diese sachlichen Quellen seines eigenen Kollageschreibstils stellen eine nachdenkliche Stimmung und anregende Atmosphäre her. Nach Werner Bellmann

\footnotetext{
${ }^{134}$ Heinrich Böll, Die verlorene Ehre der Katharina Blum oder: Wie Gewalt entstehen und wohin sie führen kann, (München: Deutscher Taschenbuch Verlag, 1974: 40. Auflage Mai 2003), S. 7. Nachher nur mit Seitenangaben.
} 
weist der Text eine, ,,komplizierte Erzählstruktur auf, die darauf angelegt ist, Aufmerksamkeit und Konzentration des Lesers zu aktivieren“. ${ }^{135}$ Die Erzählung Katharina Blum wurde ursprünglich im Spiegel veröffentlicht. Die erste Ausgabe erschien am 29. Juli 1974. ${ }^{136}$ Bölls zielte didaktische Intention wurde in dem berühmten anonymen Spiegel-Artikel „Jetzt bumst’s“, der am selben Tag wie der erste Abschnitt der Erzählung veröffentlicht wurde, angedeutet: „Die Komposition der Erzählung aus Zeugenaussagen, Zeitungszitaten und ähnlichen epischen Teilstücken“, wirkt, „,so meint Bölls Verlag - als eine “Fortschreibung des großen Romans 'Gruppenbild mit Dame'” erscheinen“" ${ }^{137}$ Das epische Element beschließt Bölls didaktische Intention der Erzählung. Böll nutze die Verfremdungseffekte der technischen Berichte und Zeitungsartikel im Roman, damit diese Verfremdung zum Zeitungslesen von der Leserschaft übertragen würde. In diesem Sinne gilt Katharina Blum zur epischen Tradition. Böll versuchte dabei die Bildungskraft des gebildeten Lesers der Bundesrepublik zu erwecken, genau die gleiche Leserschaft jener Zeitung in der Bundesrepublik, die Angriffe der Zeitungen und Massenmedien seiner Zeit greifbar zu machen. Böll zielte seine Erzählung absichtlich auf die Leserschaft des Spiegels. Böll erzielte mit seinem Roman einen pamphletisch-belehrenden Effekt, der die Meinung der Leserschaft ändern sollte. Böll behauptete, ,,diesen Terroristen-

\footnotetext{
${ }^{135}$ Werner Bellmann, „Die verlorene Ehre der Katharina Blum oder: Wie Gewalt entstehen und wohin sie führen kann," in Interpretationen: Erzählungen des 20. Jahrhunderts Band 2, (Stuttgart: Reclam, 1996), S. 194.

${ }^{136}$ Die Erzählung wurde in vier Fortsetzungen im Spiegel gedruckt: I. Fortsetzung, Nr. 31, 1974: II. Fortsetzung, Nr. 32, 5. August 1974: III. Fortsetzung, Nr. 33, 12. August 1974: IV. Fortsetzung: Nr. 34, 19. August 1974.

${ }^{137}$ Anonym, ,Bölls ,ZEITUNG”-Story: ,Jetzt bumst's”,” Der Spiegel, 29. Juli 1974, S. 72.

„Was der Nobelpreisträger von derlei Journalismus hält, hat er nun in der Geschichte vom “ZEITUNG”-Opfer Katharina Blum mit den Mitteln des Erzählers und Satirikers dargelegt."
} 
Roman (der gar keiner ist - weder ein Roman noch kommen Terroristen darin vor)“, eine, ,erzählerisch verkleidete Pamphlet”, sei. ${ }^{138}$

Böll wollte es bekannt machen, die Gefahr, in der jener Bürger von solcher verknüpften Verfolgung schwebte, damit er das Verständnis und Geduld des Lesers erwecken konnte. Durch die Erkennung dieser Gefahr mochte Böll die allgemeine Leserschaft des Spiegels - also die Bürger der Bundesrepublik - die übertriebene Wichtigkeit der Presse zeigen. Diese Schreibstrategie gelingt Böll, indem er eine Polemik gegen den sogenannten Boulevard-Journalismus treibt. Böll meinte, und wollte erweisen, dass niemand gegen die Wirkungskraft der Medienorgane geschützt wird, denn die Zeitung verwaltet in der Massenkultur die Meinungsbildung, die unbewiesen erhalten.

Jener Leser soll fähig sein, sich selbst mit Katharina zu identifizieren und voller Mitleid sein, denn Böll erweist die Möglichkeit der Zerstörung des Lebens durch eine Rufmordkampagne für jenen Bürger eines Rechtsstaats. ${ }^{139}$ Bölls Roman zwingt den Leser absichtlich zur Identifikation mit der Heldin der Geschichte. Die Struktur der Erzählung, dass von der, ,,Täterperspektive zunehmend in die Perspektive des Opfers gerückt wird, was nicht ohne Bedeutung ist für die Parteinahme des Lesers und seine Bereitschaft zur Identifikation“, trifft das Ziel Bölls. ${ }^{140}$ Mit der durch und durch

\footnotetext{
${ }^{138}$ Heinrich Böll, ,Zehn Jahre später,” Nachwort zur Katharina Blum, (München: Deutscher Taschenbuch Verlag, 2003), S. 140.

${ }^{139}$ Vgl. hier: Klaus Jeziorkowski, „Die verlorene Ehre der Katharina Blum oder: Wie Gewalt entstehen und wohin sie führen kann," in Interpretationen Heinrich Böll: Romane und Erzählungen, (Stuttgart: Philipp Reclam jun. GmbH \& Co., 2000), S. 261.

„Nach Bölls ästhetischen Maximen ist alle wahraft große Literatur einfach. In dieser Einfachheit liegt ihre Größe. Sie ist gleichermaßen für den intellektuellen Kenner wie für den literarisch nicht Vorgebildeten erfahrbar, auch für sog. [sic] > einfache< Leute."

${ }^{140}$ Werner Bellmann, ,Die verlorene Ehre der Katharina Blum oder: Wie Gewalt entstehen und wohin sie führen kann," in Interpretationen: Erzählungen des 20. Jahrhunderts Band 2, (Stuttgart: Reclam, 1996), S. 191.
} 
fleißigen und anständigen Charakterisierung der Katharina wollte Böll das Mitgefühl des Lesers verstärken.

Böll idealisierte Katharina Blum, um einen Typus der säkularen Frömmigkeit in der modernen chaotischen Welt darzustellen, eine Art Heldin, für deren Schicksal man sich interessieren kann. Im Verlauf der Geschichte lernt der Leser Katharina kennen. Ihre Charakter wird makellos im Roman dargestellt: „Katharina sei immer ein fleißiges, ordentliches, ein bisschen schüchternes, oder besser gesagt: eingeschüchtertes Mädchen gewesen, als Kind sogar fromm und kirchentreu.” (63-4) Katharina benimmt sich nicht übermenschlich. Außerdem arbeitet sie fleißig und mit einem starken Pflichtgefühl. Sie arbeitet stetig, um die Kosten ihres eigenen Eigentums und Effekten zu bezahlen, und zudem noch um die Gesundheitspflegekosten ihrer Mutter zu decken. Sie besorgt auch Tabak für ihren verhafteten Bruder. Durch dieses Verhalten übt sie eine schon veraltete Art von Pflichtbewusstsein aus, das heutzutage ausstirbt und als erstrebenswert von Böll betrachtet wird. Sie hat allerdings die alltäglichen Antriebe wie jedermann und ist ganz alltäglich und normal zu betrachten, da sie, so Böll, ,zwei weitere verfluchte Eigenschaften hat, die in allen Sagen und Märchen hochgepriesen werden: TREUE und STOLZ““ ${ }^{141}$ Nach den Meinungen vielen Menschen sind diese Tugenden wertvoll und lohnend, trotzdem sieht man, dass diese sogenannten Tugenden auch unerwünschte Folge im Rahmen einer unfairen und ungerechten Gesellschaft haben können. Da Katharina Stolz hat, vielleicht sogar einen außergewöhnlichen Niveau

\footnotetext{
${ }^{141}$ Heinrich Böll, ,Zehn Jahre später,” Nachwort zur Katharina Blum, (München: Deutscher Taschenbuch Verlag, 2003), S. 142.
} 
davon, ist sie als tragische Figur im traditionellen Sinne zu verstehen, da sie wegen ihres Stolzes einen großen Untergang begehen soll.

Die makellose Darstellung von Katharina Blum soll das tragische Element beschließen. Sie wird als idealisierte unabhängige Bürgerin dargestellt. Böll unterstreicht ihre Perfektion in seinem Nachwort zur Katharina Blum: „Diese Katharina Blum, die noch nicht viel Liebe erfahren hat, diese fleißige, tüchtige, völlig unpolitische Person, die sich, ökonomisch betrachtet - und das aus eigener Kraft und Planung - im Aufschwung befindet, ja, sie ist das verkörperte Wirtschaftswunder, mit Auto, Eigentumswohnung und einigen Ersparnissen." "142 Sie ist die idealisierte Staatsbürgerin. Sie ist das erstrebte Ziel jener Gesellschaft eines entwickelten Landes. Sie verdient allen rechtlichen Schutz des Staates. Katharina wurde als idealisierte unabhängige Staatsbürgerin geschildert. Böll wollte es deutlich zeigen, dass solche Rufmordkampagne auf irgendjemand angewandt sein können. Böll erweist, dass wenn die öffentliche Meinung einer Person durch eine Rufmordkampagne beschädigt wird, trägt der Beschädigte die Beweislast eigener Unschuld, hat aber keine Gelegenheit sich selbst öffentlich, d.h. in der Zeitung, zu verteidigen.

${ }^{142}$ Ebd., S. 141. 
Menschenwürde und Ehre

In Katharina Blum untersuchte Böll die Beziehungen der Ehre zur Liebe im Zusammenhang mit einem einfachen Menschen. Da die Ehre einer Frau immer noch in strenger Verbindung mit dem sexuellen Umgang steht, heißt das, dass die Würde einer Frau noch nicht von veralteten Lebensverhältnissen aufgeklärt worden ist. Jeziorkowski bemerkte diese Wirkung von Bölls Erzählung: „Die beiden altmodischen Wörter »Ehre « und »Gnade« mit ihrem religiösen Hintergrund tragen diese Böllsche Utopie des neuen Menschen. Böll erlöst diese Wörter aus ihrer unseligen Verengung und Instrumentalisierung." ${ }^{143}$ Böll wollte die Anerkennung der Frau als unabhängige Staatsbürgerin versichern, da Böll auch das Konzept, „Ehre”, von, „der unseligen bürgerlichen Verengung auf Jungfräulichkeit als Gefängnis um jeden Preis“, befreite. ${ }^{144}$ Böll musste die besondere Beziehung der Frauenehre zur sexuellen Enthaltsamkeit betonen. Er musste Katharina diese Ehrlichkeit zuschreiben, damit der Leser sie als Mensch antrachtet. Liebe und Ehre genießen daher in dem Werk eine besondere und zwiespältige Beziehung. Böll meinte, dass Liebe nur mit Ehrlichkeit in der Gesellschaft Erfüllung finden kann. Die Liebe wird von Böll als abhängig von Ehre dargestellt und wird durch die Verletzung der Ehre beschädigt. Ohne Ehre ist die Frau als sexuell verworren angetrachtet und alle intime Beziehungen als den bloßen Ausdruck der Begierde auch angetrachtet. Diese ehrenlose Darstellung ist genau die

\footnotetext{
${ }^{143}$ Klaus Jeziorkowski, „Die verlorene Ehre der Katharina Blum oder: Wie Gewalt entstehen und wohin sie führen kann," in Interpretationen Heinrich Böll: Romane und Erzählungen, (Stuttgart: Philipp Reclam jun. GmbH \& Co., 2000), S. 266.

${ }^{144}$ Ebd., S. 266.
} 
Entmenschlichung der Frau. Ohne Ehre, ohne die Anerkennung der Liebe und des würdigen Umgangs eines Menschen vom Staat, würde die Liebe zwischen zwei Personen als schändlich angesehen werden. ${ }^{145}$

Böll verwandte viele Seiten, um Katharinas nicht-sexuelles Lebensverhalten zu deuten. Er brauchte die Vernehmung von Katharina und ihrer Genossen diesen Fakt zu verdeutlichen. Er wollte sie lebendig darstellen, als ein ehrenhafter Mensch. Böll musste die Verdinglichung von Katharina vermeiden. Die Details ihres Lebens erhöhen ihre Schilderung als ein ehrenhafter Mensch. Katharina wird als Ausübende der sexuellen Enthaltsamkeit anerkannt. Sie zieht immer einen starken Unterschied zwischen Zärtlichkeit und Zudringlichkeit. In Vernehmungsprotokollen behauptete Katharina, „Zärtlichkeit sei eben eine beiderseitige und Zudringlichkeit eine einseitige Handlung“. (30) Ihre Einstellung zu diesem Unterschied wird immer wieder stark betont, denn, ,sie würde kein Protokoll unterschreiben, in dem statt Zudringlichkeiten Zärtlichkeiten stehe“. (30) Obwohl sie geschieden ist, wirkt dieser Zustand ihr gegenüber nicht beschädigend, denn sie führt ihr Leben in Keuschheit. Sogar die Gründe für die Scheidung steigern den ehrvollen Charakter Katharinas, da, ,einer der Gründe, warum sie sich von ihrem Mann, getrennt habe, hänge damit zusammen, der sei eben nie zärtlich, sondern immer zudringlich gewesen“. (30) Den großen Wert, dem Katharina auf Zärtlichkeit und das damit gehörende Konzept der wahre Liebe legt, schließt die wertvolle Charakter Katharinas.

\footnotetext{
${ }^{145}$ Heutzutage spielt der Staat eine große Rolle in der Anerkennung der Ehre und Liebe. Nur was ,gesetzlich' ist, kann auch als ,ehrlich' anerkannt: z.B. die Anerkennung der gleichgeschlechtlichen Ehe, das heißt in einem bestimmten Sinn, gleichgeschlechtlichen Liebe.
} 
Bölls tief greifende Untersuchung des Menschen an sich spielt eine große Rolle für die Erzählung als Literatur. Die moderne Handlung dieser traditionellen Themen erneuerte diese Konzepten und vergrößerte die mögliche Analyse von vielen gesellschaftlichen Themen und den möglichen Wortgebrauch der Menschenwürde und -rechte, der heute verfügbar ist. Böll verstand den traditionellen Wert der Ehre als ein veralteter Ausdruck, der als Synonym des modernen Konzepts von Menschenwürde gilt. Böll legte großen Wert auf das Konzept von Menschenwürden und auf aufgeklärten Sprachgebrauch. Seine Überlegungen, die er im Lauf seiner Menschenrechtsstellvertreterkarriere und als Schriftsteller entwickelten, erklären sein unkonventionelles Verständnis und tief greifende Analyse dieser Begriffe. Er bemerkte schon die Macht dieser veralteten Wörter und wollte diese Wörter im Gebrauch behalten. Böll verwandte den literarischen Rahmen der Katharina Blum die Instrumentalisierung der Wörter umzugehen. Da die Erzählung Katharina Blum teilweise von informellen Reden und Informationsquellen entsteht, leistet dieser Kontext durch die Schilderung alltäglichen Gedanken und Redensart über Liebe z.B. die Instrumentalisierung der Wörter zu vermeiden. Böll konnte freilich Begriffe anwenden, die weder in der Zeitung noch in akademischen Aufsätze angewandt werden können: Begriffe sowie Schicksal,Zudringlichkeit, Zärtlichkeit, Ehre und Liebe auf den ersten Blick.

Böll legte großen Wert auf die Anerkennung des inneren Verhältnisses der Ehre zu modernen Konzeptionen der Menschenrechte. Er spürte den leeren Klang des Wortes 
Menschenwürde, falls der Begriff Ehre des Menschen fehlt. Jeziorkowski fand, dass

Böll dieses Ziel traf:

»Ehre« wird bei Böll wieder neugeboren als humane Würde, unverletzte Menschlichkeit, als Status des freigeborenen Menschen, wie ihn das Naturrecht und danach die freiheitlichen Verfassungen seit der Französischen Revolution in Frankreich, den USA, der Bundesrepublik als die constitution of rights jedem Menschen als unveräußerliches Recht garantieren. ${ }^{146}$

Dieser Gebrauch des Wortes Ehre ist neu, denn ihre normale Verwendungsweise hat keine Beziehung zu modernen Rechten. Böll wollte die intime Beziehung von Ehre zu den Menschenrechten offenbaren. Die Wiedereinfügung veralteter Wörter und Werte, wie Ehre und Gnade, als Menschenrechte im modernen Sinne der staatlichen Verfassung wird von Böll verlangen. Dieser Unterschied im Wortgebrauch wurde auch schon in seiner Befreiung und Wiederherstellen des Begriffs Gnade. Klaus Jeziorkowski beschrieb diesen Unterschied in seinem Artikel über Katharina Blum: „Die Differenz im Wortgebrauch wird kraß offenbar am Beispiel des Wortes »Gnade«. Bölls Fragen in seinem berühmten Spiegel-Artikel über Ulrike Meinhof wurden zum gesellschaftlichen Skandal." ${ }^{147}$ Böll literarisierte diese Wörter und setzte sie in den Kontext der modernen Verfassung eines Rechtsstaats. Er drängte auf die Anerkennung der Ehre als eine veraltete Form der Menschenwürde. Jeziorkowski kam zum selben Ergebnis: „,Das alte Wort »Ehre« im Titel der Erzählung wird zur Kennzeichnung der irdischen und der himmlischen Rechte eines neuen Menschen, der ein Recht hat auf unangetastete Würde und auf Lebensglück im Sinne unserer

\footnotetext{
${ }^{146}$ Klaus Jeziorkowski, „Die verlorene Ehre der Katharina Blum oder: Wie Gewalt entstehen und wohin sie führen kann," in Interpretationen Heinrich Böll: Romane und Erzählungen, (Stuttgart: Philipp Reclam jun. GmbH \& Co., 2000), S. 264.

${ }^{147}$ Ebd., S. 264.
} 
modernen Verfassungen."148 Das Wort Ehre ist ganz außer Gebrauch gekommen, aber nach Böll zeigt es auf den gleichen Wert des Begriffs Menschenwürde: „»Ehre« wie »Gnade« werden von Böll wieder zu Ehren gebracht im Sinne einer umfassenden humanen Konzeption, gegen die verengende Instrumentalisierung dieser Wörter durch unser System und seine Funktionäre in Prägungen wie »Gnadenschuß« oder »Ehrensenator «."149 Böll zielte seine Geschichte hauptsächlich auf die Frage der Ehre und auf ihre wesentliche Gleichheit zu der Würde des Menschen. Böll wollte den Begriff Ehre aufklären und von ihrer eingeschränkten Instrumentalisierung und veralteter Assoziationen befreien.

Böll kämpfte gegen die Neigung der Instrumentalisierung der Wörter, welcher Prozess die Gewalt der Wörter steigt. ${ }^{150}$ Er gab auch Mühe diese Instrumentalisierung bekanntzumachen. Diese Bemühung um die Instrumentalisierung der Wörter war schon erkennbar in Bölls Anwendung der Begriffe christlich sowie Verfolgung unter anderen. Jeziorkowski erkannte die Beschränkung der Wörter auf das professionelle und gesetzliche Bereich:

So problematisch und des Kommentars bedürftig Bölls Wendung vom »freien Geleit« von Juristen und Experten auch immer eingeschätzt worden ist - an der Differenz im Sprachgebrauch angesichts solcher Wörter wie »Recht « und »Gnade« öffnet sich ein prinzipielles Problem des unterschiedlichen Umgangs mit Sprache bei Experten des Rechts einerseits und Künstlern andererseits. ${ }^{151}$

\footnotetext{
148 Ebd., S. 267.

${ }^{149}$ Ebd., S. 264.

${ }^{150}$ Die Entmenschlichung oder Verdinglichung von Menschen ist ein Teil vom ,Objektivismus'. Die Instrumentalisierung von Wörtern ist auch mit ,Objektivismus' verbunden. Beide hängen mit dem Geldwirtschaft stark zusammen.

${ }^{151}$ Ebd., S. 264-5.
} 
Offensichtlich verlieren Wörter ihren originellen Sinn durch Instrumentalisierung, dabei steht die Gefahr, dass die mit den Wörtern verbundenen Konzepte aussterben. Der Staat hat die Aufgabe die Würde des Menschen, d.h. die Ehre des einzelnen Menschen, zu schützen und zu bewahren, aber das Justizsystem steht denen zum Gebrauch, die amtliche Sprache anwenden können. Diese spricht, so Böll, die Garantie der Gleichheit vor dem Gesetz wider:

Laut Artikel 3 des Grundgesetzes für die Bundesrepublik Deutschland sind alle Menschen vor dem Gesetz gleich, und es ist gewiß nicht Schuld der Gerichte und Richter, daß diese Gleichheit - laut Aussage der Polizeibeamten - nur zu einem Bruchteil existiert. [...] und hier kommt ein zweites, weiteres Recht, ebenfalls aus Artikel 3, auf die Szene: »Niemand darf wegen seines Geschlechts, wegen seiner Abstammung, seiner Rasse, seiner Sprache, seiner Heimat und Herkunft, seines Glaubens, seiner religiösen oder politischen Anschauungen benachteiligt oder bevorzugt werden. ${ }^{152}$

Böll wollte die Rechte jeder Bürger versichern: „Die meisten Menschen [...] kennen sich mit dem Rechtsinstrumentarium nicht aus, sie haben

Artikulationsschwierigkeiten, es kommt zu Mißverständnissen, Resignation.." ${ }^{153}$ Die Artikulationsschwierigkeiten, die ,einfache Menschen' treffen, hängen teilweise mit der Instrumentalisierung der Sprache zusammen.

Böll wollte auch den Wortgebrauch und die Interpretationsmöglichkeiten der veralteten Werte und Wörter überliefern. Jeziorkowski schätzte die Arbeit Bölls auf eine glänzende Art:

Böll steht für die andere Möglichkeit, die eher die der Künstler ist: Er hält sich das Recht offen zu mehrdimensionalem Wortgebrauch, der die

\footnotetext{
${ }^{152}$ Heinrich Böll, „Radikalität und Hoffnung,” in Gefahren von falschen Brüdern: Politische Schriften, Auswahl aus: `Einmischung erwünscht. Schriften zur Zeit< (München: Deutscher Taschenbuch Verlag, 1980), S. 19-20. Siehe: Anhang A: Radikale in öffentlichem Dienst

${ }^{153}$ Ebd., S. 19-20.
} 
Bedeutungsvarietäten des Wortes, auch die altmodischen, zur Geltung zu bringen sucht durch Abstinenz von der Instrumentalisierung der Wörter zu Begriffen. ${ }^{154}$

Böll arbeitete mit diesen Konzepten, damit er diese Wörter in modernen Diskussionen zur Gültigkeit bringen konnte. Böll zeigte, dass Beschränkungen auf dem gewöhnlichen Wortgebrauch, die von der Aufklärung entstammte, die freie Diskussion der Menschenrechte verhindert. Böll analysierte die aktuelle geschränkte Benutzung im Wortbereich der Juristen und der Zeitung. Böll verlangte ein umfassender Wortgebrauch in modernen Diskussionen von Rechten. Die Pressefreiheit soll solche Rechte gewährleisten. Böll meinte, dass das Recht auf Meinungsäußerung am wichtigsten ist: „Es ist ja kein Zufall, dass jede Unterdrückung mit der Unterdrückung der Sprache anfängt." ${ }^{155}$ Zunächst folgt, ,,der Unterdrückung der Literatur, wenn man unter Literatur nicht ausschließlich das Geschriebene versteht““ ${ }^{156}$ Er behauptete, dass diese Unterdrückung eine rechtlose Gesellschaft erwirkt: „Eine ausgewogene Gesellschaft wäre eine problemlose Gesellschaft, in der es keine Konflikte mehr gibt, in der jeder recht hat und logischerweise jeder unrecht. Eine Gesellschaft ohne Konflikte, ohne Schuld, ohne Polemik."157 Nach Bölls Ansichten bringt das unterdrückte Recht auf Meinungsäußerung den Tod von Bürgerrechten. Jeziorkowski fand, dass Böll die Rechte jener Bürger bewahren wollte: „Böll erweist sich damit als

\footnotetext{
${ }^{154}$ Klaus Jeziorkowski, „Die verlorene Ehre der Katharina Blum oder: Wie Gewalt entstehen und wohin sie führen kann," in Interpretationen Heinrich Böll: Romane und Erzählungen, (Stuttgart: Philipp Reclam jun. GmbH \& Co., 2000), S. 264-5.

${ }^{155}$ Heinrich Böll, ,Ich bin ein Deutscher,” in Gefahren von falschen Brüdern: Politische Schriften, Auswahl aus: >Einmischung erwünscht. Schriften zur Zeit< (München: Deutscher Taschenbuch Verlag, 1980), S. 58. ${ }^{156}$ Ebd., S. 58.

${ }^{157}$ Heinrich Böll, „Radikalität und Hoffnung,” in Gefahren von falschen Brüdern: Politische Schriften, Auswahl aus: >Einmischung erwünscht. Schriften zur Zeit< (München: Deutscher Taschenbuch Verlag, 1980), S. 23.
} 
das exakte und präzise Gegenteil dessen, wozu viele ihn dämonisieren wollten eines Verfassungsfeindes, er erweist sich als einer der entscheidensten Verfassungsfreunde, die wir je hatten, der denkbar treueste Anwalt der zivilen Grundrechte."158 Bölls eigener Stellungnahme zu der Justizpolitik stimmt mit dieser Einschätzung überein.

Jeziorkowski bemerkte, dass Böll seine Befreiung der Begriffe Ehre im besonderen Zusammenhang mit der Frauenehre forttrieb. Das Frauenbild bei Böll zeigt, „daß Böll seine Hoffnung auf eine neue Menschlichkeit aus verachteten alten Werten und Worten vor allem auf die Frauen projizierte“. ${ }^{159}$ Böll legte großen Wert auf die Möglichkeiten der Zukunft. Bölls Position in Katharina Blum findet Widerspiegelung in Gruppenbild mit Dame unter anderen Romanen Bölls. Jeziorkowski bemerkte diese erfolgreiche Erzählstrategie von Böll. Er stellte oft Frauen dar, den Erfolg der Aufklärung und die demokratische Grundordnung zu bewerten: „Man stelle sich eine Galerie Böllscher Werke vor Augen: Die verlorene Ehre der Katharina Blum, Gnade für Ulrike Meinhof, Gruppenbild mit Dame, Frauen vor Flusslandschaft. “160 Er bewahrte die Ehre für alle Menschen, aber besonders für Frauen. Böll deutet hier auf dem Zusammenhang der veralteten qualitativen Werte mit modernen Konzepten wie Menschenwürde hin. Böll meinte die moderne Würde eines Menschen einen leeren Klang hat, falls die Ehrlichkeit des Menschen fehlt.

\footnotetext{
${ }^{158}$ Klaus Jeziorkowski, „Die verlorene Ehre der Katharina Blum oder: Wie Gewalt entstehen und wohin sie führen kann," in Interpretationen Heinrich Böll: Romane und Erzählungen, (Stuttgart: Philipp Reclam jun. GmbH \& Co., 2000), S. 267.

${ }^{159}$ Ebd., S. 266.

${ }^{160}$ Ebd., S. 266.
} 
Das Such nach Terroristen: systematische Entmenschlichung und Radikalisierung

Das Gespräch von Radikalität und Terroristen wurde in Bölls Erzählung thematisiert, besonders in der Persönlichkeit von Ludwig Götten. Böll wollte erweisen, dass der Such nach Terroristen den beschuldigten Terroristen radikalisiert und bringt dadurch Terroristen hervor, der Preis bleibt höher als die Belohnung. Böll argumentierte, dass die Verfolgung von Terroristen dessen Gewalt eskaliert. ${ }^{161}$ Die Kriminalisierung und Verfolgung von Terroristen schließt sie aus der Gesellschaft aus. Wenn auch ein Terrorist, oder mutmaßlicher Terrorist, das gesetzliche Leben wiederherstellen und die Beziehung zum Staat normalisieren will, wird die Möglichkeit ausgeschlossen. Die Verfolgung durch die Medien und die Regierung, so Böll, erzwingt die Radikalisierung der Betroffenen: „Nun, wir wissen doch, Vertriebene neigen zur Radikalität." ${ }^{\prime 62}$ Böll meinte, dass die Verfolgung von Terroristen dieser immer noch weiter aus der Gesellschaft treibt - zurück zur Barbarei, Unmenschlichkeit und Untermenschlichkeit - jener Naturzustand des Menschen, der vor jenem Gesellschaftsvertrag entstand. In einer Diskussion über die moderne Definition des Terrorismus bemerkte Rolf Gössner, „Terrorismus ist einer der umstrittensten Begriffe unserer Zeit, der allzu häufig politisch instrumentalisiert wird“.${ }^{163}$ Gössner bemerkte die relative Bedeutung des Begriffs Terrorismus: „Der Wortgebrauch hängt meist vom

\footnotetext{
${ }^{161}$ Vgl. hier: Rolf Gössner, Menschenrechte in Zeiten des Terrors, (Hamburg: Konkret Literatur Verlag, 2007), S. 249.

„Krieg ist Terror. Und auch Antiterrorkriege sind Terror [...] Antiterrorkriege und Menschenrechtsbellizismus produzieren letzlich das, was sie bekämpfen sollen, nämlich Hass und Elend, Massenmord und weiteren Terror und eine neue Generation von Terroristen [...] Kurz: Der Antiterrorkrieg hat die Terrorgefahr erheblich vergrößert."

${ }^{162}$ Heinrich Böll, ,Die Raubtiere laufen frei herum,” in Gefahren von falschen Brüdern: Politische Schriften, Auswahl aus: >Einmischung erwünscht. Schriften zur Zeit< (München: Deutscher Taschenbuch Verlag, 1980), S. 30 .

${ }^{163}$ Rolf Gössner, Menschenrechte in Zeiten des Terrors, (Hamburg: Konkret Literatur Verlag, 2007), S. 192.
} 
Standpunkt des Betrachters ab." ${ }^{164}$ Es ist schon der Fall, dass, ,die Großmächte nach politischem Kalkül bestimmen, ob eine aufständische Bewegung oder Organisation als legitime Widerstandsbewegung im Freiheitskampf oder als terroristische Gruppe/Vereinigung eingestuft wird““ ${ }^{165}$ Diese politische Ausnutzung zeigt die strategische Kraft des Begriffs: der Staat könnte irgendwelchen Anhänger der Opposition als Terroristen bezeichnen und Beweise für die Anwendung des Begriffs später finden oder erfinden. Die Gefahr steht ohne Zweifel, dass diese Leistung der Regierung noch weiter missbraucht werden könnte. Ironischerweise wächst die Starke und Zahl der Regimekritiker, je starker der Staat und Medien ihre Bürgern entmenschlichen: die Regimekritiker engagieren sich genau gegen solche Entmenschlichung.

In diesem Zusammenhang stehen die Regierungen der westlichen Nationen teilweise in der Verantwortung für die Eskalation der Gewalt von westfeindlichen Gruppen. Die sogenannten Notstandsgesetze, sowie der Radikalenerlass, zersetzen Menschen- und Bürgerrechte. Die Menschenwürde ist die Basis aller Grundrechte. Sie kann weder durch Nebenrecht noch Grundrecht geschränkt werden. Die unantastbare Natur der Menschenrechte, wie in jener Verfassung festgelegt und garantiert, versichert die Stelle des Bürgers als Bürger an sich und als Mensch im tiefsten Sinne: ohne diese Versicherung folgt die Entmenschlichung der ganzen Gesellschaft. Das Verlieren der Grund- und Bürgerrechte beinhaltet die de facto Entmenschlichung jeder Bürger eines Rechtsstaats.

\footnotetext{
${ }^{164}$ Ebd., S. 192-3.

${ }^{165}$ Ebd., S. 192.
} 
Mit Rucksicht sind die damaligen Reaktionen der BRD-Regierung als übertrieben zu verstehen. Rolf Gössner schrieb 2001 in Zeiten des Terrors über die Situation der Meinhof und die terroristische Gruppe dieser Zeit, besonders der 70er Jahre:

Es kam zu Überreaktionen, die nachträglich in Gesetze gegossen wurden. [...] [A]llesamt Ausnahme- oder Sondergesetze, die die Rechte der Beschuldigten erheblich einschränken und insgesamt fatale Auswirkungen auf ein rechtsstaatliches Verfahren und auf bürgerrechtliche Standards haben. ${ }^{166}$

Er bemerkte auch, dass diese Gesetze länger als ihre vermeinte Intention in Kraft waren: „Doch das Antiterrorsonderrechtssystem überdauerte die Zeiten, weil es sich für die Ermittlungsbehörden als äußerst praktisch, flexibel und ausbaufähig erwies." ${ }^{167}$ Ohne konstitutionellen Schutz wird der Mensch zurück zur Natur gefügt und er steht in Beziehung zur Gesellschaft, die vor der Entstehung jenes sozialen Vertrags im Lauf war. Er wird zu Unrecht, Untermenschlichkeit, Barbarei geopfert. Die Vereinfachung solche Menschen ist eine unvermeidliche soziale Folge von der Beschuldigung von Terrorismus.

Solche Verdachte ohne konstitutionelle Rechtfertigung heißt Kriminalisierung. Kriminalisierung ist gleichbedeutend mit Entmenschlichung, denn zivile Rechte sind für Kriminelle sowie für Terroristen nicht verfügbar. Der Kriminell steht Außerhalb des konstitutionellen Schutz. Der Mensch ist von diesem Untergang stetig bedroht. Die ungerechte Beschuldigung von Terrorismus auf Staatsbürger untergräbt konstitutionelle Rechte und kostet dabei den Untergang der Gesellschaft. Diese Gefahr besteht bei jedem in einem Rechtsstaat.

\footnotetext{
${ }^{166}$ Ebd., S. 108.

${ }^{167}$ Ebd., S. 109.
} 
Böll erkannte die mögliche Gefahr lockere Beziehungen zu Unbekannten ohne Kenntnis über ihren Werdegang zu knüpfen, in einem Staat, der größere Wert auf Staatssicherheit als auf Menschen- und Grundrechte stellt. Diese Gefahr besteht in einem Land, wo Verdächtige wie Verbrecher behandelt werden. Die Anwendung von Sondergesetzen verstärkt solche Gefahren, denn die Regierung kann Regimekritikern als Terroristen bezeichnen. Die Möglichkeit, dass diejenigen, die man trifft, verdächtigte Verbrecher oder Terroristen sind, oder eigentlicher Verbrecher oder Terroristen sind, vergrößert sich mit solchen Sondergesetzen. In einem Rechtsstaat mit ihrem vorgeschriebenen und teilweise unlegitimen Gesetzen, Sondergesetze oder Notstandsgesetze z.B., kann es gefährlich sein, ohne den Werdegang eines Menschen zu handeln, weil das Prinzip ignorantia legis non excusat in einem Rechtsstaat herrscht.

Die Komplexität der neu geschaffenen Gesetze wirkt oft contraintuitiv. In früheren Epochen des Rechtsstaats gab es vermutlich keine unlegitime Gesetze. Die Gesetze wurden in der Religion gegründet und damals hatten alle Bürger Erfahrung mit der Kirche und verstand ihre regelmäßige Lehre, nämlich die Zehn Gebote und die Sieben Werke der Barmherzigkeit z.B., die das Benehmen im Leben und in der Gesellschaft bestimmen sollten. Ein gesetzliches Verbrechen sollte auch das Verstoßen gegen ein moralisches Gebot sein. In diesem Zusammenhang wirkte das Prinzip ignorantia legis non excusat legitim, denn die kirchliche Lehre, die eben gleichbedeutend mit den Gesetzen Gottes seien, im Herzen geschrieben seien; das heißt, jeder kennt Gut und Böse ohne Ausbildung noch spezielle Erfahrungen und die Gesetze beurteilt nur das 
Tun der Gut und Böse. ${ }^{168}$ Die neue Form von Gesetzen, die nicht $a$ priori durch das Gewissen, sondern a posteriori im allgemeinen Sinne zur Erkenntnis kommen, gefährdet die Menschenrechte, denn das Prinzip ignorantia legis non excusat immer noch in Kraft steht. Man muss eine spezielle Ausbildung haben, die Gesetze ausführlich zu ahnen oder wissen. Das Prinzip ignorantia legis non excusat hat seine Rechtfertigung und seinen Entstehungsgrund verloren. Dieser widersprüchliche Zustand ist offensichtlich immer noch nicht erlöst worden. Diese Gefahr wird verstärkt in dem Fall, dass der Staat korrupt ist und gilt für Frauen wie Männer. Unveräußerliche Werte, wie Ehre und Menschenwürde, bleiben immer in der bürgerlichen Gesellschaft eines Rechtsstaats verletzbar. Die bloße Existenz eine Verfassung ist keine Garantie von diesen Rechten. Diese Ansicht findet auch Bestätigung in einer Stellungnahme von Hans Leyendecker, Redakteur der Süddeutschen Zeitung: „Die Debatte über Unschuldsvermutung und Bürgerrechte wird leider erst dann jäh enden, wenn in diesem Land der erste Anschlag Menschen in Stücke reißen sollte." ${ }^{169}$ Das heißt, dass die Diskussion über Menschenrechte, Unschuldsvermutung unter denen, nie halten darf. Mit dem Ende solcher Diskussionen kommt das Ende solcher Rechte gleich. Die Unschuldsvermutung ist die einzige Wehrung des gesetzlich gerechtfertigten Zustands des Bürgers in einem Rechtsstaat. Falls das Recht auf Unschuldsvermutung im Namen der Sicherheit geopfert wird, mit dem Radikalenerlass und solcher Sondergesetzen z.B., bleibt keine Versicherung der Menschlichkeit des Bürgers.

\footnotetext{
${ }^{168}$ Vgl. hier: Sir William Blackstone, z.B.

${ }^{169}$ Rolf Gössner, Menschenrechte in Zeiten des Terrors, (Hamburg: Konkret Literatur Verlag, 2007), S. 7. Originalabdruck: Leyendecker, „Der Preis ist heiß,“ in: Süddeutsche Zeitung (SZ) 17./18.4.04.
} 
Das Konzept der Brüderlichkeit liegt mit den Konzepten der modernen Verfassung und Grundrechten tief gewurzelt. Böll meinte, dass die Verfassung sowie alle Menschenrechte von dem Konzept der Brüderlichkeit abhängig sind. ${ }^{170}$ Der kapitalistische Objektivismus und die Medien-betriebene Volksverhetzung stehen im Gegensatz zur Brüderlichkeit und Menschenrechten. Böll betonte die rechtsmäßige Behandlung von vermutlichen Verbrechern in den Medien im Vergleich mit dieser Volksverhetzung: „In jeder Erscheinungsform von Rechtsstaat hat jeder Verdächtigte ein Recht, daß, wenn man schon einen bloßen Verdacht publizieren darf, betont wird, daß er nur verdächtigt wird." ${ }^{171}$ Unter Volksverhetzung muss man immer Angst vor Anderen haben und andere Leute als Krimineller verdächtigen. Da es gefährlich wäre, normale lockere Beziehungen zu knüpfen, würde jeder Unbekannte in Verdacht geraten. Die Folgen beinhalten die Entmenschlichung von der gesamten Gesellschaft und zeigen die Gefahr lockere Beziehungen zu knüpfen, das heißt, Verdacht und Misstrauen an Unbekannten zur wachsenden sozialen Tendenz kommen sollen, welche das Prinzip der Unschuldsvermutung und Brüderlichkeit in einem Rechtsstaat unterhöhlt.

Die Zusammenwirkung solcher Volksverhetzung und Sondergesetze treffen die Gesellschaft stark. Diese Verdachthysterie untergräbt die Basis einer Demokratie,

\footnotetext{
${ }^{170}$ Vgl. hier: Heinrich Böll, „Ich habe die Nase voll!” in Gefahren von falschen Brüdern: Politische Schriften, Auswahl aus: >Einmischung erwünscht. Schriften zur Zeit< (München: Deutscher Taschenbuch Verlag, 1980), S. 52.

In diesem Sinne sind der Kategorische Imperativ, Brïderlichkeit und Nächstenliebe zu vergleichen. Bölls Kommentar an der katholischen Lehre der „»Sieben Werke der Barmherzigkeit «” ist auch in diesem Zusammenhang zu verstehen. „Sie heißen: Die Hungernden sättigen, die Durstigen tränken, die Kranken trösten, die Toten beerdigen, die Nackten bekleiden, die Gefangenen besuchen, Fremde beherbergen. Ich finde das sehr schön. Vielleicht sollte man eine Art Litanei-Anhang machen und sagen: Die Hungernden sättigen undsoweiter, auch wenn es chilenische Kommunisten sind, auch wenn es sowjetische Dissidenten sind, auch undsoweiter..." (durch Kursivschrift hervorgehoben)

${ }^{171}$ Heinrich Böll, „Will Ulrike Gnade oder freies Geleit?” Der Spiegel, 10. Januar 1972, S. 54.
} 
denn das Vertrauen wird dadurch untergraben. Die Gesellschaft ist auf Vertrauen basiert und dieses Vertrauen verlangt, dass jeder den Schutz des Gesetzes genießt. Ohne das Vertrauen bleibt dann keine Sicherheit in der Gesellschaft. Die Tendenz eines Staates zum Polizeistaat steigt dabei und die Gefühle von Brüderlichkeit und Vertrauen, die Bausteine der Demokratie sind, werden niederrissen.

Böll warf die Frage der Werdegangerkennung in einem Rechtsstaat mit dem Prinzip ignorantia legis non excusat:

Frauen, die ein Auge auf jemand werfen, haben nicht immer alle gängigen Steckbriefe in ihrer Handtasche, tragen auch nicht das Strafgesetzbuch, nicht einmal das Bürgerliche Gesetzbuch ständig mit sich herum. Schlimm wird die Sache, weil ihre Liebe erwidert wird! Das weiß doch jeder, wie hoch die Flammen schlagen, »wenn zwei sich lieben $\ll .{ }^{172}$

Liebe auf den ersten Blick wird gefährlicher, je mehr eine Gesellschaft mit Regimekritiker, oder verdächtigte Terroristen, gefüllt worden ist. Die Gefahr wirkt aus zwei Gründen stärker bei der Jugend als bei den Erwachsenen, einerseits sind Jugendliche wenige gebildet und andererseits neigen sie dazu, sich an ihren Intuitionen und Gefühle zu orientieren, „,ie Flammen schlagen“ höher bei den Jugendlichen als bei den Erwachsenen. Durch diese Entmenschlichung des Bürgers mit der Bezeichnung Terrorist wird die Rolle der Liebe im Leben solcher ,Terroristen' nicht anerkannt. Die Liebe, die reinste Beziehung zwischen zwei Menschen, wird gefährdet von der ungerechten Verfolgung der Terroristen. Sie ist am stärksten zu sehen bei Fällen von wahrer Liebe, da die Liebe durch falsche Darstellung in der Presse verblühen wird. Die reine Liebe wird ohne konstitutionellen Schutz von dem

\footnotetext{
${ }^{172}$ Heinrich Böll, ,Zehn Jahre später,” Nachwort zur Katharina Blum, (München: Deutscher Taschenbuch Verlag,
} 2003), S. 141-2. 
weit reichenden Organen der Medien mit hässlichen unehrlichen Charakter in den Medien dargestellt, wenn einen Verdacht auf einen von einem Liebespaar überkommt. Böll schildert uns ein Beispiel davon im Fall von Katharina Blum.

\section{Liebe auf den ersten Blick:}

Das Zusammentreffen von Katharina und Ludwig von Innen angetrachtet

Böll stellt die Wirkungen eines Rufmordkampagneprozesses im Leben einer jungen Frau dar. Durch die Darstellung des Missbrauchs einer unschuldigen ehrlichen Frau durch die Massenmedien kritisierte Böll diese Medien. Böll bewertete seine 1974 erschienene Erzählung mit Bescheidenheit und gab dabei seiner Meinung nach das wichtigste Element der Geschichte an. Sie sei vor allem, ,nicht mehr als eine Liebesgeschichte mit dem »Handlungskern « (englisch und einfacher ausgedrückt, mit dem »plot «) eines Groschenheftes“ $“ .{ }^{173}$ Böll wollte eine einfache von komplizierten Zuständen umfangene Persönlichkeit schildern, um die empfindliche Natur der Ehre offen zu legen. Katharina Blum soll diese Einfachheit verkörpern - sie steht als Vorbild der modernen frommen Frau. Böll wollte Katharina als die Verkörperung der säkularen Liebe und Ehre darstellen - die moderne tugendhafte Frau. Ihr Fall zeigt die Verletzbarkeit der Ehre für jedermann der Bundesrepublik, denn niemand bleibt immun gegen die Hetze der Zeitung. Die Idealisierung der Katharina Blum sollte Gnade im Gedanken und Herzen des Lesers hervorrufen und Diese sollte auf dem Fall Ulrike Meinhof überreichen, aber wichtiger, wollte Böll diese Gnade für jene Opfer

${ }^{173}$ Ebd., S. 140. 
der Medien zurechnen. In seiner Handlung beachtet Böll die im Zusammenhang mit der Gesellschaft ursprünglichen Schwierigkeiten der Liebe.

Im sozialen Rahmen schildert Böll ein Beispiel, in welchem die Gesellschaft eine Rolle von größerer Bedeutung als wahre Liebe spielt, die Auswirkungen einer solchen Liebe zu bestimmen. Da Liebe an sich ein unmittelbares Element des Lebens ist, muss die Komplexität jener Liebesgeschichte nicht vom Selbst entstehen, sondern in der sozialen Welt. Bölls Erzählung zeigt den komplizierten möglichen Folgen, die eine einfache erscheinende Liebesgeschichte ergeben kann, wenn die Gefahr solche reine Geschehnisse im Zusammenhang mit gekoppelten unrechtlichen Handlungsweisen der Behörden mit der Zeitung passieren. Böll fand ein literarisches Mittel, wobei die Wahrhaftigkeit dieses Ereignis Ausdruck im Text finden könnte, Liebe auf den ersten Blick.

Böll wählte, „Liebe auf den ersten Blick“, (53) als literarisches Mittel eine spontane Beziehung zwischen den zwei Hauptfiguren Katharina Blum und Ludwig Götten zu entwickeln. Das Konzept Liebe auf den ersten Blick ist gleichbedeutend mit dem Konzept Schicksal. Schicksal oder Liebe auf den ersten Blick besteht informell gesehen als unanzweifelbarer Fakt. Im alltäglichen Leben sind Erklärungen weder nötig noch möglich. Das Schicksal verengt zwei Menschen so nah, dass weder gesellschaftliche Erklärungen noch wissenschaftliche Gründen für diese außergewöhnliche Art der Beziehung gegeben worden können. Das gewöhnliche Erlebnis, wenn zwei Personen sich in einander verlieben, wird im grotesken Licht gestellt, wenn im sozialen Rahmen untersucht. Die Liebe an sich wirkt von innen 
heraus. Sie ist durch empirische Erklärungsmethoden unfassbar und gehört nicht zum Bereich der Ratio, denn sie ist unzählbar, unmessbar. Wenn man das Thema Liebe auf den ersten Blick ernst nimmt, wird es möglich dieses Thema im Bezug auf der Gesellschaft zu analysieren.

Max Horkheimer und Theodor W. Adorno in ihrem Artikel „Dialektik der Aufklärung“, bestätigten, dass dieses Konzept schon seit der Aufklärung von intellektuellen Diskurs ausgewogen sei: „Was dem Maß von Berechenbarkeit und Nützlichkeit sich nicht fügen will, gilt der Aufklärung für verdächtig. [...] Die Abstraktion, das Werkzeug der Aufklärung, verhält sich zu ihren Objekten wie das Schicksal, dessen Begriff sie ausmerzt: als Liquidation." ${ }^{174}$ Das Wort Schicksal überlebte die Aufklärung nicht. Böll musste das Wort zurück zum Leben in einer literarischen Form führen. Da der Begriff Schicksal noch nicht in wissenschaftlichen Diskussionen gilt, das heißt der Begriff noch nicht instrumentalisiert worden ist, noch zu vielen Interpretationsmöglichkeiten offen bleibt, musste Böll einen literarischen Kontext verwenden, dieses Konzept zur Diskussion zu fügen. Vom Schicksal zu reden bleibt eine Möglichkeit im Rahmen der Literatur, wendet sich aber nicht, sowie Liebe, zur rationalen Untersuchung. Wenn es möglich wäre, die Liebe zu verstehen, hätte Böll dieses Geschehen in einem Sachartikel zur Diskussion führen sollen. ${ }^{175}$ Böll zeigt dagegen, dass Liebe gar kein Thema für die genaue und eingeschränkte Redensart des

\footnotetext{
${ }^{174}$ Max Horkheimer und Theodor W. Adorno, „Dialektik der Aufklärung,” in Texte zur modernen Mythentheorie, herausgegeb. von Wilfried Barner, Anke Detken und Jörg Wesche, (Stuttgart: Philipp Reclam jun., 2003), S. 28, 34.

${ }^{175}$ Es wird wohl anerkannt, dass die Psychologie eine Beziehung der Liebe mit chemischen Reaktionen forscht. Die Wissenschaft hat den Versuch die Liebe auf Chemikalien und chemischer Reaktionen zu reduzieren. Es ist die Hoffnung der Literatur, dass Liebe nicht auf Chemieaktien reduzierbar ist. Die Frage bleibt offen und ist von großer Bedeutung der Literatur gegenüber.
} 
Gerichts und Rechtsstaats sei. Böll musste das Thema einen literarischen Kontext geben, damit er das Thema der Liebe in der Gesellschaft eindeutig zur Diskussion führen konnte. Böll führte dieses Phänomen zum Brauch in der Form einer Erzählung um die komplizierte Natur der Liebe und Schicksal in der Rahmen des menschlichen Umgangs in der Gesellschaft ausdrücklich darzustellen.

Das Konzept der Liebe als eine persönliche Erfahrung, die von der Gesellschaft unbezähmbar ist, wird oft in der Literatur behandelt. Obwohl die Liebe keine direkte Rolle im Beruf oder in der Ausbildung spielt, unternimmt es die Gesellschaft, solche Freiheiten zu beeinflussen und zu instrumentalisieren. Auf die eine oder andere Art spielt Liebe eine störende Rolle in der konservativen Kreisen der Gesellschaft. In der streng geordneten feudalen Gesellschaft schloss die Liebe einen unerwünschten Zufall in der geregelten Beziehungen ein. Kiermeier-Debre notierte diese Beziehung der Liebe zur Gesellschaft in seinem Nachwort zum Leonce und Lena. Die, „feudalaristokratische Gesellschaft”, legte großen Wert auf intime Wirtschaftskreisen: „Das gilt insbesondere für ihr Liebessystem, das um der Exklusivität der gesellschaftlichen Kontaktkreise willen den Zufall, eine gewisse natürliche Notwendigkeit, stets als Bedrohung ausgeblendet hat." ${ }^{, 176}$ Der bedrohende Einfluss des Zufalls in feudalen Beziehungen wurde gekämpft. In der modernen und von Massenmedien beherrschten Gesellschaft spielt die Liebe eine ähnliche störende Rolle. Die Gesellschaft will die Liebe bestimmen oder bestrafen. Die altmodische übliche Praxis der arrangierten Ehe ist schon veraltet, aber die Liebe wird instrumentalisiert, gesellschaftliche Verhältnisse

\footnotetext{
${ }^{176}$ Joseph Kiermeier-Debre, Herausgeb., „Leonce und Lena,” Nachwort zum Leonce und Lena von Georg Büchner, (München: Deutscher Taschenbuch Verlag, 3. Auflage März 2004), S. 98.
} 
zu behalten. Böll meinte, dass die Rückkehr zur zentralen Macht, feudalen Beziehungen und veralteten amtlichen Rechtfertigungen muss bekämpft worden. Der riesige Impetus der staatlichen Kontrolle und Anwendung der Gewalt wird vermutlich heute durch solche Rechte, wie Bewegungsfreiheit und Meinungsfreiheit überwunden, aber es gibt immer noch die Tendenz zur gesellschaftlichen Kontrolle von Liebe und Ehe. Gesellschaftliche Institutionen sollen die Ehre und die Liebe behüten.

Der Fall von Katharina und Ludwig betont besonders den Kern der persönlichen und gesellschaftlichen Probleme: Die Liebe an sich ist geregelt, aber nicht von außen, sondern von innen, d.h. die Liebe ist persönlich. Da Liebe, so Böll, als ein, „uraltes Motiv der Kriminal-Literatur", sich versteht, wird sie sich auch als grundlegend für Menschen verstanden. ${ }^{177}$ Die Liebe wird sofort als ein durchdringendes Element des Lebens anerkannt. Es wird auch sofort angenommen, dass es keine universelle Erklärung der Liebe überhaupt gibt. Als Mysterium selber spielt das Thema Liebe eine besondere Rolle in der Literatur, da die Liebe sich selbst in eine Geschichte verwickelt und eine größere Rolle als irgendeiner Figur einer Geschichte oft spielt. Eine klassische Definition des Schicksals stellt es gleichbedeutend mit Vorsehung. Nach dieser Definition deuten die beiden Begriffe auf vorherbestimmte Geschehnisse im Leben. Die Liebe, die mit der Vorsehung oder Schicksal verbunden sei, sei auch ehrlich. Somit ist Bölls Roman mit Romeo und Julia vergleichbar, da beide Geschichten das Thema der mit der Vorsehung verbundenen tragischen Liebe

\footnotetext{
${ }^{177}$ Heinrich Böll, ,Zehn Jahre später,” Nachwort zur Katharina Blum, (München: Deutscher Taschenbuch Verlag, 2003), S. 142-3.
} 
verkörpern. ${ }^{178}$ Katharina und Ludwig stehen in einem ähnlichen Verhältnis zueinander wie Romeo und Julia, denn Katharina und Ludwig - vielleicht ein wenig zu radikal ausgedrückt - gehören verfeindeten Teilen der Gesellschaft an: sie zum normalen ehrlichen bürgerlichen Teil; er zum ungesetzlichen radikalen Teil, der als echter Bestandteil der Gesellschaft nicht anerkannt wird, sondern zum ausgegliederten Untergrund. ${ }^{179}$ Sie stehen in eine Beziehung zur Gesellschaft, die das Paar als Liebespaar nicht akzeptieren kann. In beiden Geschichten wurden die Paare durch den gesellschaftlichen Druck voneinander getrennt. Derartige Analysen von Romeo und Julia z. B. sind wohlbekannt. Die tragischen Hauptfiguren gehören verfeindeten Familien an. Das Paar darf aus gesellschaftlichen Gründen nicht zusammen kommen. Trotzdem ist das Paar in einander verliebt. Man kann sein Schicksal nicht ändern und solche Liebe ist unvermeidlich, wenn getroffen. Wahre Liebe übertritt alle Grenzen und Beschränkungen, die es in der phänomenalen Welt, d.h. u.a. die Gesellschaft, gibt. Die Liebe, wenn auch gefährlich, übertritt alle Grenze: Verliebte sind gezwungen der Liebe $\mathrm{zu}$ folgen.

\footnotetext{
${ }^{178}$ Klaus Jeziorkowski, „Die verlorene Ehre der Katharina Blum oder: Wie Gewalt entstehen und wohin sie führen kann," in Interpretationen Heinrich Böll: Romane und Erzählungen, (Stuttgart: Philipp Reclam jun. GmbH \& Co., 2000), S. 253.

„Nach Bölls ästhetischen Maximen ist alle wahrhaft große Literatur einfach. In dieser Einfachheit liegt ihre Größe. [...] Für Böll beweist und bewährt sich das an zweien seiner Lieblingsautoren: Johann Peter Hebel und Franz Kafka.” Hebels Kalendergeschichten, ,die in den alemannischen Bauernhäusern nachweisbar gelesen wurden, wird Böll zum Beweis dafür, daß wahre Volkstümlichkeit bis in den höchsten Rang der Weltliteratur reichen kann; Ernst Bloch und Goethe hatten Hebel ebenfalls diesen Rang zugesprochen. [...] Böll sagte 1964 im Frankfurter PoetikSeminar, er halte es für ausgemacht, daß man die Texte Kafkas auch Kindern und der sprichwörtlichen Putzfrau zu lesen geben könne. Für ihn sind also Volkstümliches, Triviales, Einfaches, Populäres einerseits und das Niveau höchster Kunstvollendung andererseits keine einander ausschließenden Gegensätze. Im Ideal des gelungenen Werkes kommen für ihn beide zur Deckung und zur Identität, wofür auch Shakespeare ein Beleg wäre“.

${ }^{179}$ Vgl. hier: Rolf Gössner, Menschenrechte in Zeiten des Terrors, (Hamburg: Konkret Literatur Verlag, 2007), S. 116.

Gössners Analyse von Freiheitskämpfer gilt als eine moderne Betrachtung der Situation:

„Handelt es sich um eine terroristische Vereinigung oder um legitime Formen des Widerstands gegen Diktaturen oder um eine Befreiungsbewegung? [...][S]chließlich ist der Terrorist des einen der Freiheitskämpfer des anderen und umgekehrt."
} 
Die Liebe des Zufalls, das heißt Begierde, sei unehrlich. Die Gesellschaft hält gesellschaftliche Beziehungen als mit dem Schicksal verbunden, d.h. ehrlich, und assoziiert die Liebe innerhalb von gesellschaftlichen Kreisen mit Schicksal Ehre. Die Liebe, die von der Gesellschaft als zufällig angetrachtet sei, sei unehrlich. Liebe unter anderen persönlichen Freiheiten wird oft als unabhängig von der Gesellschaft betrachtet. Die Wichtigkeit des Zufalls ist doch offensichtlich anerkannt in der Entwicklung der Liebe. Das allgemeine Erlebnis des zufälligen Zusammentreffens, in dem Liebe eine wichtige Rolle spielt und eine Beziehung sich rasch entwickelt, wird sofort erkannt. Eine andere Möglichkeit, die vereinbar mit dem Konzept der Liebe des Zufalls bleibt, ist den Begriff Schicksal als die Qualität eines Geschehens oder einer Beziehung definieren. Diese Interpretation des Begriffs Schicksal steht als eine mögliche aufgeklärte Definition dessen. Dieser qualitative Aspekt wird oft in der ungezwungenen Unterhaltung verwandt, wenn man über Liebe von großer Bedeutung redet.

Böll zielte mit dem zufälligen Treffen von Ludwig und Katharina auf eine ungewöhnliche Qualität von Liebe. Die hektischen Partys und die surrealistische Umgebung mit Kostümen, und festlicher Atmosphäre der Weiberfastnacht, die man mit Fasching assoziiert, haben eine besondere Magie, eine unerklärbare Qualität von Gefühl, die eine vermeinte romantische Atmosphäre wirken sollen. Diese romantische Darstellung ist nicht gewöhnlich, aber vielleicht ideal angetrachtet, was wichtig für die Identifikation des Lesers ist. Trotz der surrealistische Kostüme und Masken besitzen Katharina und Ludwig die Fähigkeit Äußerlichkeiten zu überwinden und sich auf das 
Innere zu konzentrieren. Dieses sofortige Konzentrieren auf das Innere baut das Grundereignis der Erzählung und bestätigt die Starke der tiefen Beziehung zwischen Blum und Götten.

Böll beschrieb die Handlung selbst in seinem Nachwort: ,[E]in »einfaches Mädchen« [...] verliebt sich in einen Menschen, von dem sich später herausstellt, daß er von der Polizei gesucht wird." 180 Sie hilft dem zärtlichen Ludwig, ohne sich Gedanken über die mögliche Folge ihrer Aktionen zu machen und ohne seinen Werdegang zu erkennen. Katharina handelt im Roman eher aus Mitleid und Intuition. Katharinas Niedergang fängt mit dem zufälligen Treffen eines Unbekannten an, der nach den Worten Katharinas, ,zärtlich“, sei. Auf dieser Weise gilt die Erzählung zur Tradition von,

Moritaten, und Bänkelsang-Gedichten, von Liedern aus der Küche, Liedern von verlorener Ehre, die in aller Regel von jüngeren Frauen und Mädchen erzählen, deren Ehre von gewissenlosen Abenteurern angetastet und geraubt worden ist. [...] Text fürs sogenannte >einfache Volk $<{ }^{181}$

Katharina, als die Verkörperung eines , einfachen Mädchens’, zeigt in ihrer eigenen Intuition und Gefühlen mehr Vertrauen, als diese leisten sollen - kürzer ausgedrückt: scheinen ihre Aktionen naiv. Das Treffen der Katharina Blum mit Ludwig Götten, obwohl es zufällig geschah, ist der Ausgangspunkt der besonderen Entwicklung der Geschichte.

\footnotetext{
${ }^{180}$ Heinrich Böll, ,Zehn Jahre später,” Nachwort zur Katharina Blum, (München: Deutscher Taschenbuch Verlag, 2003), S. 140-1.

${ }^{181}$ Klaus Jeziorkowski, „Die verlorene Ehre der Katharina Blum oder: Wie Gewalt entstehen und wohin sie führen kann," in Interpretationen Heinrich Böll: Romane und Erzählungen, (Stuttgart: Philipp Reclam jun. GmbH \& Co., 2000), S. 256-7.
} 
Intensiv auf die Qualität von Ludwigs und Katharinas Charakterzüge einzugehen ist notwendig, um diesen gezielten Effekt Bölls zu erreichen, sonst wäre die folgenden dramatischen Verfolgung von Katharina und Ludwig ohne Wirksamkeit. Die Austreibung aller Zweifel an die wahre Liebe zwischen Katharina und Götten zieht der Gebrauch der Liebe auf den Ersten Blick das Weitertreiben der Handlung voll. Diese wahre Liebe ist der Kern der Geschichte: Die Erzählung ist genauso stark wie die Liebe zwischen Katharina Blum und Ludwig Götten. In Anbetracht von Katharinas Charakter scheint dem Leser die enge Beziehung zwischen Katharina und Ludwig als wahre Liebe. Da Katharina mit Ehrlichkeit dargestellt wird, ist es zu verstehen, dass ihre Beziehung zum Götten aus reiner Liebe statt aus Begierde entstand. Da Katharina sich nicht auf Gelegenheitssex einlässt, ist es zu verstehen, dass Ludwig, der wegen seines Desertierens eben eine pazifistische Wirkung hat, besonders zärtlich und nicht zudringlich sei, sonst er hätte Katharina überhaupt nicht gefallen können. Diese Interpretation stimmt mit den Gedanken Bölls selbst überein, da, ,Ihrem Charakter nach hätte sie sich sogar in ihn verliebt, wenn sie vorher gewusst hätte, dass er von der Polizei gesucht wird“. ${ }^{182}$ Der Leser stellt sich vor, dass Katharina ein frommes Mädchen sei und liest eine tiefe Verbindung in das schnell Zusammenkommen Katharinas und Ludwigs hinein.

Die Titelfigur Katharina macht sich, so Böll, ,»»aus Liebe strafbar «". ${ }^{183}$ Sie ist wegen der spontanen Entscheidung mit einem Mann zu schlafen kompromittiert. Katharina beschloss zur Party mit Freunden zu gehen. Da ihre Gruppe unterwegs zum Party

\footnotetext{
${ }^{182}$ Heinrich Böll, ,Zehn Jahre später,” Nachwort zur Katharina Blum, (München: Deutscher Taschenbuch Verlag, 2003), S. 141.

183 Ebd., S. 143.
} 
einen jungen gut aussehenden Mann traf, luden Katharinas Freundinnen ihn zur Party ein. Die normalerweise zurückhaltende Katharina, die, so Katharina, seit vier Jahren nicht an einem, „,Tanzvergnügen”, (28) teilgenommen habe, verliebte sich am Vorabend der Weiberfastnacht bei einer Tanzveranstaltung zufälligerweise in Ludwig Götten, mit dem sie zusammen nach Hause ging und intim wurde. Die Qualität und zärtliche Atmosphäre dieses Treffens steht im großen Unterschied zum polizeilichen Stürmen Katharinas Wohnung am folgenden Morgen. Ludwig, der, unbekannt Katharina und vielleicht Ludwig selbst, eines Bankraubs und eines Mordes verdächtigt wurde, war am Morgen der Weiberfastnacht, als die Polizei Katharinas Wohnung stürmte, verschwunden. Statt Ludwig festzunehmen, verhaftete Inspektor Erwin Beizmenne dann Katharina Blum. Katharina wurde vernommen, damit ihre Beziehung zum Götten bestimmt worden konnte.

Vernehmungen:

Das zufällige Zusammentreffen von Katharina und Ludwig von außen angetrachtet

Im Fall Katharinas wird dem zufälligen Treffen mit Ludwig vom Staat großer Bedeutung zugemessen. In derartigen politischen Fällen müssen die Behörden, als Stellvertreter für die Regierung, eine rationale Erklärung anbieten; rational gesehen bedarf es, derartige Treffen in einer sozialen Zusammenhang zu stellen. Die Regierung muss die Fakten behandeln, damit keine wichtigen Details ausbleiben. Im Vergleich zur qualitativen Kategorien, wie die Liebe, die von Katharina und Götten 
hochgeschätzt worden sind, müssen derartige Erklärungen durch Fakten in einen Zusammenhang gesetzt werden. Liebe und andere qualitative Kategorien werden als Erklärungsmittel von den Inspektoren und Kriminalbeamter im Voraus ausgeschlagen, denn Nach der Meinung des Hauptkommissars sei Ludwig zur Liebe unfähig - er sei eben kein Mensch, sondern bloß ein Terrorist. Nach Beizmennes Meinung sei Ludwig ein Terrorist, ein der Liebe unfähiger Monster und Katharina sei nur seine Komplizin. Im Verlauf der Geschichte wurden Katharina und ihre Bekannten hauptsächlich vom Kriminalhauptkommissar Erwin Beizmenne vernommen. ${ }^{184}$ Viele Geschehnisse von diesem besonderen Vorabend der Weiberfastnacht kommen ab und zu geliefert in den Text zum Licht in der Form der polizeilichen Vernehmungen von Inspektoren und anderen Polizeibeamten. Durch diese Vernehmungen trieb Böll eine Auseinandersetzung der politischen Perspektiven mit der persönlichen Perspektiven der Liebesgeschichte, die sich ganz plötzlich am diesen Vorabend der Weiberfastnacht um die Titelfigur Katharina Blum entwickelt. Böll brachte durch die Vernehmungen Katharina die Einzelheiten und Hintergrundgeschehnisse der Geschichte zur Licht.

\footnotetext{
${ }^{184}$ Böll brachte die Frage der Rechte auf Bewegungsfreiheit in die Geschichte in subtiler Form. Die Verhörung kreuzt die Privatsphäre Katharinas Leben in die Untersuchung ihres freizeitlichen Zeitgebrauchs. Diese tastet die gründrechtliche Freiheit von Bewegungsfreiheit:

„Man käme also auf etwa 8000 km jährlich, sie - Katharina Blum - habe aber, wie aus der schriftlichen Abmachung mit dem Koch Klormer ersichtlich sei, den VW vor sechs Jahren bei einem Kilometerstand von 56000 übernommen. Rechne man nun 2x8000 hinzu, so müsse ihr Kilometerstand jetzt etwa bei 72000 liegen, in Wirklichkeit aber betrage er fast 102000 km.” (47) „Fasziniert, auch entsetzt hörte nicht nur Katharina Blum, hörten auch alle anderen Anwesenden dieser mit sanfter Stimme von Beizmenne vorgebrachten Berechnung zu, und es scheint so, als habe die Blum, während Beizmenne ihr das alles vorrechnete, nicht einmal Arger empfunden, sondern lediglich eine mit Entsetzen und Faszination gemischte Spannung, weil sie, während er sprach, nicht etwa nach einer Erklärung für die $50000 \mathrm{~km}$ suchte, sondern sich selbst darüber klarzuwerden versuchte, wo und wann sie warum wohin gefahren war." (48)
} 
Von der Vernehmung der zwei Mädchen, die Freundinnen Katharinas, die zufälligerweise Ludwig zur Party einluden, erfahren wir, dass Katharina, ,den ganzen Abend mit ihm tanzte, als würden sie sich schon ewig kennen“. (69) Die gleiche Prognose, leicht verändert, steht am nächsten Tag in der, „ZEITUNG““, zu lesen: „Die, wie die miteinander tanzten (gemeint sind die Blum und der Bandit Götten) - als hätten sie sich schon ewig gekannt. Das war kein zufälliges Treffen, das war ein Wiedersehen.” (115) Diese bedeutungsvolle Änderung im Protokoll wird ohne Überprüfung gedruckt. Das zweite Mädchen zeigte auch ihre Überraschung. Sie war erstaunt, ,wie rasch die als spröde bekannte Katharina Blum mit Götten vertraut, ja fast vertraulich geworden sei“. (69) Diese Aussagen zeigen die vom Anfang an intensive Beziehung zwischen Katharina und Götten und unterstreichen das ungewöhnliche Benehmen Katharinas an diesem Abend vor Weiberfastnacht. Diese beiden Mädchen zeigten eine Art von Ungezwungenheit, da sie trotz Vernehmung locker sprachen und sich nicht um ihre Wortwahl kümmerten. Ihre Aussagen erklären die unerwartete Bindung des Liebespaares nicht, denn sie verstehen die Entstehung dieser spontanen Beziehung nicht. Ihre Protokolle verstärken aber den Eindruck des unerwarteten schnell geschehenen Zusammenkommens des Liebespaars. Die Mädchen verlassen sich auf unbezweifelte Akzeptanz mit einer unkritischen Erklärung — „als würden sie sich schon ewig kennen“. (69) Die Beziehung kam völlig unerwartet.

Böll fügte die Vernehmungen der zwei Mädchen hinzu, um den tatsächlichengrund Erklärung zu zeigen. Der Leser soll verstehen, dass Katharina sich in Ludwig wirklich 
verliebt hat. Ihre Gefühle wurden ausdrücklich dargestellt: „Mein Gott, er war es eben, der da kommen soll, und ich hätte ihn geheiratet und Kinder mit ihm gehabt und wenn ich hätte warten müssen, jahrelang, bis er aus dem Kittchen wieder raus war." (59) Diese verschiedenen Aussagen stehen als Beweise für die Wahrhaftigkeit der Vermutung der Liebe auf den ersten Blick. Der Leser soll verstehen, dass Katharina wirklich in Ludwig verliebt ist.

Der Kommissar Beizmenne, der von Fakten ausgehend zu einem Zusammenhang hinarbeitet, erfasst nur die allermöglichste Erklärung, die nichts mit der normalen menschlichen Liebe zu tun hat, denn Liebe sei in diesem Fall keine Erklärung. Ohne das einfachste Erklärung der Liebe zu geben, muss man einen Verschwörungstheorie entwickeln, die alle die angebende Fakten zusammenfassen kann. Dieses zusammenhangsbezogene Geschehnis muss erklärt werden:

[I]ch halte Sie nämlich nicht für unmittelbar kriminell, sondern nur für naiv und ein bißchen zu romantisch. Wie wollen Sie mir - uns erklären, daß Sie, die Sie als zimperlich, fast prüde bekannt sind, die Sie von Ihren Bekannten und Freunden den Spitznamen "Nonne" erhalten haben, die Diskotheken meidet, weil es dort wüst zugeht, sich von ihrem Mann scheiden läßt, weil er "zudringlich" geworden ist wie wollen Sie uns dann erklären, daß Sie - angeblich - diesen Götten erst vorgestern kennengelernt haben und noch am gleichen Tage - man könnte sagen stehenden Fußes - ihn mit in Ihre Wohnung genommen haben und dort sehr rasch - na sagen wir - intim mit ihm geworden sind. (52-3)

Beizmenne konnte die Fakten in Übereinstimmung nicht bringen: „Es sollte nämlich nun eine Frage geklärt werden, die im Zusammenhang mit Beizmennes Verabredungsund Verschwörungstheorie wichtig genug war: Wie war Ludwig Götten zum Hausball bei Frau Woltersheim gekommen?" (59) Derartige Liebesentwicklungen von Außen 
gesehen haben den Schein einer geplanten Verabredung statt eines spontanen Geschehens der Liebe auf den ersten Blick.

Hier musste Beizmenne, der sich die Ratio verwendet, von der Voraussetzung ausgehen, dass Katharina und Ludwig einander seit langem kannten und ihr Treffen eine geplante Verabredung war. Nach Beizmenne, die Vorgeschehen des Treffens zwischen Katharina und Ludwig waren geplant:

[Das] Telefongespräch mit der Scheumel, die Pünktlichkeit, mit der sie bei der Woltersheim auftauchte, auch die verfluchte Innigkeit und Zärtlichkeit, mit der die beiden von der ersten Sekunde an getanzt haben - und wie rasch sie dann miteinander abgezischt sind -, alles spricht gegen Zufall. (73-4)

Beizmenne hat Recht mit der Behauptung, dass alles gegen Zufall spricht. Die so genannte Liebe, besonders true love oder wahre Liebe spielt eine außerordentliche Rolle im Leben der Menschheit. Sie ist besonders geregelt und im alläglichen Sinne nicht dem Zufall überlassen. Diese, so der Inspektor, ,,verfluchte Innigkeit und Zärtlichkeit“, mit denen Ludwig und Katharina zusammenkamen, bleiben außerhalb der Ratio. Dieser qualitative Unterschied bleibt unerklärbar. Rationale Erklärungen können die innere Bedeutung derartige Geschehen nicht erreichen, sondern muss man solche Geschehnisse mit unwiderstreitig Akzeptanz treffen. Ohne die Erklärung der Liebe wird die Verengung so schnell und vollzogen, dass der Prozess des Zusammenkommens vorgeplant zu sein scheint. Beizmennes Ungläubigkeit fand direkten Ausdruck: „Wie nennen Sie das? Liebe auf den ersten Blick? Verliebtheit? Zärtlichkeit? Wollen Sie nicht einsehen, daß es da einige Ungereimtheiten gibt, die den Verdacht nicht so ganz auslöschen?" (52-3) Im Rahmen der Geschichte Katharina 
Blum wird Hauptkommissar Beizmennes Ungläubigkeit lustig, weil er, wegen der Behauptung der Liebe auf den ersten Blick, nicht an Katharinas Aussage glaubt. Wenn sie gesagt hätte, dass das Treffen nur aus Lust geschehen war, hätte er an ihre Aussage glauben können. Beizmenne im Vergleich mit Böll, ist von der Ratio abhängig und unfähig solche Spontaneität. Beizmenne stellt ein ein-dimensionalem Typus dar. Er kann wohl sexuelle Begierde in diesem Kontext verstehen, aber wahre Liebe bleibt ihm ohne Sinn. Das Einzige, was ihn an der Glaubhaftigkeit Katharinas Aussagen verhindert, ist die Behauptung, dass sie sich eigentlich in Ludwig verliebt hatte.

Die Entmenschlichung und Radikalisierung von Katharina durch staatliche Vernehmungen mit Rufmordkampagne gekoppelt

Katharinas Beziehung zu einem tatverdächtigen Terrorist wurde zum wichtigen Thema der Presse. Kompromittierende Details aus den von der Polizei geführten Vernehmungsprotokollen wurden auch illegal an der, „ZEITUNG”, geliefert. Die gekoppelten Natur der redaktionellen Meinungen mit der Handlung und Zielen der Regierung wird gezeigt. Der verwirrende Effekt für eine ,völlig unpolitische’ Persönlichkeit wird stark betont. Katharinas Hingabe auf die Qualität der Liebe, ihr grenzenloser Stolz und ihre Hingabe auf Ehre vertreiben sie zum tragischen Niedergang aufgrund dieser Vernehmung: „Da sie dauernd fragte: “Aber wieso, wieso denn, was habe ich denn verbrochen"”, (20), erkennt man, dass sie ihre Tat nicht als kriminell verstand. Es, ,,wurde ihr schließlich von der Kriminalbeamtin Pletzer in 
höflicher Form mitgeteilt, daß Ludwig Götten ein lange gesuchter Bandit sei, des Bankraubes fast überführt und des Mordes und anderer Verbrechen verdächtig“. (20) Sie musste unter unrechtlichen Folgen leiden, aufgrund Verdacht-gefüllter Zeitungsartikel. Katharina und Ludwig, zwei ziemlich alltägliche Menschen, würden als Bonnie und Clyde- Figuren in den Medien geschildert. Die falschen Vermutungen über Ludwigs Werdegang und Katharinas Rolle als Komplizin, die in der Presse verbreitet wurden, vollbringen Katharinas Niedergang und ihre gesellschaftliche Austreibung. Diese gedruckten Vermutungen und Verdachte missachteten Katharinas Recht auf Unschuldsvermutung. Dieses ungerechte Leiden durch das Mittel der Presse ist genau, ,wie Gewalt entstehen”, kann und der Prozess der Radikalisierung, erfasst in dem Untertitel der Erzählung, ist genau, ,wohin sie führen kann“. Die totale Hilflosigkeit Katharinas wird klargemacht:

In diesem Augenblick erst zog Katharina die beiden Ausgaben der ZEITUNG aus der Tasche und fragte, ob der Staat - so drückte sie es aus - nichts tun könne, um sie gegen diesen Schmutz zu schützen und ihre verlorene Ehre wiederherzustellen. (60)

Die Vernehmungen und Interviews ihrer Bekannten und Familie, besonders das illegale Interview ihrer todkranken Mutter, wurden in den Medien falsch dargestellt. Blum wurde durch diese ungerechte Darstellung in der Zeitung verstört: „,[A]ber es sei unbegreiflich, wie Einzelheiten aus der Vernehmung - etwa der Herrenbesuch - hätten zur Kenntnis der ZEITUNG gelangen können, und alle diese erlogenen und erschwindelten Aussagen." (60) Die Amten verteidigten die Offenbarung dieser Informationen: „Hier griff Staatsanwalt Hach ein und sagte, es habe natürlich angesichts des riesigen öffentlichen Interesses am Fall Götten eine 
Presseverlautbarung herausgegeben werden.” (60) Dass Götten als Terrorist verdächdigt wird, soll die Teilung dieser Fakten und Verdachte mit der Zeitung rechtfertig sein. Nach diesem Prozess blieb nichts übrig, womit Katharina ein privates Leben hätte führen können. Die Zerstörung von Katharinas Leben folgte. Katharina zerstörte in ihrer Hilflosigkeit ihre eigene Eigentumswohnung. Bellman teilt auch die auch das Ansicht, dass, ,[i] [i]re Hilflosigkeit und das Gefühl eigener Ohnmacht werden verstärkt durch den Umstand, daß die Staatsorgane offenkundig mit der »ZEITUNG « kooperieren“. ${ }^{185}$ Das Gefühl von Hilflosigkeit brachte ihr zur Gewalt. Diese Gewalt, obwohl gegen Objekten angewandt, steht nur einen bloßen Schritt von der Selbstzerstörung. Diese Objekten, mit denen Katharina sich identifiziert, versteht sie als integraler Teil ihres Lebens. Diese Zerstörung des eigenen Eigentums ist fast eine innere Zerstörung. Wenn sie überhaupt kein Eigentum hätte, hätte sie nur den einen eigentümlichen Objekt zur Zerstörung zu treiben, d.h. ihr eigenen Körper: d.h. Selbstmord. Dass sie sich selbst nicht umbringt, ist das Zeigen, dass sie sich vermutlich gegen Selbstmord entschieden hat. Diese Szene gilt als die Radikalisierung Katharinas. Sie ist jetzt der Gewalt fähig.

In diesem wahnsinnigen Zustand wurde Katharina zur Mordtat getrieben. Die Pistole sie in Griff hat, wurde vermutlich um den eigenen Schutz besorgt, wegen der vielen Hasspost und anonymen Telefonanrufe. In der Konfrontation mit dem, „Kerl”, (135) so Katharina, Tötgen, leidete sie besonders stark unter dieser Hilflosigkeit und wurde noch mal zur Gewalt gezwungen, diesmal stärker als je vorher gemäß ihrer äußersten

\footnotetext{
${ }^{185}$ Werner Bellmann, „Die verlorene Ehre der Katharina Blum oder: Wie Gewalt entstehen und wohin sie führen kann,” in Interpretationen: Erzählungen des 20. Jahrhunderts Band 2, (Stuttgart: Reclam, 1996), S. 198.
} 
Ohnmacht. Werner Bellmann beschrieb diese rasche Aktion in seinem akademischen Artikel über Katharina Blum:

Von Verdächtigungen, Verleumdungen und Belästigungen umzingelt und in die Enge gepreßt, wird Katharina schließlich zu physischer Gegengewalt provoziert, die angesichts der eskalierenden Gewalt des Meinungsapparats durchaus als Akt der Notwehr anzusehen ist. Sie richtet die Waffe gegen ihren Peiniger Tötges, die Inkarnation eines skrupellosen Journalismus - und nicht gegen sich selbst, wie der Autor zunächst erwogen hatte. ${ }^{186}$

Sie hat sich entschieden keine Gewalt gegen ihren eigenen Körper zu führen und musste jener latenten Gewalt nach außen auf einen anderen Gestalt oder Gegenstand anrichten. Sie musste sich selbst gegen Tötgen rächen. Sie wurde zum niedrigsten Niveau in der öffentlichen Meinung als Mensch gebracht:

Katharina Blum ist darin im Kern verletzt und angetastet worden, vor allem durch den Zugriff der staatlichen Organe, durch die Sprach-Hetze der »ZEITUNG «, durch journalistische Gewissenlosigkeit, durch den kriegerischen Sexualchauvinismus des Reporters. ${ }^{187}$

Sie erschießt den Bildjournalisten Werner Tötges, der, so Katharina, ihr Leben, „zerstört hat““. (134)

${ }^{186}$ Ebd., S. 198.

${ }^{187}$ Klaus Jeziorkowski, „Die verlorene Ehre der Katharina Blum oder: Wie Gewalt entstehen und wohin sie führen kann," in Interpretationen Heinrich Böll: Romane und Erzählungen, (Stuttgart: Philipp Reclam jun. GmbH \& Co., 2000), S. 264. 
Die Entmenschlichung von Götten beinhaltet Katharinas verlorene Ehre

Dieser Verdacht auf Götten und Katharina verdirbt ihre Liebe durch sensationalisierten Zeitungsberichte und Schlagzeilen. Die Wirklichkeit, die Katharina bisher kannte und genoss, wird durch das Treffen mit einem bestimmten Ludwig Götten und damit durch die öffentliche Medien auf den Kopf gestellt. Die dramatische Handlung, meistens die Tätigkeiten von Katharina selbst, scheint unerklärbar angesichts Katharinas Eigenschaften und Persönlichkeit. Die Zerstörung ihres Lebens durch das zufällige Treffen eines Menschen folgt. Sie schätzt Götten als zuverlässig ein, der aber unter der Verdacht der Regierung als Terrorist steht. Katharinas ungewöhnliches Benehmen findet Erklärung in der Beziehung zwischen ihren Vernehmungen und den ungerechten Darstellungen solcher Fakten in der Zeitung. Böll fasste den Kern der Geschichte im Betracht der Gesellschaft nah am Ende der Erzählung:

Man muß sich natürlich die Frage erlauben dürfen, wieso oder warum eigentlich? Da ist eine junge Frau gut gelaunt, fast fröhlich zu einem harmlosen Tanzvergnügen gegangen, vier Tage später wird sie - da hier nicht ge-, sondern nur berichtet werden soll, soll es bei der Mitteilung von Fakten belassen bleiben - zur Mörderin, eigentlich, wenn man genau hinsieht, auf Grund von Zeitungsberichten. (131)

Im Text Katharina Blum ist es nicht zu erkennen, ob Ludwig sich eigentlich in Katharina verliebt ist. Es ist klar, dass Katharina sich in ihn verliebt ist, aber es wird nicht ausführlich bestätigt, dass er in sie eigentlich verliebt ist.

Der Entmenschlichungsprozess gegen Terroristen und Staatsfeinden wird an Götten verwandt. Der Prozess der Entmenschlichung, der im Zusammenhang mit dem 
Konzept Terrorismus steht, wird hier an Götten und Katharina demonstriert, als verdächtigte Feinde des Staates. In der Darstellung der Regierung müssen solche Täter als Untermensch angesehen werden. Alle Kontakte werden instrumentalisiert zum persönlichen Brauch als Schutz oder als Komplize. Im sozialen Rahmen, erscheint Ludwig nicht als Mensch sondern als Terrorist. Der entmenschlichte Terrorist wird als kein Mensch angetrachtet, sondern als Ungeheuer. Als Terrorist wird er zu einer Art Social Monster oder Feind der Menschlichkeit. Solche Ungeheuer sind liebunfähig. Ihre Unmenschheit zeigt auf ihre Tendenz immer sozial zu berechnen. Sie instrumentalisieren alle Kontakte. Auch in dieser Rubrik muss direkten Kontakt mit der Familie eingefügt werden. Die Eltern und Geschwistern werden kontaktiert, nur um Versteck oder Lebensmittel zu bekommen. Persönliche Beziehungen zwischen dem Terrorist und der Familie gelten eben auch nicht. Der Terrorist ist zum Ungeheuer transformiert. Er ist ein Parasit in der Gesellschaft. Er hält Kontakt mit Anderen, nur wegen der Möglichkeit, sie auszunützen. In seiner Lage kann Ludwig von einer kurzen Beziehung nur profitieren. Er braucht Nährung, Verkehrsmittel, Unterkunft und ein Versteck. Dies alle zusammen mit der Gesellschaft einer jungen schönen Frau dazu wirkt noch besser.

Da Ludwigs Lage als tatverdächtigter Terrorist kurzzeitig unerklärt bleibt, wird der Leser wohl annehmen, dass Ludwig tatsächlich die Schuld an den angegebenen Vermutungen habe. Der Leser wird Götten als ,Terrorist' oder ,Freiheitskämpfer' wohl einbilden oder phantasieren. Da Böll diese Zweideutigkeit erlaubt, stehen dem 
Leser eine Zeit mehrere Interpretationsmöglichkeiten offen. ${ }^{188}$ Bölls Roman spielt auf die romantische Darstellung der Freiheitskämpfer wie Che Guevara. Sowie Che Guevara, der als Symbol der Freiheit und des Kampfes gegen den Kapitalismus im Allgemeinen und gegen das amerikanische Regime insbesondere steht, könnte Götten auch in der Phantasie des Lesers romantisch dargestellt und als Befreier der Menschen vom Kapitalismus und von der Geldgier idealisiert werden. Böll schrieb selbst, „ein großer Teil der aktiven und engagierten Jugend mehr für die Modelle Kuba und Chile interessiert und interessiert hat als für das Modell USA“. ${ }^{89}$ Che Guevara, das Bild dieser Bewegung, gewinnt hier diese Assoziationen. Dass das Bild Ludwigs als Befreier der Gesellschaft romantisiert werden könnte, lässt Mitleid auf den Leser für ihn aufkommen und zwingt den Leser zur Identifikation. Bölls Entscheidung Göttens wirklichen Zustand ohne Erklärung darzustellen verstärkt diesen Effekt, gezielt wobei Götten, obwohl nur als Terrorist oder Freiheitskämpfer verdächtigt, ähnliche Eigenschaften wie Guevara annimmt. Ironischerweise wird Ludwig wohl, als mutmaßlicher Terrorist, als vermuteter Kämpfer gegen Kapitalismus und noch mehr als Idealist, in der Phantasie des Lesers voll von romantischen Ideen gefüllt betrachtet. Ludwig soll den Geist der Spontaneität verkörpern, da er sein Leben mit Gefühl führt. Als Idealist, soll er eine Tendenz zeigen, dem Pfad der Liebe zu folgen, Werte wie Freiheit und Liebe zu unterstützen und deshalb wirklich in Katharina verliebt zu sein.

\footnotetext{
${ }^{188}$ Die eigentlichen Verbrechen Ludwigs sind schon teilweise auf Seite 44 in Katharina Blum erklärt: „Götten war u. a. Bundeswehrdeserteur.” Und noch ausführlicher auf Seite 127: Er hat u.a. die, ,totale Ausplünderung eines Safes", begangen.

${ }^{189}$ Heinrich Böll, ,Radikalität und Hoffnung,” Gefahren von falschen Brïdern: Politische Schriften, Auswahl aus: >Einmischung erwünscht. Schriften zur Zeit< (München: Deutscher Taschenbuch Verlag), S. 22.
} 
Dieser unerklärte, zweideutige Zustand soll die Leserschaft zum Mitleid für Blum bringen, denn die Schwierigkeit, die Liebe zu erkennen, wird von den Lesern erlebt. Die mögliche Ausnützung Katharinas steigt das Mitleid des Lesers für Blum. Auf die gleiche Art, indem Katharina sich in Ludwig verliebt - ohne seinen Werdegang zu erkennen - entschied sie sich, Ludwig zu helfen der Polizei zu entkommen. Sie war allerdings naiv, denn für sie sind Intuitionen von höherem Wert als die Ratio. Solche von Intuitionen und Naivität inspirierten Aktivitäten werden gefährlich in einem Rechtsstaat, in dem Fall, dass die Behörden ungerecht handeln. Ihre Intuitionen waren allerdings korrekt: Ludwig war nur mutmaßlicher Terrorist.

Ungerechte Entmenschlichung: Ludwig als Mensch

Böll erklärt diesen Zustand in seinem Nachwort: „Es gibt in dieser Erzählung nicht einen einzigen Terroristen, auch keine Terroristin; was es allerdings gibt, das sind des Terrorismus Verdächtige. ${ }^{\prime 190}$ Vor der Bluttat Katharinas war sie keine große Verbrecherin, da Ludwig kein Terrorist war. Inspektor Beizmenne konnte die Aussagen der zwei Mädchen mit den Aussagen Katharinas und den von der Polizei gesammelten Fakten über Ludwig nicht in Übereinstimmung bringen. Er bemerkte, „[a]lle diese Personen sind eindeutig als Zufalls-, nicht als Plankontakte identifiziert worden, und keins der mit jeder einzelnen Person gewechselten Worte läßt Rückschlüsse auf einen Code zu“. (73-4) Jede Geste wird gelesen, als ein Teil eines

\footnotetext{
${ }^{190}$ Heinrich Böll, ,Zehn Jahre später,” Nachwort zur Katharina Blum, (München: Deutscher Taschenbuch Verlag, 2003), S. 139.
} 
Codes, etwas künstliches und unmenschliches. Als ob der Täter, hier Götten, nur ein Automate wäre und er alle sein Tun und seine Aktionen ohne Gefühl und Leben führt. Beizmenne erwartet die heimlich trainierte Geste des Guerillakämpfers. Götten soll nur ein Automate des Undergrounds sein. Die polizeiliche Beobachtung von Ludwig Götten ging so weit, in jedes Treffen Ludwigs nach einem Code zu suchen.

Die Personen, mit denen Götten bis zum Betreten des Café Polkt in Berührung kam, sind alle erfasst und überprüft worden: ein Schankkellner, an dessen Theke er Bier trank zwei Mädchen, mit denen er in einem Altstadtlokal tanzte ein Tankwart in der Nähe Holzmarkt, wo er den gestohlenen Porsche auftankte ein Mann am Zeitungskiosk in der Matthiasstraße ein Verkäufer in einem Zigarettenladen ein Bankbeamter, bei dem er siebenhundert amerikanische Dollar tauschte, die wahrscheinlich aus einem Bankraub stammen. (73)

Das Problem der Entmenschlichung wird auch als Thema im akademischen Artikel von Werner Bellmann eingehend behandelt. Das Buch personalisierte das Geschehnis zwischen Blum und Tötgen, ,,so werden in der filmischen Version die ökonomischen Hintergründe bewusst gemacht: die Verdinglichung des Menschen zum Presseartikel, zur Ware, die sich lukrativ vermarkten lässt"“. ${ }^{191}$ Die Verdinglichung des Menschen ist einer integralen Teil des Marktsystems, da der Mensch selbst zur Marke oder Markenname kommt. Die übertriebene Verdinglichung und Entmenschlichung, die durch die Medien getrieben werden, zeigen Hass und Unvertrauen. Die Schilderung in der Zeitung als Terrorist oder Sympathisant ist eine Form der Entmenschlichung. Böll zeigte dieses Problem ausdrücklich in Katharina Blum: die menschliche Beziehung Katharinas zum Götten wird unernst genommen. Böll demonstriert, dass

\footnotetext{
${ }^{191}$ Werner Bellmann, „Die verlorene Ehre der Katharina Blum oder: Wie Gewalt entstehen und wohin sie führen kann," in Interpretationen: Erzählungen des 20. Jahrhunderts Band 2, (Stuttgart: Reclam, 1996), S. 201.
} 
die Liebe bei Menschen nicht länger gilt. Die Liebe zu Geld wird größer als die ,Liebe zu Menschen'. ${ }^{192}$ Da Ludwig leidenschaftlich lebt - er ist Deserteur -, wird die wahre Liebe bei ihm voraussichtlicher passieren als bei Beizmenne, deswegen kann der Hauptkommissar Göttens Liebesfähigkeit nicht begreifen. Bölls eigene Erklärung steht im Gegensatz zu der von Beizmenne. Böll argumentiert, dass Katharina der Zärtlichkeit fähig ist, ,,[u]nd Götten, der wirklich Straffällige - er ist ein Defraudant und Deserteur -, ist tatsächlich »der Liebe fähig«! “193 Der Leser könnte zuerst annehmen, dass Ludwig als Deserteur angeblich pazifistische Einstellungen hat. Diese einfühlsame Haltung hat Katharina angeblich gefallen und erklärt seine Natur, die im Roman als zärtlich beschrieben wird.

\footnotetext{
${ }^{192}$ Vgl. hier: Heinrich Böll, „Radikalität und Hoffnung,” Gefahren von falschen Brüdern: Politische Schriften, Auswahl aus: >Einmischung erwünscht. Schriften zur Zeit< (München: Deutscher Taschenbuch Verlag), S. 23. Böll warnte vor der Schwächung von Liebe, die den Tod der Liebe in der Gesellschaft im allgemeinen Sinne endlich einleiten könnte: „Man stelle sich das einmal vor: eine ausgewogene Literatur [...] ausgewogene Ehe und dann ausgewogene Programme in allen Funk- und Fernsehanstalten. Dann sollte man doch besser gleich ein Gesetz vorbereiten, das allen Staatsbürgern ein Recht auf das tägliche Schlafmittel sichert. Man sollte endlich Automaten erfinden, die entweder das eine oder das andere je nach Wunsch auswerfen: Gold oder Liebe oder beides."

${ }^{193}$ Heinrich Böll, ,Zehn Jahre später,” Nachwort zur Katharina Blum, (München: Deutscher Taschenbuch Verlag, 2003), S. 142.
} 


\section{Zusammenfassung}

Heinrich Böll wurde in der Enge gepresst in Zusammenhang mit seinem Streit mit der Zeitung. Er wollte die Instrumentalisierung der Wörter vermeiden, benutzte dies aber selbst in seinen kritischen Artikeln. Bölls Kritik an dem ,gewissenlosen Journalismus” vereinfachte die wirkliche Schwierigkeiten der Journalisten mit einer Hinsicht auf soziale Verantwortung. Er zog sich mit der Veröffnung seiner Erzählung aus der immer intensivierenden Hetze solcher öffentlichen Beschimpfung. Böll schrieb Katharina Blum mit dem Ziel einer Auseinandersetzung mit dem verhetzenden Gebrauch von der Instrumentalisierung der Wörter und erhielt scharfe Kritik auf die christliche Rechtfertigung der westlichen Kultur. Böll wollte in seinem Roman zeigen, dass die katholische Praxis der Barmherzigkeit z.B. in der heutigen, vermutlich katholischen, Gesellschaft nicht möglich sei. Bölls Kritik der christlichen Einstellung der westlichen Konsumkultur steht in starkem Zusammenhang mit dieser gesellschaftlichen Kritik. Er wollte erweisen, dass Hetzkampagnen und die geldwirtschaftlich inspirierte Liebe zu Geld weder mit der christlichen Einstellung noch mit jener modernen Konzeption von Menschenrechten vereinbar sind. In seiner Erzählung Katharina Blum argumentierte Böll für das Recht auf Unschuldsvermutung. Böll behauptete, dass als Bürger eines Rechtsstaats verdient der Bürger solche Menschenechte und, dass eine falsche Darstellung in der Medien zugleich entmenschlichend und kriminalisierend wirkt. Zugleich zeigt solche Kriminalisierung Hass auf den Beschuldigten und dabei, ohne das Gefühl von Brüderlichkeit, folgt die 
Entmenschlichung der Betroffene. Böll meinte, dass die Entmenschlichung und Kriminalisierung eines Menschen in der Öffentlichkeit durch Schlagzeilen und Rufmordkampagne das stärkste Mittel den Ruf und das Leben eines Menschen in einem Rechtsstaat zu zerstören sei. 


\section{Literaturhinweise}

\section{Primärliteratur}

Anonym. „Bölls ,ZEITUNG”-Story: „Jetzt bumst's”.” Der Spiegel, 29. Juli 1974. Anonym. ,"Da man sie schlagen wird, kennen sie das Risiko": Dokumentation über Studenten-Unruhen: Die Eskalation der Gewalt, 2. Fortsetzung und Schluß." Der Spiegel, 13. Mai 1968.

Anonym. ,"Eine ,Bild'-Schlagzeile ist mehr Gewalt als ein Stein am Polizisten-Kopf”: Eine Dokumentation über die Oster-Unruhen und ihre Ursachen: die Rolle des Verlagshauses Axel Springer.” Der Spiegel, 6. Mai 1968.

Anonym. ,"Einseitig, lückenhaft, unsachlich”: Urteile über Springer und seine Zeitungen." Der Spiegel, 6. Mai 1968.

Anonym. „Nächstenliebe zum Klassenfeind?: DKP-Pfarrer Rolf Trommershäuser über seinen Konflikt mit der evangelischen Kirche.” Der Spiegel, 18. Dezember 1972.

Anonym. „Nein, nein, nein.” Der Spiegel, 5. Juni 1967.

Anonym. „Schnaps für den Knaben.” Der Spiegel, 22. August 1994. Rezension von „Die Hoffnung ist wie ein wildes Tier”. Der Briefwechsel zwischen Heinrich Böll und Ernst-Adolf Kunz 1945-1953. Herausgegeben von Herbert Hoven. Köln: Kiepenheuer \& Witsch Verlag, 1994.

Böll, Heinrich. „Der verwaltete Mensch.” Der Spiegel, 22. April 1974.

Böll, Heinrich. Die verlorene Ehre der Katharina Blum oder: Wie Gewalt entstehen und wohin sie führen kann. Erzählung. 40. Auglage Mai 2003. München: Deutscher Taschenbuch Verlag, 1974.

Böll, Heinrich. „Keine so schlechte Quelle: Heinrich Böll über Konrad Adenauer: "Erinnerungen 1945-1953"." Der Spiegel, 1. Dezember 1965.

Böll, Heinrich. Gefahren von falschen Brüdern: Politische Schriften. Auswahl aus: $>$ Einmischung erwünscht. Schriften zur Zeit<. München: Deutscher Taschenbuch Verlag, 1980.

Böll, Heinrich. „Verfolgt war nicht nur Paulus.” Der Spiegel, 31. Januar 1972.

Böll, Heinrich. „Was soll aus dem Jungen bloss werden?” Die Zeit, Nr. 36, 28. August 1981.

Böll, Heinrich. „Will Ulrike Gnade oder freies Geleit?” Der Spiegel, 10. Januar 1972.

Böll, Heinrich. „Zehn Jahre später.” Nachwort zur Die verlorene Ehre der Katharina Blum. München: Deutscher Taschenbuch Verlag, 1984.

Frei, Norbert. Vergangenheitspolitik: Die Anfänge der Bundesrepublik und die NSVergangenheit. München: Deutscher Taschenbuch Verlag, 1996/1999. 2. Auflage, April 2003.

Gössner, Rolf. Menschenrechte in Zeiten des Terrors: Kollateralschäden an der »Heimatfront «. Hamburg: Konkret Literatur Verlag, 2007.

Grefe, Christiane und Adam Soboczynski. „Wo ist Böll?” ZEITmagazin, Nr. 32, 2. August 2007. 
Kiermeier-Debre, Joseph, Herausgeber. „Lena und Leonce.” Nachwort zum Lena und Leonce von Georg Büchner. 3. Auflage. München: Deutscher Taschenbuch Verlag, März 2004.

Meinhof, Ulrike Marie. Everybody talks about the weather...We don't: The Writings of Ulrike Meinhof. Verfasserin, Karin Bauer. New York: Seven Stories Press, 2008.

Meinhof, Ulrike Marie. Ulrike Marie Meinhof: Die Würde des Menschen ist antastbar: Aufsätze und Polemiken. Berlin: Wagenbachs Taschenbücherei, 1986.

Schmale, Holger. „Ein tödlicher Moment.” Berliner-Zeitung, 1. Juni 2007.

Schmidt, Helmut. „Was ich noch glaube.” Der Zeit, 11. September 2008. Vorabdruck von Außer Dienst. Siedler Verlag, 2008.

Schmitter, Elke., ,Warten auf das Ende.” Der Spiegel, 24. September 2001.

Schönbohm, Wulf, Jürgen Bernd Runge und Peter Radunski. Die herausgeforderte Demokratie: Deutschlands Studenten zwischen Reform und Revolution. Mainz: Hase \& Koehler Verlag, 1968.

Wassermann, Rudolf. „Wer arm ist bekommt weniger Recht.” Die Zeit, 2. November 1973.

\section{Sekundärliteratur}

Bellman, Werner und Christine Hummel, Herausgeb. Erläuterungen und Dokumente: Heinrich Böll: Die verlorene Ehre der Katharina Blum. Stuttgart: Philipp Reclam jun. GmbH \& Co., 1999.

Jeziorkowski, Klaus. „Die verlorene Ehre der Katharina Blum oder: Wie Gewalt entstehen und wohin sie führen kann," in Interpretationen Heinrich Böll: Romane und Erzählungen. Stuttgart: Philipp Reclam jun. GmbH \& Co., 2000.

\section{Internethinweise}

Anonym. Heinrich Böll Biografie, in der Lebendiges virtuelles Museum Online (LeMO) Website. http://www.dhm.de/lemo/html/biografien/BoellHeinrich/ (nachgeschlagt am 28. Juni 2009.)

Böll, Heinrich. „Notstandsnotizen,” in der Glasnost.de Website. Originalabdruck in der Zeitschrift konkret. Nr. 10, 1968. http://www.glasnost.de/hist/apo/koment.html (nachgeschlagt am 20. Juni 2009)

Böll, Heinrich. „Über mich selbst,” in der Heinrich-Boell.de Website. Originalabdruck: Köln: Kiepenhauer und Witsch Verlag, 1959. http://www.heinrich-boell.de/HeinrichBoellUebermich.htm (nachgeschlagt am 8. August 2009) 
Haffner, Sebastian. „Nacht der langen Knüppel: Der 2. Juni 1967 - ein geplanter Pogrom," in der Glasnost.de Website. Originalabdruck in Stern, Nr. 26, 1967. http://www.glasnost.de/hist/apo/haf2Juni.html (nachgeschlagt am 22. Juni 2009)

Meinhof, Ulrike Marie, (RAF-Mitgliederin). Das Konzept Stadtguerilla. Rote Armee Fraktion, in der Nadir.org Website. Aus: Ausgewählte Dokumente der Zeitgeschichte: Bundesrepublik Deutschland (BRD) - Rote Armee Fraktion (RAF), GNN Verlagsgesellschaft Politische Berichte, 1. Auflage Köln Oktober 1987.

http://www.nadir.org/nadir/archiv/PolitischeStroemungen/Stadtguerilla+RAF/RA F/brd+raf/004.html (nachgeschlagt am 9. April 2009)

InternationalPEN.org Website. Pen Charter.

http://www.internationalpen.org.uk/go/about-us/charter/pen-charter 


\section{Anhang A: Radikale im öffentlichem Dienst}

In seinem Schreiben Radikalität und Hoffnung bemerkte Bö̈l: ,,[E]s war

Polizeibeamte - es war am 2. November 1973 in der Wochenzeitung Die Zeit zu lesen

-, die zu 83 Prozent die Meinung äußerten, daß - ich zitiere wörtlich - »reiche Leute

vor Gericht in der Regel besser davonkommen. «"194 Das Ansicht, dass Ulrike Meinhof einen fairen Prozess bekommen sollte, wirkt naiv auf zwei Gesichtspunkte: erstens sollen reiche Leute vor Gericht in der Regel besser davonkommen und zweitens sollte Meinhof eine Revolutionärin oder Terroristin sein, welche Begriffe ihre Wirklichkeit eigentlich nicht trifft, da sie selbst ihre Aktivitäten nicht voll verstand und sich selbst falsch darstellte, aber die ihr angewandt blieben. Diese Vorurteilung untergräbt die konstitutionelle Versicherung einen fairen Prozess. Böll sagte weiter:

Was die Polizeibeamten da geäußert haben, klingt ziemlich radikal, man könnte es als geradezu vernichtendes Urteil bezeichnen, von denen ausgesprochen, die die Einhaltung von Gesetzen zu beobachten, deren Verletzung zu verfolgen haben. ${ }^{195}$

Böll bemerkte die radikale Neigung dieser Äußerung und fragte, ,,sollte man die Polizeibeamten Radikale im öffentlichen Dienst Nennen?" ${ }^{, 196}$ Er bemerkte auch die wenige, ,Verständlichkeitsmöglichkeiten”, zwischen Linksradikaler und

\footnotetext{
${ }^{194}$ Heinrich Böll, „Radikalität und Hoffnung,” Gefahren von falschen Brïdern: Politische Schriften, Auswahl aus: >Einmischung erwünscht. Schriften zur Zeit< (München: Deutscher Taschenbuch Verlag), S. 19.

${ }^{195}$ Ebd., S. 19.

${ }^{196}$ Ebd., S. 19.
} 
Polizeibeamte und bemerkte, dass es, „tragisch”, war, dass, ,,sich diese beiden Gruppen, die zu vergleichbaren, vielleicht zu den gleichen Erkenntnissen kommen, nur per Steinwurf, Wasserwerfer und via Beschimpfung kennen, nur als Gegner oder gar als Feinde“. ${ }^{197}$ Diese Radikaler in Öffentlichen Dienst waren vielleicht noch radikaler als die Linksradikaler Deutschlands: „Möglicherweise würden von 100 befragten Linksradikalen nicht einmal 83 so weit gehen wie diese Beamten, die nicht theoretisch, sondern aus Erfahrung zu diesem Urteil gekommen sind.“198 Böll stellte die Richtigkeit des Justizsystems in Frage.

\footnotetext{
${ }^{197}$ Ebd., S. 19.
}

${ }^{198}$ Ebd., S. 19. 
Anhang B: Radikale

Bölls Einstellung zur Notstandsgesetzen spiegelte sich in seiner Kritik an dem

Radikalenerlass wider. Böll kritisierte den Radikalenerlass im Jahre 1976:

„Systemveränderer haben wenig Chancen hier - und der Radikalenerlaß hat sogar die

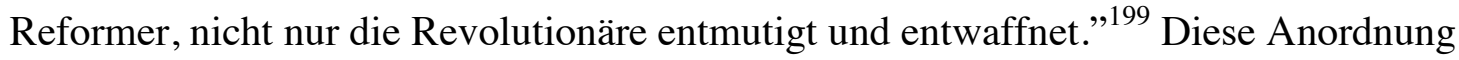

hielte verdächtigte Radikaler außer öffentlichem Dienst. Böll hob Kritik gegen die

Regierung, die Radikalen aus dem öffentlichem Dienst behalten. Diese Doktrin,

meinte er, „,die man den Radikalenerlaß genannt hat, ein Gesetz, das keins ist und doch

gelegentlich wie ein solches angewandt wird, ist der Bundesrepublik Deutschland

unwürdig“. ${ }^{200}$ Böll notierte den großen Einfluss dieses Gesetz:

Der Radikalenerlaß verhindert radikale politische und geistige, theoretische und praktische Auseinandersetzung mit Problemen; er entmutigt Jugendliche und junge Leute, die im öffentlichen Dienst arbeiten wollen, er zwingt sie zu demütigender Anpassung oder zur Heuchelei. $^{201}$

Böll notierte die Existenz noch gewalttätiger Organisationen in Nebenländer:

In keinem anderen freiheitlich-demokratischen westeuropäischen Land wäre ein solches Gesetz möglich, und es gibt in Großbritannien, Italien und Frankreich weitaus mehr Radikale und Extremisten als hierzulande - und viele davon im öffentlichen dienst. ${ }^{202}$

Er verstand die nützlichen Wirkungen der Radikalen in der Reform: „,Was wäre aus der Bundesrepublik geworden, hätte es nicht Radikale und Extremisten gegeben, die

\footnotetext{
${ }^{199}$ Heinrich Böll, „Die Angst der Deutschen und die Angst vor ihnen,” in Gefahren von falschen Brüdern: Politische Schriften, Auswahl aus: >Einmischung erwünscht. Schriften zur Zeit< (München: Deutscher Taschenbuch Verlag, 1980), S. 106.

${ }^{200}$ Heinrich Böll, „Radikalität und Hoffnung,” in Gefahren von falschen Brüdern: Politische Schriften, Auswahl aus: >Einmischung erwünscht. Schriften zur Zeit< (München: Deutscher Taschenbuch Verlag, 1980), S. 21.

${ }^{201}$ Ebd., S. 22.

${ }^{202}$ Ebd., S. 22.
} 
nicht auf persönliche Bereicherung, sondern auf Veränderung der bestehenden Verhältnisse aus waren?"203 Die Anerkennung, dass die Gesellschaft, den absoluten

Wohlstand des Menschen und gesellschaftliche Ungleichheiten verbessert worden können, erklären den Anlass der modernen Verfassungen. Die Hoffnung auf die Zukunft wurde aber durch den Radikalenerlass vermindert:

Es ist ein Erlaß gegen die Hoffnung, er verordnet Hoffnungslosigkeit und Lähmung, denn er trifft ja nicht die radikale und extreme Prominenz, die der verständnisvollen Schlagzeilen sicher sein kann, er trifft die Unbekannten, junge Lehrer und Lehrlinge, Juristen und Ärzte, die keine Chance haben, öffentliches Aufsehen zu erregen. ${ }^{204}$

Die Gesellschaft steht nicht ohne Konflikt und soziale Problemen vermehren sich stetig. Die Einstellung, dass Änderungen in den sozialen Beziehungen unerwünscht sind, kann nur mit einem vollkommenen Pessimismus entstehen. Böll bemerkte diese Neigung in der Bundesrepublik:

Und wenn bei jedem großzügig-humanen Projekt, selbst wenn alle psychologischen, soziologischen, religiösen und ästhetischen Erkenntnisse dafür sprechen, letzten Endes Profitinteressen dagegen entscheiden, dann ist wieder jener Zustand der Resignation erreicht, den alle beklagt haben, bevor die Studentenbewegung begann. ${ }^{205}$

Böll erkannte den Anlass der Radikalen an:

Wenn laut Grundgesetz alle vor dem Gesetz gleich sind und ein erheblicher Teil der Hüter des Gesetzes diese Gleichheit bestreitet, dann muß man den Radikalen das Wort Klassenjustiz genehmigen, ohne sie zu denunzieren; und wenn die Gleichheit in einem so erheblichen Ausmaß nicht erfüllt ist, kann man die Radikalität mit der sie verlangt wird, weder verwerflich noch kriminell nennen, nicht einmal idealistisch. ${ }^{206}$

\footnotetext{
${ }^{203}$ Ebd., S. 20-1.

${ }^{204}$ Ebd., S. 22.

${ }^{205}$ Ebd., S. 23.

${ }^{206}$ Ebd., S. 20-1.
} 
Bölls Verteidigung von Radikalen steht im engen Zusammenhang mit seiner Verteidigung von Menschenrechten.

Die Studenten der 68-Bewegung schätzten die Gefahr hoch, dagegen Böll in seinem Aufsatz „Radikalität und Hoffnung” scharf polemisierte:

Wenn man dann gleichzeitig politische Motive von Kriminalität leugnet und politische Häftlinge über das gesetzlich zugelassene $\mathrm{Ma}$ hinaus, durch Isolation etwa, bestraft, Gesetzesbrecher also mit gebrochenem Gesetz behandelt, so weiß ja dann die Jugend, ob radikal oder nicht, wohin Radikalität führt. ${ }^{207}$

Böll sorgte sich um die Ehre und das internationale Ansehen Deutschlands, und verteidigte die rechtlich zulässige Handlung der Inhaftierten. Böll kämpfte auch gegen die Isolation der Inhaftierte. Auf der internationalen Etage könnten solche Methoden als unrechtlich angesehen. Böll würde die Ehre Deutschlands gegen solche mögliche Kritiken bewehren.

${ }^{207}$ Ebd., S. 23. 